SERVIÇO DE PÓS-GRADUAÇÃO DO ICMC-USP

Data de Depósito: 07/11/2007

Assinatura:

\title{
Mineração e visualização de coleções de séries temporais
}

\author{
Aretha Barbosa Alencar
}

Orientadora: Profa. Dra. Maria Cristina Ferreira de Oliveira

Dissertação apresentada ao Instituto de Ciências Matemáticas e de Computação - ICMC-USP, como parte dos requisitos para obtenção do título de Mestre em Ciências - Ciências de Computação e Matemática Computacional.

USP - São Carlos

Novembro/2007 

Mineração e visualização coleções de séries temporais

\author{
Aretha Barbosa Alencar
}



Dedicatória

Dedico este trabalho aos meus amores: meus pais, Silmar e Maria; e minha irmã, Silmara. 
À Profa. Dra. Maria Cristina Ferreira de Oliveira, pela excelente orientação fornecida, pelo incentivo, apoio e parceria na realização deste projeto.

Aos Profs. Drs. Rosane Minguim e Marinho Gomes de Andrade Filho pela colaboração e orientação adicional. Ao aluno de doutorado Fernando Paulovich, pelo apoio e incentivo em minha pesquisa.

Aos meus pais, Silmar e Maria, pelo exemplo e apoio incodicional. À minha irmã Silmara. À grande amiga Ana Luísa pelo companheirismo, cooperação, apoio e incentivo. Aos amigos: Alessandra, Otávio, Aparecido Fabiano, Deodato, Cláudia, Camila e Marcella.

Ao meu avô paterno, Irineu, que não se encontra mais junto de nós, e que me ensinou a ver a vida com simplicidade e alegria.

Ao Instituto de Ciências Matemáticas e de Computação (ICMC), pela oportunidade de realização do curso de mestrado. Aos funcionários e professores sempre dispostos na prestação de seus serviços e pela colaboração.

À Fundação de Amparo à Pesquisa do Estado de São Paulo (FAPESP) pela concessão da bolsa de mestrado e pelo apoio financeiro para a realização desta pesquisa. 
ALENCAR, Aretha. Mineração e visualização de coleções de séries temporais. 2007. Dissertação (Mestrado) - Instituto de Ciências Matemáticas e de Computação, Universidade de São Paulo, São Carlos, 2007.

A análise de séries temporais gera muitos desafios para profissionais em um grande número de domínios. Várias soluções de visualização integrada com algoritmos de mineração já foram propostas para tarefas exploratórias em coleções de séries temporais. À medida que o conjunto de dados cresce, estas soluções falham em promover uma boa associação entre séries temporais similares. Neste trabalho, é apresentada uma ferramenta para a análise exploratória e mineração de conjuntos de séries temporais que adota uma representação visual baseada em medidas de dissimilaridade entre séries. Esta representação é criada usando técnicas rápidas de projeção, de forma que as séries temporais possam ser visualizadas em espaços bidimensionais. Vários tipos de atributos visuais e conexões no grafo resultante podem ser utilizados para suportar a exploração dessa representação. Também é possível aplicar algumas tarefas de mineração de dados, como a classificação, para apoiar a busca por padrões. As visualizações resultantes têm se mostrado muito úteis na identificação de grupos de séries com comportamentos similares, que são mapeadas para a mesma vizinhança no espaço bidimensional. Grupos visuais de elementos, assim como outliers, são facilmente identificáveis. A ferramenta é avaliada por meio de sua aplicação a vários conjuntos de séries. Um dos estudos de caso explora dados de vazões de usinas hidrelétricas no Brasil, uma aplicação estratégica para o planejamento energético.

Palavras-chave: Visualização de informação. Mineração de dados. Séries temporais. 

ALENCAR, Aretha. Mining and visualization of time series collections. 2007. Dissertation (Master) - Institute of Mathematics and Computer Science, University of São Paulo, São Carlos, 2007.

Time series analysis poses many challenges to professionals in a wide range of domains. Several visualization solutions integrated with mining algorithms have been proposed for exploratory tasks on time series collections. As the data sets grow large, though, the visual alternatives do not allow for a good association between similar time series. In this work, we introduce a tool for exploratory visualization and mining of large time series data sets that adopts a visual representation based on distance measures between series. This representation is created employing fast projection techniques, so the time series can be viewed in two-dimensional spaces. Various types of visual attributes and connection on the resulting graph can be applied to support exploration. It also supports data mining tasks, such as classification, to search for patterns. The resulting visualizations have proved very useful for identifying groups of series with similar behavior, which are mapped to the close neighborhoods in twodimensional spaces. Visual clusters of elements, as well as outliers, are easily identifiable. Case studies on several domains are presented to validate the tool. One of them is on a data set of streamflows in hydroelectric power plants in Brazil, a strategic application for energy planning.

Keywords: Information visualization. Data mining. Time series. 

Lista de Figuras

Lista de Tabelas $\quad$ xvii

Lista de Siglas $\quad$ xix

\begin{tabular}{lll}
\hline $\mathbf{1}$ & Introdução & $\mathbf{1}$
\end{tabular}

1.1 Organização da Dissertação . . . . . . . . . . . . . . . . . . 3

2 Visualização de Séries Temporais 5

2.1 Considerações Iniciais . . . . . . . . . . . . . . . . . . . . . . . 5

2.2 Visualização de Séries Temporais $\ldots \ldots$. . . . . . . . . . . . . . . . . 7

$2.2 .1 \quad$ Visualização Baseada em Espirais . . . . . . . . . . . . . . . . . . . 8

2.2 .2 Visualização Exploratória Interativa . . . . . . . . . . . . . . . . . . . 10

2.2 .3 Visualização Baseada em Agrupamento e Calendário . . . . . . . . . 10

2.2 .4 Visualização Baseada em Projeções Geométricas . . . . . . . . . . . . 12

2.2 .5 Visualização Baseada em Preenchimento de Espaço . . . . . . . . . . 14

2.3 Projeções Multidimensionais . . . . . . . . . . . . . . . . . . . . 15

$2.3 .1 \quad$ Interactive Document Map (IDMAP) . . . . . . . . . . . . . . . . 18

2.3.1.1 Fastmap . . . . . . . . . . . . . . . . . 18

2.3.1.2 $\quad$ Nearest Neighbors Projection (NNP) . . . . . . . . . . . . 21

2.3.1.3 Aperfeiçoamento da Projeção: Force Scheme . . . . . . . . . 23

2.3 .2 Least Square Projection (LSP) . . . . . . . . . . . . . . . 24

2.3.2.1 Definindo a Vizinhança dos Objetos . . . . . . . . . . . . 24

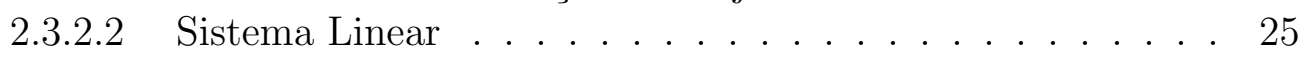

2.3 .2 .3 Pontos de Controle . . . . . . . . . . . . . . . . . . . . . . . . 26

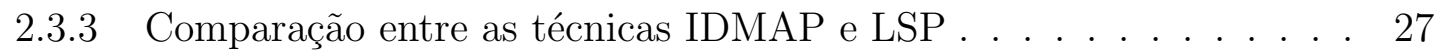

2.4 Considerações Finais $\ldots \ldots \ldots \ldots$ 
3 Mineração de Séries Temporais

3.1 Considerações Iniciais $\ldots \ldots \ldots \ldots$. . . . . . . . . . . . . . . 31

3.2 Mineração de Dados $\ldots \ldots \ldots \ldots$. . . . . . . . . . . . . . . . . . 32

3.3 Conceitos Básicos do Domínio de Interesse . . . . . . . . . . . . . . . . . . 34

3.4 Pré-Processamento $\ldots \ldots \ldots \ldots$. . . . . . . . . . . . . . . . . . . . . . 37

3.4 .1 Suavização . . . . . . . . . . . . . . . . . . . . . . . . . 37

3.4 .2 Normalização . . . . . . . . . . . . . . . . . . . . . . . . . 38

3.4 .3 Remoção da Sazonalidade . . . . . . . . . . . . . . . . . . . . . 40

3.5 Métricas de Dissimilaridade entre Séries Temporais . . . . . . . . . . . . . 41

3.5 .1 Distância Euclidiana . . . . . . . . . . . . . . . . . . . . . . 42

3.5.2 Dynamic Time-Warping . . . . . . . . . . . . . . . . . . 43

3.5.2.1 Limite Inferior para o DTW] . . . . . . . . . . . . . . 47

3.5.3 Compression-based Dissimilarity Measure. . . . . . . . . . . . . . . . 49

3.6 Tarefas de Mineração de Séries Temporais . . . . . . . . . . . . . . . . . 50

3.6 .1 Representações de Séries Temporais . . . . . . . . . . . . . . . . . 51

3.6.1.1 Symbolic Aggregate approXimation (SAX) . . . . . . . . . 52

3.6 .2 Classificação . . . . . . . . . . . . . . . . . . 55

3.6 .3 Consulta por Conteúdo . . . . . . . . . . . . . . . . . . 57

3.7 Considerações Finais $\ldots \ldots \ldots$. . . . . . . . . . . . . . . . . 60

4 Temporal-PEx: Ferramenta e Resultados $\quad 61$

4.1 Considerações Iniciais $\ldots \ldots \ldots \ldots$. . . . . . . . . . . . . . . . . . . . . . . . . . . . . . . . . .

4.2 A Ferramenta Temporal-PEx . . . . . . . . . . . . . . . . . . . . . 62

4.2 .1 Tarefas de Mineração de Dados . . . . . . . . . . . . . . . . . 66

4.2.1.1 Casamento de Subseqüências . . . . . . . . . . . . . 67

$4.2 .1 .2 \quad$ Classificação . . . . . . . . . . . . . . . . . . . . . . 68

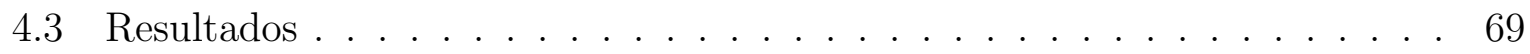

$4.3 .1 \quad$ Synthetic Control Chart . . . . . . . . . . . . . . . . 69

4.3 .2 Gun-Point . . . . . . . . . . . . . . . . . . . . . 69

4.3 .3 Ações de Empresas . . . . . . . . . . . . . . . . . . . . . . . . 73

$4.3 .4 \quad$ Eletrocardiogramas . . . . . . . . . . . . . . . . . . . . . 74

4.3.4.1 $\quad$ Busca por batimentos anormais . . . . . . . . . . . . 76

4.3 .5 Vazões Médias Mensais de Usinas Brasileiras . . . . . . . . . . . . . . . 80

4.3.5.1 Detecção de Anos Chuvosos e Secos . . . . . . . . . . . . . 82

4.3.5.2 Região Hidrográfica do Paraná . . . . . . . . . . . . . . . 83

$4.3 .5 .3 \quad$ Comportamento climático de um ano . . . . . . . . . . . 87

4.4 Escolha da técnica de projeção e da medida de dissimilaridade . . . . . . 87

4.5 Tempo de Processamento . . . . . . . . . . . . . . . . . . . . . . . . . . . 89

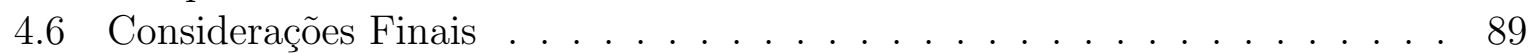

$\begin{array}{lll}5 & \text { Conclusões } & 93\end{array}$

5.1 Limitações . . . . . . . . . . . . . . . . . . . . . . . . . . . . . . . . . . . 93

5.2 Desenvolvimentos Futuros $\ldots \ldots \ldots$. . . . . . . . . . . . . . . . . . . . . . . 94 
\begin{tabular}{lr}
\hline Referências Bibliográficas & 97
\end{tabular} 



\section{Lista de Figuras}

2.1 Modelo de referência de visualização de Card et al. (Card et al., 1999)] . . 6

2.2 Balanço comercial da Inglaterra vs. Dinamarca e Noruega durante 1700 a 1780 (Playfair, 1786). . . . . . . . . . . . . . . 7

2.3 Visualização do preço de 1430 ações durante 52 semanas (Hochheiser e

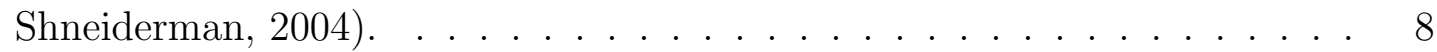

2.4 Uso de espirais para visualização de séries temporais. . . . . . . . . . . . . . 9

2.5 TimeSearcher. . . . . . . . . . . . . . . . . . . 11

2.6 Visualização baseada em clustering e calendário para séries temporais que registram o número de empregados presentes em uma determinada hora do dia em uma empresa holandesa (Wijk e Selow, 1999). . . . . . . . . . . . . 12

2.7 Coordenadas Paralelas (Novotny, 2004). . . . . . . . . . . . . . . . . . . . 13

2.8 Visualização baseada em eixos (Tominski et al., 2005). . . . . . . . . . . . . 14

2.9 Técnica de mapeamento em layouts baseados em importância para 19 séries sobre vendas de um produto. O produto A tem a maior média de vendas, importância de acordo com este contexto, sendo mapeado no topo (Hao et

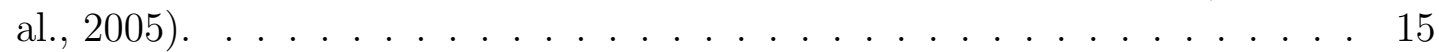

2.10 Projeção multidimensional para o conjunto de séries Cylinder-Bell-Funnel (CBF), cor das classes: cylinder (azul), bell (verde) e funnel (vermelho). . 17

2.11 Ilustração da lei do cosseno - projetando $O_{i}$ sobre a linha $O_{a} O_{b} . \quad \ldots$. . . 18

2.12 Projeção no hiperplano $H$, perpendicular à linha $O_{a} O_{b}$ da figura anterior. $\quad 19$

2.13 Casos de intersecção na projeção Nearest Neighbors Projection (NNP). . . 21

2.14 Formação de agrupamentos: projeção multidimensional para o conjunto de

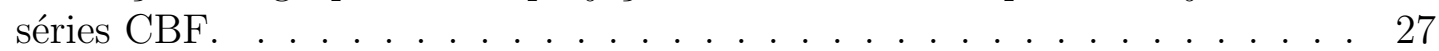

2.15 Projeção multidimensional para o conjunto de séries $\mid$ CBF $\mid$ com presença de

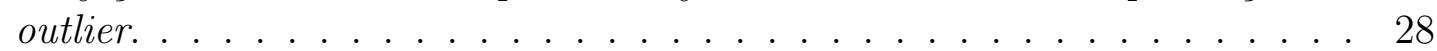

3.1 Etapas do processo de Mineração de Dados (Rezende et al.[ 2003). . . . . . . 33

3.2 Um processo estocástico interpretado como uma família de séries temporais. 35 
3.3 Uma série temporal $T$ de tamanho 128, uma subseqüência $C_{67}^{16}$ de tamanho $n=16$ e offset $=67$ sendo extraída pela janela de deslizamento, e as primeiras 8 subseqüências extraídas pela janela. Note que as subseqüêencias extraídas se sobrepõem $($ Keogh et al., 2003). . . . . . . . . . . . . . . . . . 36

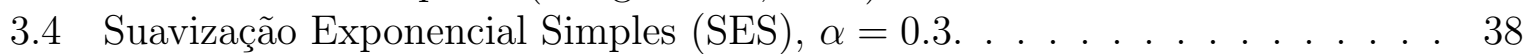

3.5 Normalização de séries temporais. As linhas em cinza representam a distância Euclidiana (Keogh e Kasetty, 2002). . . . . . . . . . . . . . . . . . . 39

3.6 Método de Momentos Sazonais. . . . . . . . . . . . . . . . . . . . . 41

3.7 Noção intuitiva da distância Euclidiana, que pode ser vista como a soma das linhas cinzas entre os pares de pontos. . . . . . . . . . . . . . . . . 42

3.8 Abandono prematuro do cálculo da distância Euclidiana (Keogh et al., 2006a). 43

3.9 Apesar das duas séries terem formas similares, elas não estão alinhadas no eixo do tempo. A distância Euclidiana gera uma medida de dissimilaridade pessimista, já o Dynamic Time-Warping (DTW) produz uma medida de dissimilaridade mais intuitiva devido aos alinhamentos não-lineares (Keogh

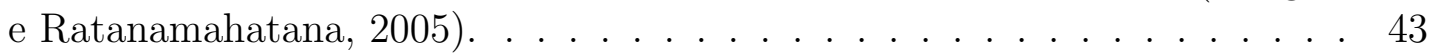

3.10 Matriz de alinhamento para o cálculo do DTW, A área em cinza mostra uma janela de alinhamento (Keogh e Ratanamahatana, 2005). . . . . . . . 44

3.11 Janelas de alinhamento. Em (b), $E_{M A X}=2 \ldots \ldots . \ldots . . \ldots 46$

3.12 Uso de medidas de limite inferior para buscar séries similares a uma série de consulta $Q$ dentro de uma base de dados. . . . . . . . . . . . . . . 48

3.13 Envelopes para cálculo da estimativa $L B_{-} K \operatorname{Keogh}$ (Keogh e Ratanamahatana $(2005) . \ldots \ldots \ldots \ldots \ldots . \ldots \ldots \ldots$

3.14 Função de Limite Inferior $L B_{-} K \operatorname{Keogh}(Q, C)$ (Keogh e Ratanamahatana, 2005). 49

3.15 Representações de séries temporais. A série original está em azul, e a representação em vermelho. . . . . . . . . . . . . . . . . . . . . 51

3.16 A série temporal (linha preta), já normalizada, é discretizada, obtendo-se uma representação PAA (linha cinza grossa). Depois uma lista de breakpoints é usada para mapear os coeficientes PAA em letras (em negrito). Neste exemplo, $n=128, w=8$ e $a=3$, a série é discretizada para a string cbccbaab (Keogh et al. [2005). . . . . . . . . . . . . . . . 54

3.17 Exemplo das classes do conjunto de dados Cylinder-Bell-Funnel (CBF). . . 57

3.18 Casamento de subseqüências (Vlachos, 2004). $\ldots \ldots \ldots$. . . . . . . 58

3.19 Para quase toda subseqüência $C$ em uma série temporal, as subsequiências mais similares são as subseqüências imediatamente à esquerda e à direita de $C$ (Keogh et al., 2003). . . . . . . . . . . . . . . . . . 59

4.1 Visão geral do processo para projeção de séries temporais aplicado pela ferramenta Temporal-Projection Explorer (Temporal-PEx). . . . . . . . . . 62

4.2 Triangulação de Delaunay. . . . . . . . . . . . . . . . . . . . 64

4.3 Janela principal da ferramenta Temporal-PEx. O conjunto de dados exibido é o Cylinder-Bell-Funnel discutido na Seção [2.3. . . . . . . . . . . . . . . . 65 
4.4 Casamento de subseqüências interativo. Subseqüência de consulta selecionada interativamente por meio do mouse, e destacado em vermelho. Porcentagem de diferença máxima $=10 \%$. Com normalização. . . . . . . . . 67

4.5 Classes do conjunto de dados Synthetic Control Chart. Cada classe é representada na figura por sua série temporal média. . . . . . . . . . . . 70

4.6 Conjunto de dados Synthetic Control Chart projetado com a técnica Interactive Document Map (IDMAP). . . . . . . . . . . . . . . . . . . . . . . . 70

4.7 Conjunto de dados Gun-Point. . . . . . . . . . . . . . . . . . . . . . 71

4.8 Projeção do conjunto de dados Gun-Point com a técnica Least Square Projection (LSP) e a medida de dissimilaridade DTW Classe point em azul, e classe gun em vermelho. . . . . . . . . . . . . . . . . . 72

4.9 Séries com valores médios semanais de ações de 1430 empresas durante 26 semanas. Projeção gerada com técnica IDMAP e distância Euclidiana. . . 75

4.10 Exemplos de séries temporais extraídas de cada um dos quatro pacientes. . 77

4.11 Projeção do conjunto de eletrocardiogramas por meio da técnica|LSP|, Cada cor indica um paciente . . . . . . . . . . . . . . . 77

4.12 Eletrocardiograma de paciente com arritmia. Anotações: V - contração ventricular prematura; $\bullet$-batimento normal. . . . . . . . . . 78

4.13 Casamento de subseqüências para busca por batimentos anormais em um eletrocardiograma (ECG). . . . . . . . . . . . . . . . 79

4.14 Usinas Hidrelétrica de Furnas. . . . . . . . . . . . . . . . . . . . . . . . . 81

4.15 Regiões hidrográficas do Brasil. . . . . . . . . . . . . . . . . . . . 82

4.16 Projeção das séries de vazões anuais da usina Furnas ao longo dos anos de 1931 a 2005. Projeção criada com a técnica|IDMAP| e com a distância Euclidiana. ....................... 83

4.17 Diagrama da localização geográfica das usinas da região hidrográfica do

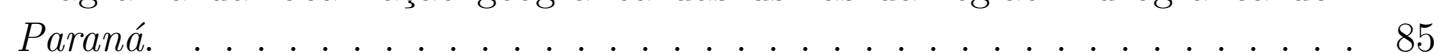

4.18 Projeção para a Região Hidrográfica do Paraná. ........... . 86

4.19 Projeção (IDMAP e distância Euclidiana) das séries de vazões registradas no ano de 1982, nas usinas da região hidrográfica do Paraná. Cada cor identifica uma sub-bacia. . . . . . . . . . . . . . . 88 



\section{Lista de Tabelas}

2.1 Matriz de distância. . . . . . . . . . . . . . . . . . . . 17

3.1 Estimação não paramétrica da sazonalidade. . . . . . . . . . . . . . . . . . 40

3.2 Principais representações de séries temporais. . . . . . . . . . . . . 52

3.3 Tabela de breakpoints para a etapa de discretização, com o tamanho do alfabeto variando de 3 a $10 . \ldots \ldots \ldots \ldots$. . . . . . . . . . . . 54

3.4 Comparação de Medidas de Similaridade para Classificação. . . . . . . . . 57

4.1 Exemplo do formato Time Series Datafile (TSD). . . . . . . . . . . . . . . 63

4.2 Matriz de distância. . . . . . . . . . . . . . . . . . . . . 63

4.3 Comparação de medidas de similaridade para classificação das séries do conjunto gun-point. . . . . . . . . . . . . . . . . 73

4.4 Matriz de confusão para a classificação dos dados gun-point. . . . . . . . . 73

4.5 Técnicas de projeção: vantagens e desvantagens . . . . . . . . . . . . . . . 89

4.6 Medidas de Dissimilaridade: vantagens e desvantagens . . . . . . . . . . . 90

4.7 Tempo de processamento . . . . . . . . . . . . . . . . . . 91 

APCA Adaptive Piecewise Constant Approximation

CBF Cylinder-Bell-Funnel

CDM Compression-based Dissimilarity Measure

CSV Comma-Separated Values

CVP contração ventricular prematura

DFT Discrete Fourier Transform

DTW Dynamic Time-Warping

DWT Discrete Wavelet Transform

ECG eletrocardiograma

ICC Insuficiência Cardíaca Congestiva

IDMAP Interactive Document Map

LSP Least Square Projection

MD Mineração de Dados

MMS Médias Móveis Simples

NNP Nearest Neighbors Projection

ONS Operador Nacional do Sistema Elétrico

PAA Piecewise Aggregate Approximation

PEX Projection Explorer

PLA Piecewise Linear Approximation 
SAX Symbolic Aggregate approXimation

SES Suavização Exponencial Simples

SIN Sistema Interligado Nacional

SVD Singular Value Decomposition

Temporal-PEx Temporal-Projection Explorer

TSD Time Series Datafile

VDM Visual Data Mining

XML eXtensible Markup Language 
Nos últimos dois anos houve um crescimento dramático na armazenagem de informação em todos os tipos de mídias, principalmente as mídias digitais. Esse crescimento é decorrente de dois fatores: o crescimento da produção intelectual da humanidade, proporcionada pela automação das atividades em inúmeras áreas; e o aumento na capacidade de armazenagem das bases de dados, sustentada pelo avanço tecnológico. Esses dados são colecionados porque são fontes potenciais de informações valiosas, provendo uma vantagem competitiva para quem detem essa informação. No entanto, identificar informação útil de conjuntos de dados tão massivos é uma tarefa difícil, e se nenhuma informação for extraída o armazenamento dos dados terá sido inútil (Keim, 2002).

Com objetivo de automatizar e auxiliar a extração de informações de grandes bases de dados surgiu a área conhecida como mineração de dados. Essa área é voltada ao processo de extração de conhecimento útil e previamente desconhecido em dados, por meio da aplicação de algoritmos, que extraem modelos e padrões representativos desse. No entanto, a aplicação de algoritmos de mineração tornar-se-á inútil se o usuário não conseguir analisar os padrões extraídos, ou não entender o processo relativo ao algoritmo aplicado. Nesse último caso, o usuário pode ser incapaz de ajustar os parâmetros para obter os melhores resultados. Dessa forma, para que a mineração de dados seja efetiva é importante que este seja um processo interativo com a participação do ser humano (Fayyad et al., 1996a). 
Paralelamente ao desenvolvimento de algoritmos de mineração de dados, surgiu a área de visualização focada em explorar a sofisticada capacidade visual do ser humano para identificar padrões nos dados. Uma abordagem que combina essas duas linhas de pesquisa é a área conhecida como mineração visual de dados, que busca tornar o processo de mineração mais interativo e eficaz por meio da inserção da visualização em seu processo. Essa combinação oferece muitas possibilidades, pois é capaz de apresentar padrões obtidos pela mineração de dados visualmente, apoiando a extração do conhecimento dirigida pelo usuário, que pode incorporar o seu conhecimento do domínio e experiência.

Séries temporais são um tipo de dado recorrente, o que é altamente esperado, já que elas são obtidas como resultado em várias áreas, como em biologia, finanças, geologia, análise de movimentos humanos, entre outras. A larga presença em várias áreas de aplicação garante a esse tipo de dado uma alta importância. Já que uma série temporal $T=\left(T_{1}, \ldots, T_{m}\right)$ pode ser definida como um conjunto de $m$ observações seqüenciadas no tempo, esta também pode ser interpretada como um ponto definido em um espaço $m$-dimensional. Essa alta dimensionalidade dificulta a análise de dados dessa natureza em sua forma bruta.

Este trabalho se insere neste contexto, propondo o estudo e implementação de uma ferramenta de mineração visual de dados orientada especificamente a dados expressos na forma de séries temporais. Após um levantamento de trabalhos relacionados em visualização de séries temporais, e a identificação de tarefas típicas de mineração de dados dessa natureza, diversas funcionalidades foram implementadas e incorporadas a esse ambiente. Técnicas denominadas projeções multidimensionais são adotadas como arcabouço para a geração de representações visuais. Essas técnicas buscam projetar os dados definidos em um espaço de dimensionalidade alta para um espaço $p$-dimensional com $p \in\{1,2,3\}$ e $p \ll m$, na medida do possível retendo, no espaço projetado, as relações de similaridade observadas entre os itens de dados no espaço original. O ambiente também incorpora funcionalidades que apóiam a execução de tarefas de mineração, que auxiliem na descoberta de padrões. Dessa forma utilizando essas abordagens, apresentamos neste projeto uma ferramenta de mineração visual de dados útil para apoiar a análise de conjuntos de séries, proporcionando ao analista uma visão geral dos dados que favorece a identificação de elementos com padrões similares/dissimilares, provendo um ponto de partida para explorações mais detalhadas. 


\subsection{Organização da Dissertação}

Esta dissertação está organizada da seguinte maneira:

- No Capítulo 2 é apresentada uma revisão bibliográfica sobre a área de visualização de informação aplicada a séries temporais. Neste capítulo também são apresentadas técnicas de projeção multidimensional como forma de gerar representações visuais de conjuntos de dados.

- O Capítulo 3, por sua vez, traz uma revisão bibliográfica sobre mineração de dados aplicada à séries temporais. Neste capítulo também são apresentados conceitos e tarefas de mineração utilizadas para o desenvolvimento deste projeto.

- No Capítulo 4 são apresentados a ferramenta proposta e implementada, e os resultados obtidos com o seu uso em diferentes conjuntos de séries.

- Por fim, no Capítulo 5 apresenta-se as conclusões desse projeto de mestrado, caracterizando as contribuições e limitações do trabalho, bem como sugestões de desenvolvimentos futuros desta abordagem. 


\section{Visualização de Séries Temporais}

\subsection{Considerações Iniciais}

Seres humanos estão sempre procurando por estruturas, características, padrões, tendências, anomalias, e relacionamentos em dados (Fayyad et al., 1996b). No entanto, esta nem sempre é uma tarefa fácil, o que motivou o surgimento de uma nova área conhecida como visualização, que procura na visão humana um auxílio para esta busca. A visualização tem por objetivo a criação de modelos gráficos e representações visuais de dados, com o objetivo de apoiar a interação do usuário com estes dados, facilitando a exploração e aquisição de informações úteis neles contidas (Oliveira e Levkowitz, 2003).

Card et al. (1999) descrevem a visualização como uma seqüência de mapeamentos ajustáveis de dados para uma representação visual, de modo a possibilitar a interação do usuário com o espaço de informação, objetivando o que foi chamado de cristalização do conhecimento. Esta seqüência de mapeamentos encontra-se reproduzida na Figura 2.1. Esse modelo de referência busca retratar os componentes essenciais de uma visualização. No primeiro passo os dados brutos (coletados ou gerados por algum processo) são transformados num conjunto de relações (tabelas de dados), que são estruturadas e mais facilmente mapeadas para formas visuais. Um segundo passo prevê a escolha de estruturas visuais para mapear essas tabelas de dados, que utilizam marcas e propriedades gráficas 
para mapear a informação contida nos dados. Para finalizar, o usuário deve ser capaz de interagir com as visões para controlar a quantidade de informação exibida na tela e para alterar as propriedades da visualização. A interação do usuário com o espaço de informação retratado pelas visões apóia a percepção de estruturas interessantes, favorecendo a aquisição de conhecimento.

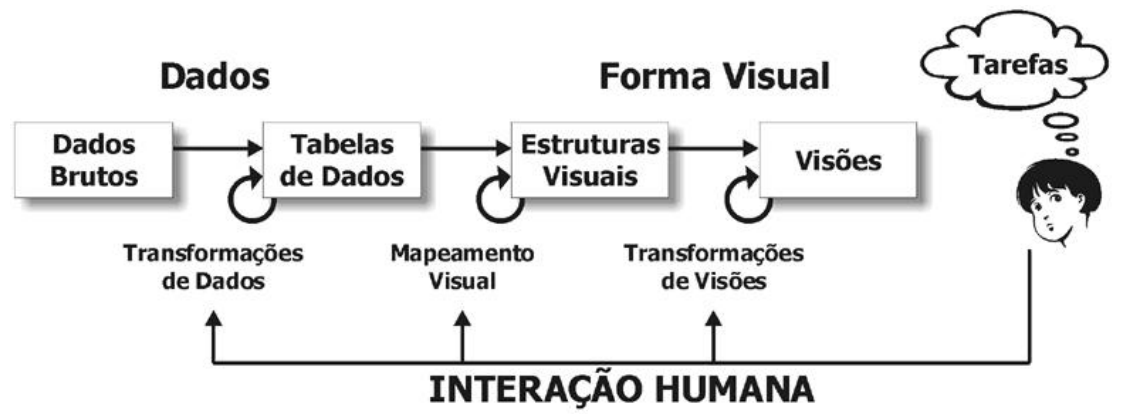

Figura 2.1: Modelo de referência de visualização de Card et al. (Card et al., 1999)

É possível destacar duas linhas na área de visualização: a Visualização Científica e a Visualização de Informação. A Visualização Científica, em geral, cria modelos gráficos de dados do mundo físico - o corpo humano, a terra, moléculas, e outros. Mesmo que a visualização gerada mostre alguma abstração do espaço físico, a informação é inerentemente geométrica. Como exemplo, pode-sel citar uma visualização da concentração de ozônio na atmosfera, que pode ser baseada numa representação física 3D da Terra.

As informações de natureza não-física - como dados financeiros, informações de negócio, coleções de documentos, e outras concepções abstratas - também podem ser representadas por modelos gráficos. A Visualização de Informação manipula tipos de dados que não possuem um mapeamento espacial óbvio. Assim, um desafio da Visualização de Informação é criar novas metáforas visuais capazes de representar esses dados abstratos.

A visualização de séries temporais enquadra-se na área de Visualização de Informação, pois requer a criação de metáforas visuais. Atualmente, existem várias técnicas de visualização de séries temporais. Isso é plausível e altamente esperado já que elas ocorrem várias áreas, como em biologia, finanças, geologia, análise de movimentos humanos, entre outras e, conseqüentemente, é um tipo de dado de grande importância. No entanto, a visualização de séries temporais é de extrema dificuldade pela alta dimensionalidade desses dados.

Na Seção 2.2 serão apresentadas técnicas de visualização de séries temporais encontradas na literatura. Já na Seção 2.3 é apresentado o conceito de projeções multidimensionais, 
abordagem utilizada neste projeto para criar metáforas visuais para conjuntos de séries temporais.

\subsection{Visualização de Séries Temporais}

Uma das formas mais simples e antiga de visualizar séries temporais é o gráfico de linha, obtido pela ligação de segmentos de reta unindo os pontos que representam os dados. William Playfair (1759-1823) argumentava que gráficos comunicavam informações melhor do que tabelas de dados, e a ele é atribuído a criação de gráficos como o de linha. Na Figura 2.2, por exemplo, são mostrados gráficos de séries que registram a importação e exportação da Inglaterra versus Dinamarca e Noruega entre 1700 a 1780. A área entre as curvas foi enfatizada para representar o balanço comercial.

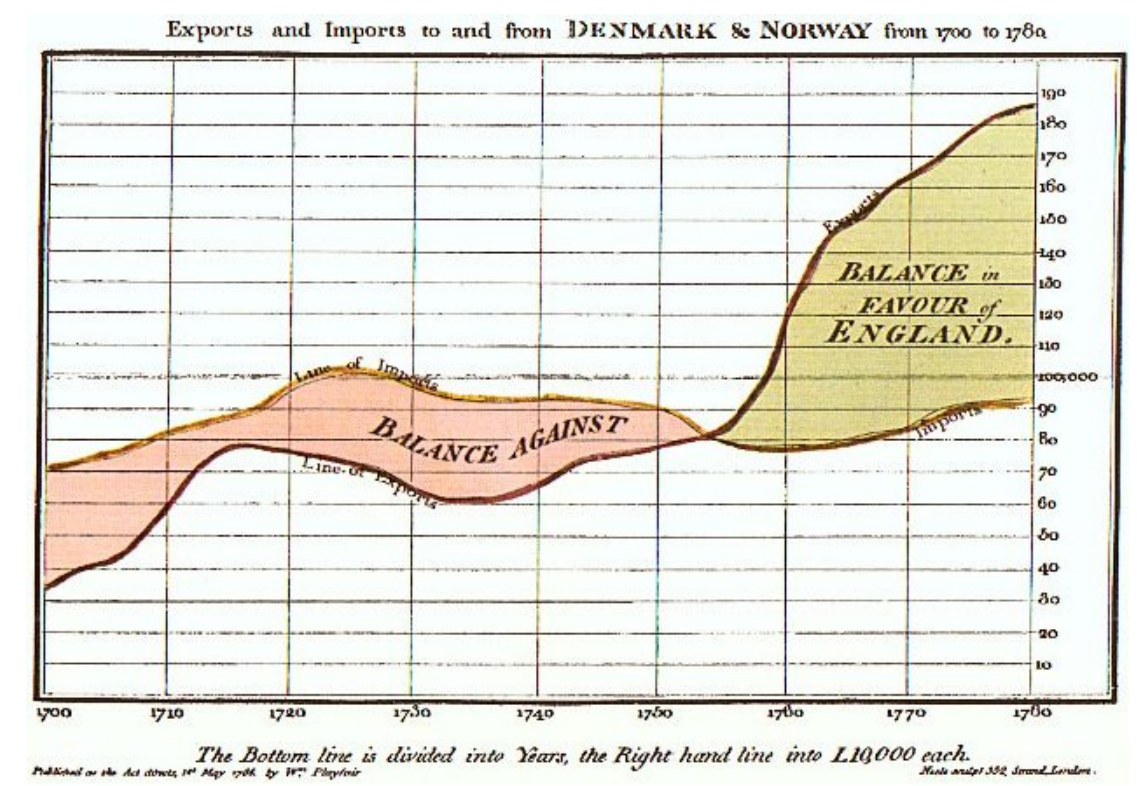

Figura 2.2: Balanço comercial da Inglaterra vs. Dinamarca e Noruega durante 1700 a 1780 (Playfair, 1786).

Mas, essa aplicação da visualização nem sempre é fácil ou direta. Muitas das técnicas tradicionais, como o gráfico de linha, não são escaláveis, do ponto de vista visual, para volumes de dados muito grandes. O problema é ilustrado na Figura 2.3, que mostra uma visualização de séries pelo tradicional gráfico de linhas: a sobreposição de elementos visuais é tão grande que inviabiliza a sua interpretação.

Entre os problemas associados ao uso de técnicas de visualização para conjuntos de dados volumosos estão (Novotny, 2004): 


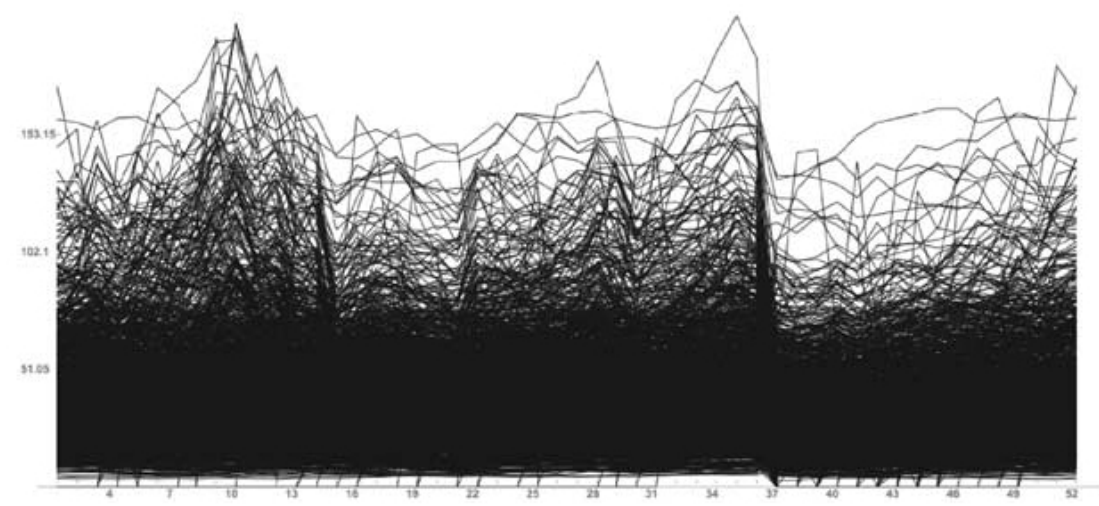

Figura 2.3: Visualização do preço de 1430 ações durante 52 semanas (Hochheiser e Shneiderman, 2004).

- Perda de velocidade e interação - Como boa proporção do tempo de computação é gasto na visualização dos elementos, quando o conjunto de dados cresce o tempo necessário para completar o desenho desses elementos cresce proporcionalmente, o que reduz o tempo de resposta da aplicação e dificulta o uso de técnicas de interação.

- Oclusão visual - A oclusão ocorre quando dois ou mais elementos visuais se sobrepõem, obstruindo sua percepção, dificultando a interpretação da visualização e impedindo o reconhecimento de relações e detalhes. A oclusão é agravada proporcionalmente à quantidade de itens exibidos.

Outra questão é a necessidade de evidenciar certas características ou padrões nas séries, o que nem sempre é fácil em técnicas como o gráfico de linhas. Em vista destas dificuldades e interesses existem diversos trabalhos para visualização de séries temporais, que serão destacados nas seções seguintes.

\subsubsection{Visualização Baseada em Espirais}

Espirais têm sido utilizadas para evidenciar padrões periódicos em séries temporais. Uma primeira técnica proposta por Carlis e Konstan (1998) usou espirais para destacar atributos seriais ao longo do eixo espiral e periódicos ao longo do eixo radial. Estruturas como círculos ou barras tridimensionais são dispostas nas intersecções dos eixos espiral e radial. Na Figura 2.4(a) a técnica é ilustrada em dados sobre o consumo da planta chamada Baphia Capparidifolia por chimpanzés em uma reserva na Tanzânia, durante os anos de 1980 a 1988. Cada volta na espiral representa um ano e cada eixo radial um mês. O mês de Janeiro começa no que seria 3 horas em um relógio, e o sentido é anti-horário. 
A área dos círculos é proporcional ao consumo daquele mês. Nota-se um maior consumo da planta no período chuvoso, que vai aproximadamente de Outubro a Abril. No entanto, essa técnica faz um uso exagerado de estruturas tridimensionais em sua extensão para visualizar mais de uma série temporal. Ela também não é adequada para séries muito longas e pode gerar oclusão visual para séries com ciclo periódico longo.

A técnica Spiral Graphs, proposta por Weber et al. (2001), também utiliza espirais para visualização de séries. Nesta técnica, atributos como cor, textura e espessura das linhas da espiral são utilizados para mapear os valores dos dados. Se o tamanho do cilo periódico da série é desconhecido é possível animar a espiral, mudando continuamente o tamanho do ciclo, usando a habilidade visual para detectar o tamanho do período. Já a extensão chamada Multiple Spiral Graphs visa suportar a comparação de múltiplas séries. A Figura 2.4(b) lustra esta técnica para visualização de dados que registram o consumo de energia de uma cidade da Holanda a cada 15 minutos durante o ano de 1997. Cada volta da espiral representa o período de uma semana. As cinco áreas mais densas na espiral representam o aumento do consumo de energia durante os dias úteis da semana. Esta segunda técnica é mais adequada para séries longas e/ou com ciclos periódicos longos.

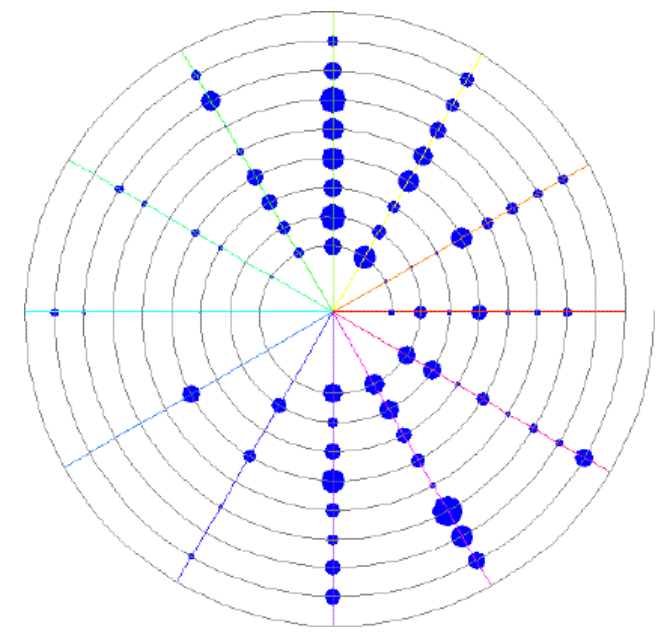

(a) Abordagem de Carlis e Konstan (1998).

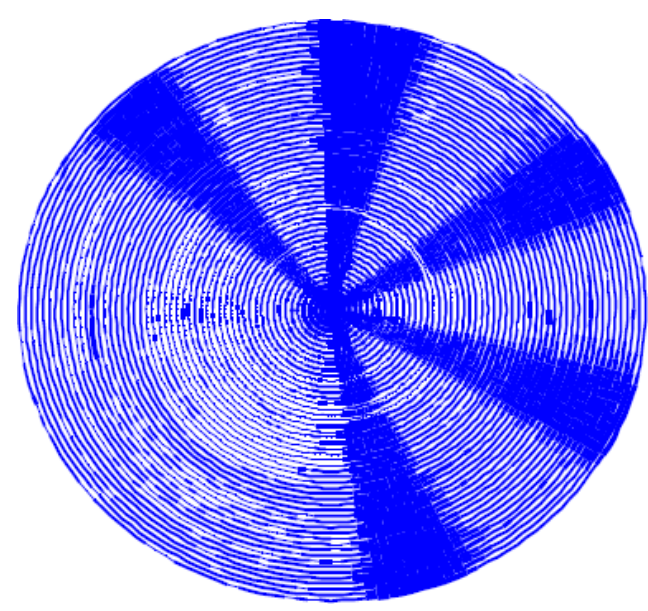

(b) Spiral Graphs de Weber et al. (2001).

Figura 2.4: Uso de espirais para visualização de séries temporais.

Apesar do uso de espirais ser muito interessante para a visualização de séries, essa abordagem somente é adequada para séries temporais periódicas. 


\subsubsection{Visualização Exploratória Interativa}

O projeto TimeSearcher for Time-Series Data desenvolvido no laboratório de Interação Humano-Computador da Universidade de Maryland, busca desenvolver ambientes de consulta e exploração interativa de conjuntos de séries. Duas ferramentas desenvolvidas no âmbito deste projeto são descritas a seguir.

O TimeSearcher1 (Hochheiser e Shneiderman, 2004) é uma ferramenta de visualização exploratória de séries, cujo principal atrativo é o uso de timeboxes. Timeboxes são regiões de consultas visuais retangulares desenhadas diretamente sobre o gráfico de linha das séries. A extensão do eixo $x$ especifica o período de tempo de interesse, e a extensão do eixo $y$ especifica o intervalo de valores permitidos para aquele período de tempo. Múltiplos timeboxes podem ser utilizados para especificar consultas conjuntivas. Séries devem obedecer a todas as restrições estabelecidas pelos timeboxes para serem inclusas no resultado. A Figura 2.5(a) apresenta o uso de múltiplos timeboxes (regiões em verde água) na ferramenta TimeSearcher1. Ao contrário de algoritmos convencionais de busca por similaridade em séries, que precisam que uma série de consulta inteira seja fornecida, esta ferramenta permite a flexibilidade de se especificar o comportamento desejado somente em algumas regiões de interesse.

A principal extensão de uma segunda ferramenta, chamada TimeSearcher2, em relação à primeira, é a busca por padrões internos as séries, especificada por uma estrutura chamada searchbox (ver Figura 2.5(b)). O usuário seleciona um padrão, primeiro selecionando uma única série temporal (série destacada em azul na figura), e então desenhando uma searchbox (região em vermelho) que confina o padrão. A searchbox também é associada a um slider de tolerância. Ativada a busca, a ferramenta irá procurar por padrões similares ao padrão de consulta, conforme a tolerância permitida, em todas as séries do conjunto. No entanto, essa busca não é eficiente, pois é seqüencial e a medida que quantifica a similaridade entre dois padrões é a distância Euclidiana. Como discutido no próximo capítulo, essa distância é sensível a artefatos como ruído e distorções no eixo temporal.

O grande problema da abordagem dessas ferramentas é a necessidade de conhecimento prévio sobre o conjunto de dados, pois o usuário deve saber qual seria um padrão interessante a ser procurado.

\subsubsection{Visualização Baseada em Agrupamento e Calendário}

O trabalho chamado Cluster and Calendar based Visualization of Time Series Data (Wijk e Selow, 1999) busca apresentar padrões presentes nos dados por meio de um calendário. 


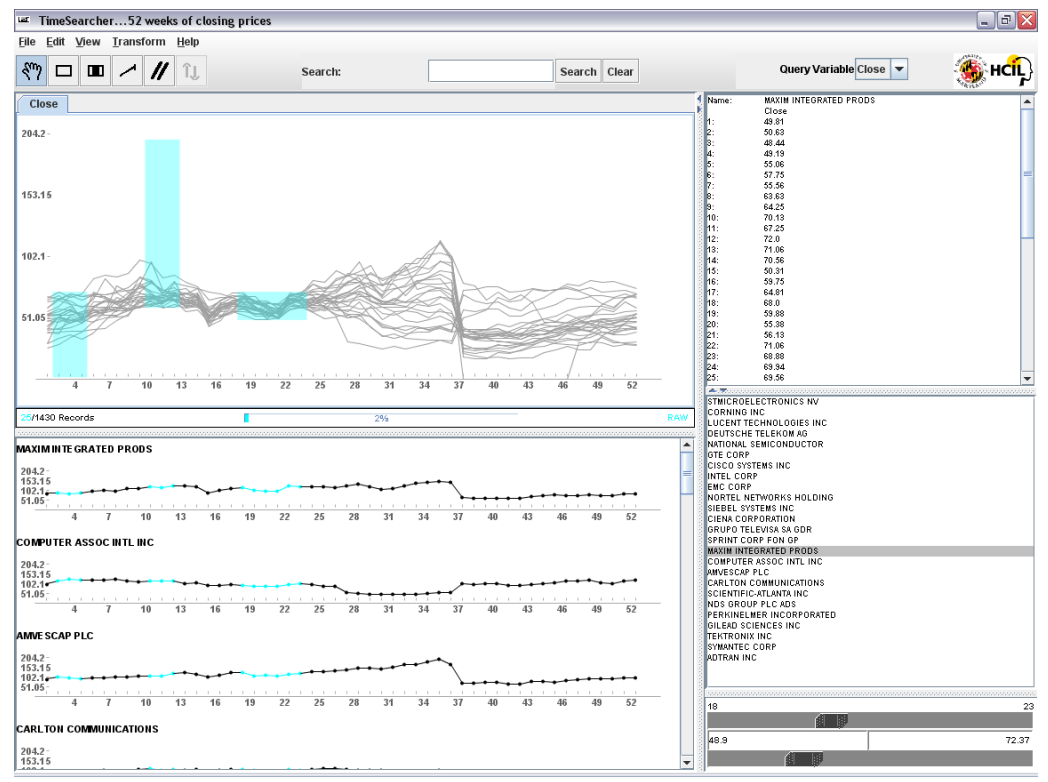

(a) TimeSearcher 1

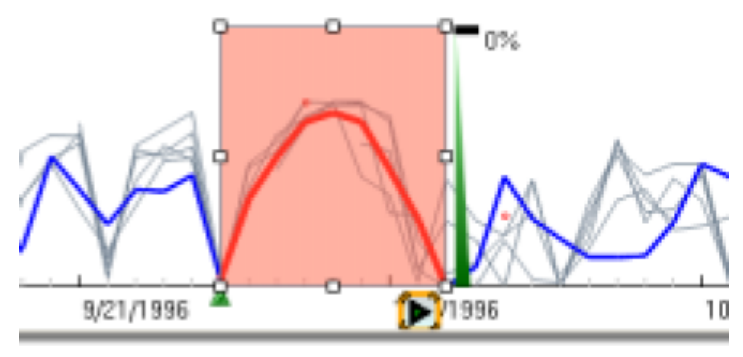

(b) Extensão SearchBox presente no TimeSearcher2

Figura 2.5: TimeSearcher. 
Primeiramente, os dados a serem analisados devem ser subdivididos de forma que cada série resultante englobe somente uma escala no calendário (diária, semanal, mensal, etc.). Um segundo passo aplica um clustering para agrupar series similares. Os padrões encontrados pelo clustering são, então, visualizados como na Figura 2.6. Nesta visualização cada cluster é representado pela série média das séries que o compõem, e a cor de cada dia (escala escolhida) irá mapear o cluster ao qual a série daquele dia pertence.

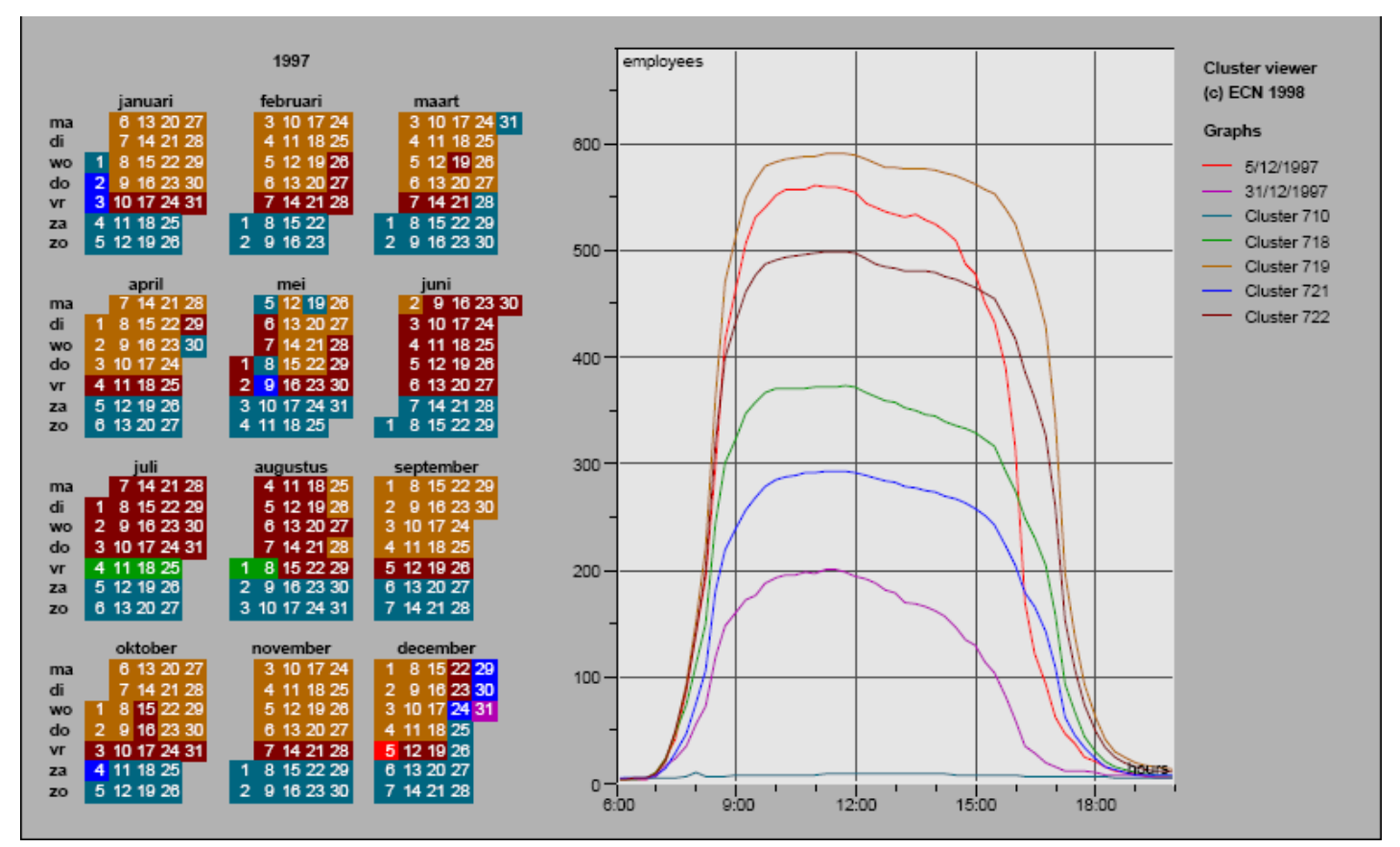

Figura 2.6: Visualização baseada em clustering e calendário para séries temporais que registram o número de empregados presentes em uma determinada hora do dia em uma empresa holandesa (Wijk e Selow, 1999).

Essa técnica é limitada a dados que apresentam alguma regularidade imposta por dependência social ou financeira ao calendário. Essa proposta também é de pouca utilidade para dados cujos padrões não são apresentados em uma escala específica (diária, por exemplo). Outra desvantagem é a necessidade de algum conhecimento prévio sobre os padrões presentes nos dados para escolher, por exemplo, o número de clusters a serem encontrados.

\subsubsection{Visualização Baseada em Projeções Geométricas}

Técnicas de projeção geométrica suportam usuários na tarefa de procura por projeções informativas de conjuntos de dados multi-dimensionais. A técnica clássica chamada Coordenadas Paralelas (Wegman, 1990) mapeia o espaço $m$-dimensional dos dados em um 
display bidimensional pelo uso de $m$ eixos eqüidistantes, paralelos a um dos eixos do display. Os eixos correspondem aos atributos, e são linearmente escalados do mínimo para o máximo valor do atributo correspondente. Cada instância do conjunto de dados é apresentada como uma linha poligonal, que intercepta cada um dos eixos no ponto correspondente ao valor daquele atributo. Um exemplo é apresentado na Figura 2.7.

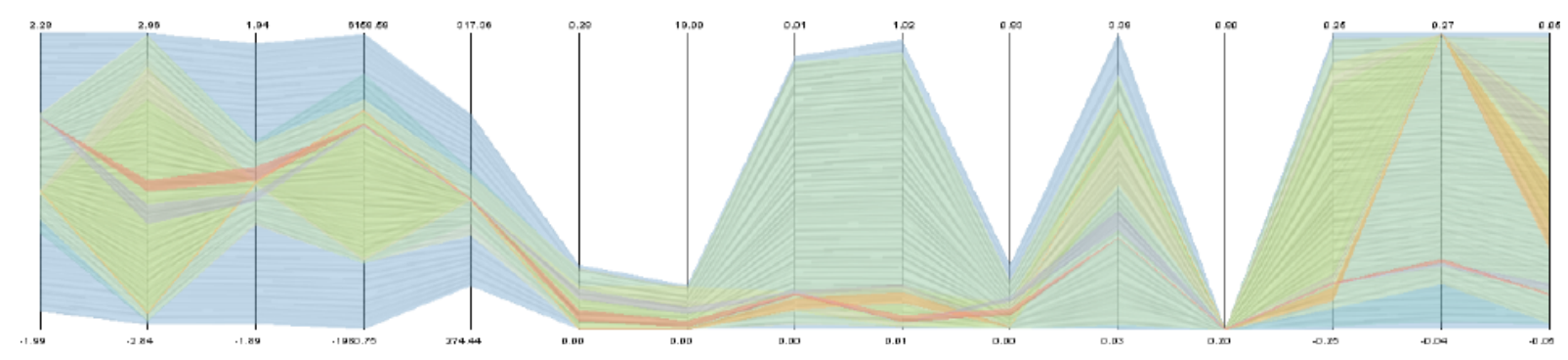

Figura 2.7: Coordenadas Paralelas (Novotny, 2004).

Apesar do conceito básico ser bastante simples, essa é uma poderosa técnica para a identificação da distribuição dos dados e de correlações entre atributos. Cruzamentos de linhas poligonais no formato de um "X", por exemplo, indicam uma correlação inversa entre os atributos. No entanto, como as linhas poligonais podem se sobrepor, o número de elementos que podem ser exibidos simultaneamente sem oclusão visual é limitado a cerca de 1.000 itens. Para minimizar este problema, podem ser usadas funcionalidades como cores para destacar itens de dados, ou técnicas de interação, como zoom, e de filtragem. Outro problema relevante é determinar uma ordenação representativa dos eixos.

Séries temporais também podem se beneficiar de visualizações geradas por Coordenadas Paralelas. Para tal, cada eixo deve mapear um instante do eixo temporal das séries, e estes eixos devem seguir a ordenação natural do eixo temporal. No entanto, séries temporais têm, em geral, uma alta dimensionalidade, o que torna inviável a aplicação direta de técnicas de projeção geométrica às séries temporais.

A técnica 3D Time Wheel (Tominski et al., 2005) busca superar tais problemas. Essa técnica visa à análise de séries multivariadas, cuja característica é a presença de múltiplos atributos. Uma série multivariada sobre condições meteorológicas, por exemplo, pode conter três atributos multivariados para um mesmo instante no eixo temporal: temperatura, umidade e quantidade de chuva. A Figura 2.8(a) ilustra esta técnica. O eixo central representa o atributo temporal de referência, e os atributos dependentes são arranjados ao redor dele. De forma similar à técnica Coordenadas Paralelas, um segmento de linha colorido entre dois eixos faz a conexão entre um instante no tempo (eixo central) e o valor correspondente para um atributo (eixo periférico) naquele instante. Os eixos dos atributos 
também possuem um marcador (pequeno disco em azul) que oferece uma indicação visual da média dos valores daquele atributo. Também é possível dispor os planos de forma que dois deles fiquem com um ângulo de $180^{\circ}$ (ver Figura 2.8(b)]. A análise desses atributos adjacentes torna-se mais fácil com essa disposição. O 3D Time Wheel promove a identificação da distribuição de valores para um determinado atributo e de relações entre os atributos. No entanto, permite visualizar uma série multivariada por vez.

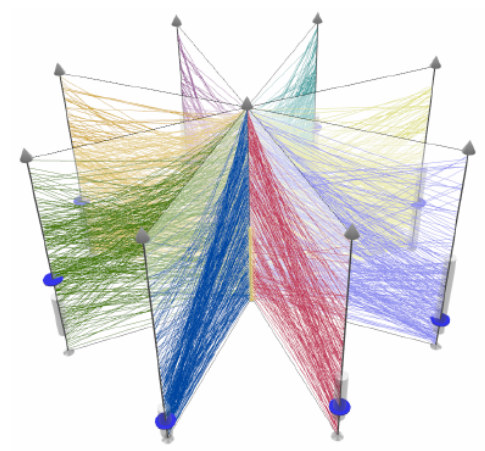

(a) Disposição padrão.

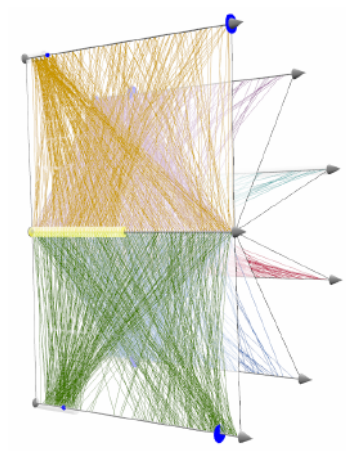

(b) Disposição em formato de livro.

Figura 2.8: Visualização baseada em eixos (Tominski et al., 2005).

\subsubsection{Visualização Baseada em Preenchimento de Espaço}

Hao et al. (2005) utilizam o conceito de layouts baseados na 'importância' da série temporal para visualização de grandes coleções de séries. Séries individuais são visualizadas como gráficos de barras, já os conjuntos delas são arranjadas num layout de preenchimento de espaço que reflete a importância relativa de uma série dentro da coleção. A percepção de importância de uma série no layout é mapeada para duas propriedades: posição e tamanho. Séries temporais no topo e à esquerda são ditas mais importantes, e quanto maior a área reservada para a série maior a sua importância. A medida de importância de uma série é dependente da aplicação e deve ser selecionada por um especialista do domínio. No entanto, os autores implementaram algumas medidas de importância básicas, como agregações (média, soma, mínimo, máximo), que são adequadas para diversas aplicações. Esse trabalho pode visualizar também coleções estruturadas de séries, que possuem uma organização hierárquica. A abordagem de preenchimento de espaço garante a não sobreposição das séries, mas o número de séries que podem ser inspecionadas simultaneamente ainda é limitado. A Figura 2.9 mostra o layout gerado por esta técnica para séries referentes a vendas de produtos. 


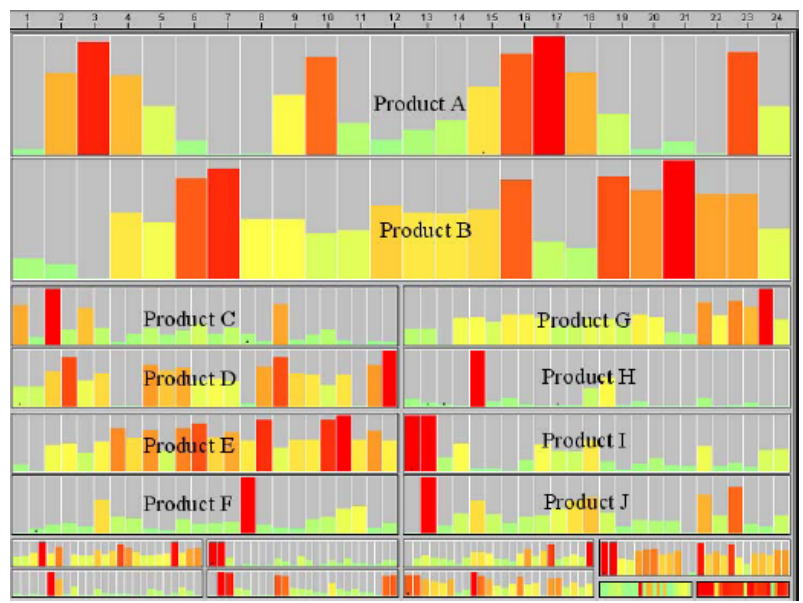

Figura 2.9: Técnica de mapeamento em layouts baseados em importância para 19 séries sobre vendas de um produto. O produto A tem a maior média de vendas, importância de acordo com este contexto, sendo mapeado no topo (Hao et al., 2005).

\subsection{Projeções Multidimensionais}

Neste projeto de mestrado foi utilizada a abordagem de projeções multidimensionais para criar mapas para conjuntos de séries temporais. A representação visual gerada por projeções multidimensionais é capaz de descrever visualmente e eficientemente a distribuição de dados multidimensionais volumosos.

Uma série temporal consistindo de $m$ observações pode ser interpretada como um ponto definido em um espaço $m$-dimensional. Uma forma de visualizar um conjunto desses pontos consiste em projetá-los em um espaço de dimensionalidade 2 ou 3, construindo, a partir da projeção, uma representação visual do conjunto de séries. Existem diversas técnicas de projeção multidimensional, sendo que todas elas buscam projetar os dados definidos em um espaço de dimensionalidade alta para um espaço $p$-dimensional com $p \in\{1,2,3\}$ e $p \ll m$, na medida do possível retendo, no espaço projetado, as relações de distância observadas entre os itens de dados no espaço original. A seguir tem-se a definição formal de uma técnica de projeção multidimensional, segundo Tejada et al. (2003) para o caso específico de $p=2$ :

Definição 2.1 . Projeção Multidimensional: Para $p=2$, seja $X=\left\{x_{1}, x_{2}, \ldots, x_{m}\right\}$ um conjunto de dados $m$-dimensional, e $\delta: \mathbb{R}^{m} \rightarrow \mathbb{R}$ uma medida de dissimilaridade entre instâncias $m$-dimensionais dos dados. Deseja-se encontrar um conjunto de pontos $X^{\prime}$ em $\mathbb{R}^{2}$ tal que se $\alpha: X \rightarrow X$ é uma função bijetora, que mapeia o conjunto de dados para o espaço bidimensional, e $d: \mathbb{R}^{2} \rightarrow \mathbb{R}$ é uma distância para espaços bidimensionais (normal- 
mente a distância Euclidiana), então busca-se minimizar $\left|\delta\left(x_{i}, x_{j}\right)-d\left(\alpha\left(x_{i}\right), \alpha\left(x_{j}\right)\right)\right|$ para $\forall x_{i}, x_{j} \in X$.

O resultado da projeção é um conjunto de pontos $X^{\prime}$ em $\mathbb{R}^{2}$, cada um representando uma instância dos dados, cujas coordenadas podem ser usadas para gerar uma representação gráfica. A similaridade é expressa por meio da vizinhança espacial entre os elementos na projeção, permitindo utilizar nossa habilidade de interpretação visual para analisar os dados. Essas representações fornecem uma visão geral dos dados que favorece a identificação de elementos com padrões similares/dissimilares, provendo um ponto de partida para uma exploração mais detalhada.

No entanto, visualizar os dados projetados como pontos no plano pode comprometer a interpretação e exploração de dados similares. Para ressaltar a percepção de vizinhança é possível conectar os pontos segundo algum critério, ou gerar uma triangulação. Outro recurso visual interessante é o mapeamento de informações adicionais, que por exemplo se existir uma classificação dos dados pode-se mapear a classe para a cor ou o tamanho dos marcadores gráficos, que representam os pontos.

A Figura 2.10 exemplifica uma representação gráfica de uma projeção multidimensional do conjunto de séries Cylinder-Bell-Funnel (CBF ${ }^{1}$. A cor dos círculos mapeia a classe à qual a série pertence e a triangulação de Delaunay (Edelsbrunner, 2001) dos pontos foi utilizada. Esta figura ilustra a utilidade de projeções para identificar visualmente a distribuição de padrões nos dados, pois o grau de proximidade física entre dois pontos representa o grau de similaridade entre os dois itens de dados por eles representados. Um fato interessante é a localização de uma série temporal da classe cylinder, em foco na figura, junto às séries da classe funnel. Fato explicado pelo declive com certo grau de suavidade (característica da classe funnel), onde deveria ser encontrada uma queda brusca (característica da classe cylinder).

Como discutido, as projeções multidimensionais oferecem grandes possibilidades na visualização de conjuntos de séries. Segundo a Definição 1, é necessário fornecer uma medida de dissimilaridade $\delta$ entre as instâncias $m$-dimensionais. Dessa forma, a matriz de distâncias é a base para a projeção. Dado um conjunto de $n$ séries, $S=\left\{S_{1}, \ldots, S_{n}\right\}$, uma matriz de distância contém a distância entre os pares de séries (ver Tabela 2.1). Nesta tabela a expressão $\delta\left(S_{i}, S_{j}\right)$ representa a distância entre as séries temporais de índices $i$ e $j$, segundo alguma métrica de dissimilaridade. A definição de funções de distância para

\footnotetext{
${ }^{1} \mathrm{O} \widehat{\mathrm{CBF}}[($ Saito, 1994) é um conjunto de séries temporais classificadas em três classes: cylinder, bell e funnel. Obtido por Hettich e Bay (1999) contém 100 séries, de tamanho 128, de cada classe.
} 


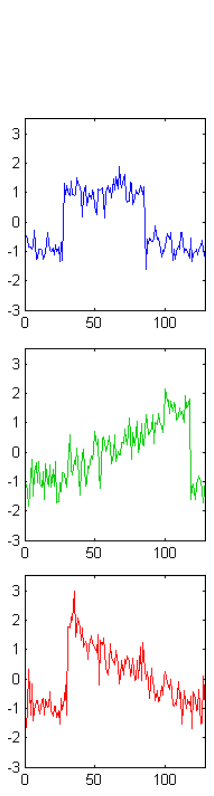

(a) Exemplos das classes.

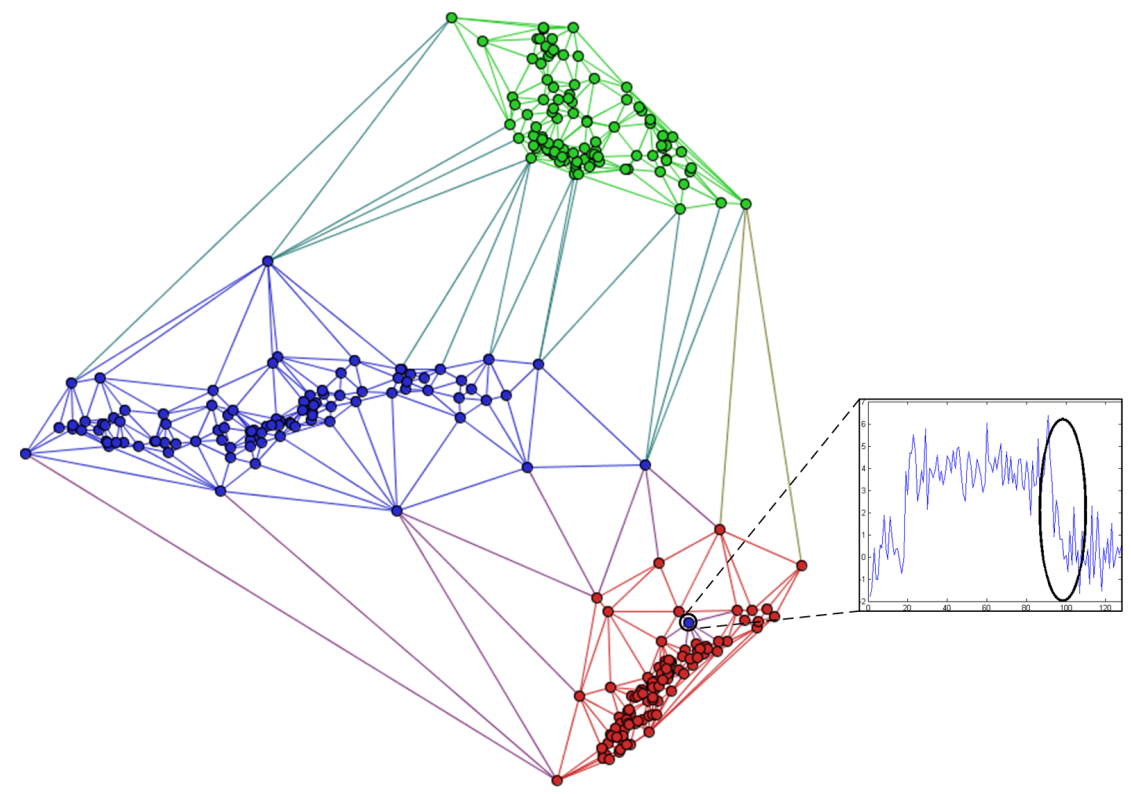

(b) Representação gráfica, e o foco em uma série projetada "erroneamente".

Figura 2.10: Projeção multidimensional para o conjunto de séries CBF cor das classes: cylinder (azul), bell (verde) e funnel (vermelho).

séries temporais é tratada no próximo capítulo, sendo que sua escolha é determinante para a qualidade da projeção.

Tabela 2.1: Matriz de distância.

\begin{tabular}{|ccccc|}
\hline 0 & & & & \\
$\delta\left(S_{2}, S_{1}\right)$ & 0 & & & \\
$\delta\left(S_{3}, S_{1}\right)$ & $\delta\left(S_{3}, S_{2}\right)$ & 0 & & \\
$\vdots$ & $\vdots$ & $\vdots$ & $\ddots$ & \\
$\delta\left(S_{N}, S_{1}\right)$ & $\delta\left(S_{N}, S_{2}\right)$ & $\delta\left(S_{N}, S_{3}\right)$ & $\cdots$ & 0 \\
\hline
\end{tabular}

No âmbito de nosso grupo de pesquisa diversas técnicas de projeção multidimensional vêm sendo investigadas e incorporadas à ferramenta denominada Projection Explo$\operatorname{rer}$ (PEX) (Paulovich et al., 2007), inicialmente desenvolvida para visualização exploratória de coleções de documentos (Paulovich et al., 2008). A seguir são apresentadas duas técnicas desenvolvidas para a ferramenta $\mathrm{PEX}$, que foram utilizadas neste trabalho: Interactive Document Map (IDMAP) e Least Square Projection LSP. A maior vantagem dessas técnicas em comparação a abordagens anteriores é o balanço obtido entre escalabilidade e precisão. Elas são rápidas o suficiente tratar conjuntos de dados grandes a taxas interativas, enquanto retêm alta precisão (Paulovich et al., 2007). 


\subsubsection{Interactive Document Map (IDMAP)}

A técnica Interactive Document Map (IDMAP) (Minghim et al., 2006) gera projeções multidimensionais segundo uma abordagem em duas etapas:

1. Projeção inicial dos dados com uma técnica de projeção rápida. Duas alternativas foram utilizadas: as técnicas Fastmap; e NNP, descritas a seguir.

2. Aperfeiçoamento da projeção, recuperando parte da informação perdida na primeira etapa com a técnica Force Scheme.

Apesar de geralmente apresentar bons resultados, a IDMAP possui um custo computacional alto $O\left(n^{2}\right)$.

\subsubsection{Fastmap}

A técnica de projeção multidimensional Fastmap, proposta por Faloutsos e Lin (1995), busca projetar os pontos em um espaço $m$-dimensionais, em $p$ direções mutuamente ortogonais. Essa técnica projeta recursivamente os objetos em $p$ hiperplanos ortogonais.

A idéia central é projetar os objetos em uma linha 'selecionada'. Primeiramente, para cada hiperplano é necessário selecionar dois objetos pivôs $O_{a}$ e $O_{b}$. Os objetos serão projetados na linha definida por esses objetos pivôs. A projeção de um objeto $O_{i}$ nesta linha é calculada pela Lei dos Cossenos (ver Figura 2.11):

Definição 2.2 . Lei dos cossenos: Em qualquer triângulo $O_{a} O_{i} O_{b}$, a lei dos cossenos afirma que:

$$
D\left(O_{b}, O_{i}\right)^{2}=D\left(O_{a}, O_{i}\right)^{2}+D\left(O_{a}, O_{b}\right)^{2}-2 x_{i} D\left(O_{a}, O_{b}\right)
$$

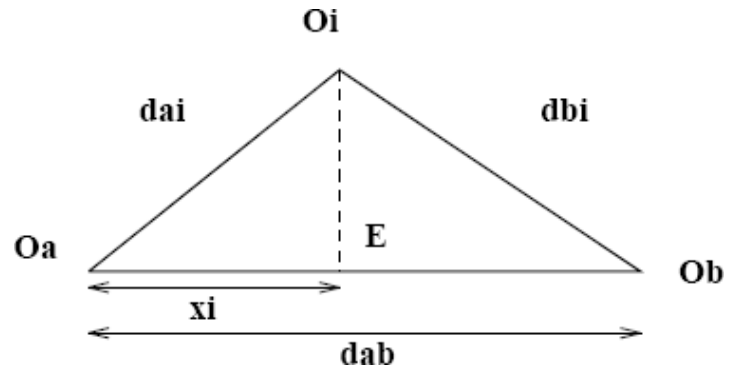

Figura 2.11: Ilustração da lei do cosseno - projetando $O_{i}$ sobre a linha $O_{a} O_{b}$. 
A Equação 2.1 pode ser manipulada para determinar a posição $x_{i}$, a coordenada do objeto $O_{i}$ para aquele hiperplano:

$$
x_{i}=\frac{D\left(O_{a}, O_{i}\right)^{2}+D\left(O_{a}, O_{b}\right)^{2}-D\left(O_{b}, O_{i}\right)^{2}}{2 D\left(O_{a}, O_{b}\right)}
$$

A Equação 2.2 permite mapear os objetos $O_{i}$ na linha, preservando as relações de distância do espaço original. Se o objeto $O_{i}$ estiver mais próximo do pivô $O_{a}$ do que de $O_{b}, x_{i}$ terá um valor pequeno. Caso contrário, $x_{i}$ terá um valor maior.

A escolha dos pivôs $O_{a}$ e $O_{b}$ é baseada na matriz de distâncias. Esses objetos devem ser o mais distante possível entre si para obter boas projeções. Apesar da busca pela maior distância $D\left(O_{a}, O_{b}\right)$ possuir complexidade $O\left(N^{2}\right)$, os autores propuseram uma heurística que executa uma busca aproximada com complexidade $O(N)$ : um objeto qualquer é inicialmente escolhido; em seguida procura-se o objeto mais distante dele de acordo com a matriz de distância; utilizado esse objeto encontrado procura-se o mais distante dele. Esses dois últimos objetos serão os pivôs.

A Equação 2.2 reduz a dimensionalidade de $i$ para $i-1$. Desta forma, basta aplicar recursivamente esta equação para obter a dimensionalidade desejada $p$. As coordenadas $x_{i}$ armazenam as coordenadas do objeto para cada dimensão da recursão. Falta determinar como as novas dissimilaridades $D^{\prime}\left(O_{i}, O_{j}\right)$ são calculadas entre os objetos projetados num hiperplano, para aplicar a recursão.

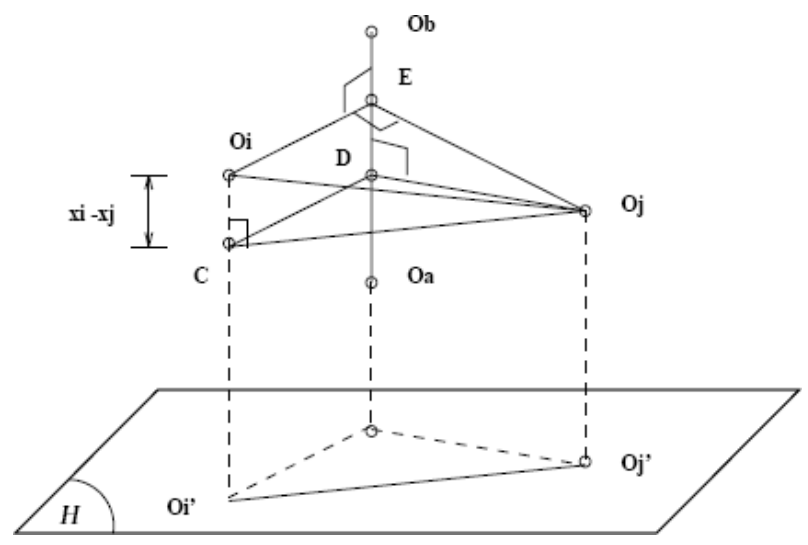

Figura 2.12: Projeção no hiperplano $H$, perpendicular à linha $O_{a} O_{b}$ da figura anterior.

A Figura 2.12 mostra dois objetos $O_{i}$ e $O_{j}$, e suas projeções $O_{i}^{\prime}$ e $O_{j}^{\prime}$ no hiperplano $\mathcal{H}$. A dissimilaridade entre $O_{i}^{\prime}$ e $O_{j}^{\prime}$ é calculada da Equação refeq:lema:

$$
\left(D^{\prime}\left(O_{i}^{\prime}, O_{j}^{\prime}\right)\right)^{2}=D\left(O_{i}, O_{j}\right)^{2}-\left(x_{i}-x_{j}\right)^{2}
$$


A Equação 2.3 é permite atualizar os valores da matriz de projeção, que agora armazena as dissimilaridades a serem utilizadas na próxima recursão. Essa nova dissimilaridade $D^{\prime}($ ) permite a projeção em uma segunda linha no hiperplano $\mathcal{H}$, ortogonal à primeira $\left(O_{a}, O_{b}\right)$. Portanto é possível aplicar estes passos recursivamente quantas vezes forem necessárias para qualquer valor de $p$. O Algoritmo básico da técnica Fastmap é apresentado em Algoritmo 1.

Apesar do Fastmap apresentar complexidade $O(N p)$, há uma perda de informação considerável quando usada para criar projeções bidimensionais.

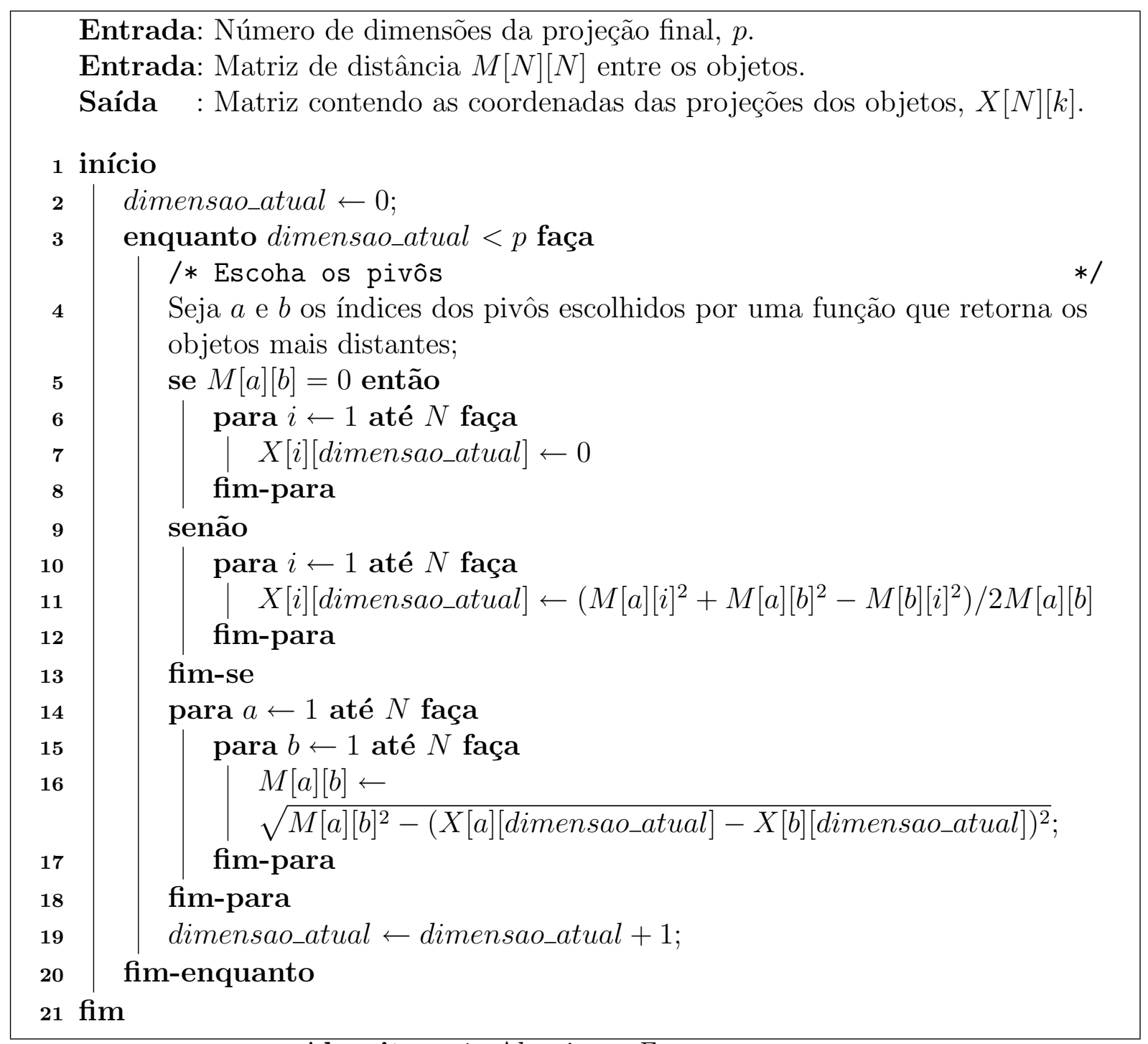

Algoritmo 1: Algoritmo Fastmap. 


\subsubsection{Nearest Neighbors Projection (NNP)}

A técnica de projeção multidimensional Nearest Neighbors Projection (NNP) (Tejada et al., 2003) busca preservar as relações entre vizinhos locais no espaço multidimensional no espaço projetado.

Para preservar essa vizinhança local, as posições dos dois vizinhos mais próximos no espaço projetado já projetados, determinam a posição projetada do novo ponto. Seja $\tilde{X} \subset X$ o subconjunto de pontos já projetados. Suponha $x \in X$ um novo ponto a ser projetado e $x_{q}^{\prime}$ e $x_{r}^{\prime}$ os dois pontos em $\widetilde{X}$ mais próximos de $x$, tal que $\forall x_{k}^{\prime} \in \widetilde{X}, x_{k}^{\prime} \neq x_{q}^{\prime}, x_{r}^{\prime}$, $\delta\left(x, x_{k}\right) \geq \delta\left(x, x_{r}\right)$ e $\delta\left(x, x_{k}\right) \geq \delta\left(x, x_{q}\right)$. A posição do novo ponto $x^{\prime}=\alpha(x)$ ( $\alpha$ é a função de projeção) no espaço projetado está na intersecção entre os dois círculos com centros em $x_{q}^{\prime}=\alpha\left(x_{q}\right) x_{r}^{\prime}=\alpha\left(x_{r}\right)$, e raio igual a $\delta\left(x, x_{q}\right)$ e $\delta\left(x, x_{r}\right)$.

No caso dos círculos serem tangentes, o único ponto de intersecção é utilizado. Quando duas intersecções existem, escolhe-se aleatoriamente uma delas (ver Figura 2.13(a)). Quando não existem intersecções, um ponto intermediário entre os centros é utilizado, o qual é determinado pelo raio dos dois círculos e pela posição relativa entre eles. As Figuras 2.13(b) e 2.13(c) ilustram os casos possíveis para a inexistência de intersecções. O Algoritmo 2 mostra o algoritmo básico para esta técnica.

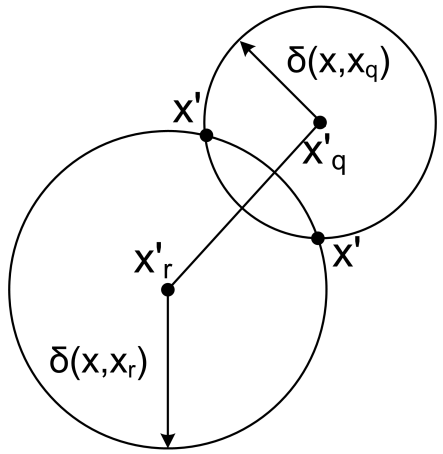

(a) Dois pontos de intersecção.

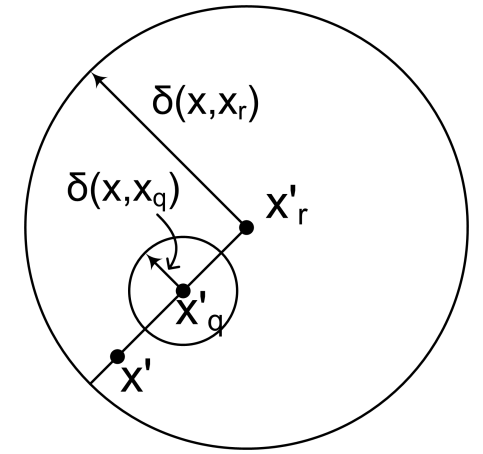

(b) Nenhuma intersecção, um círculo interno.

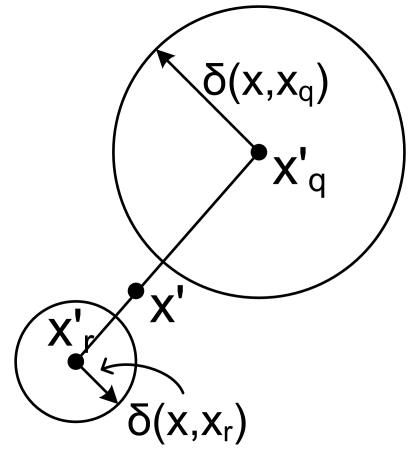

(c) Nenhuma intersecção, um círculo externo.

Figura 2.13: Casos de intersecção na projeção NNP.

Para um conjunto de dados com $n$ instâncias, essa técnica possui complexidade $O\left(n^{2}\right)$ quando a busca pelo vizinho mais próximo é seqüencial. Se forem utilizadas estruturas de dados para acelerar essa busca, a complexidade pode cair para $O(\log (n !))$. 


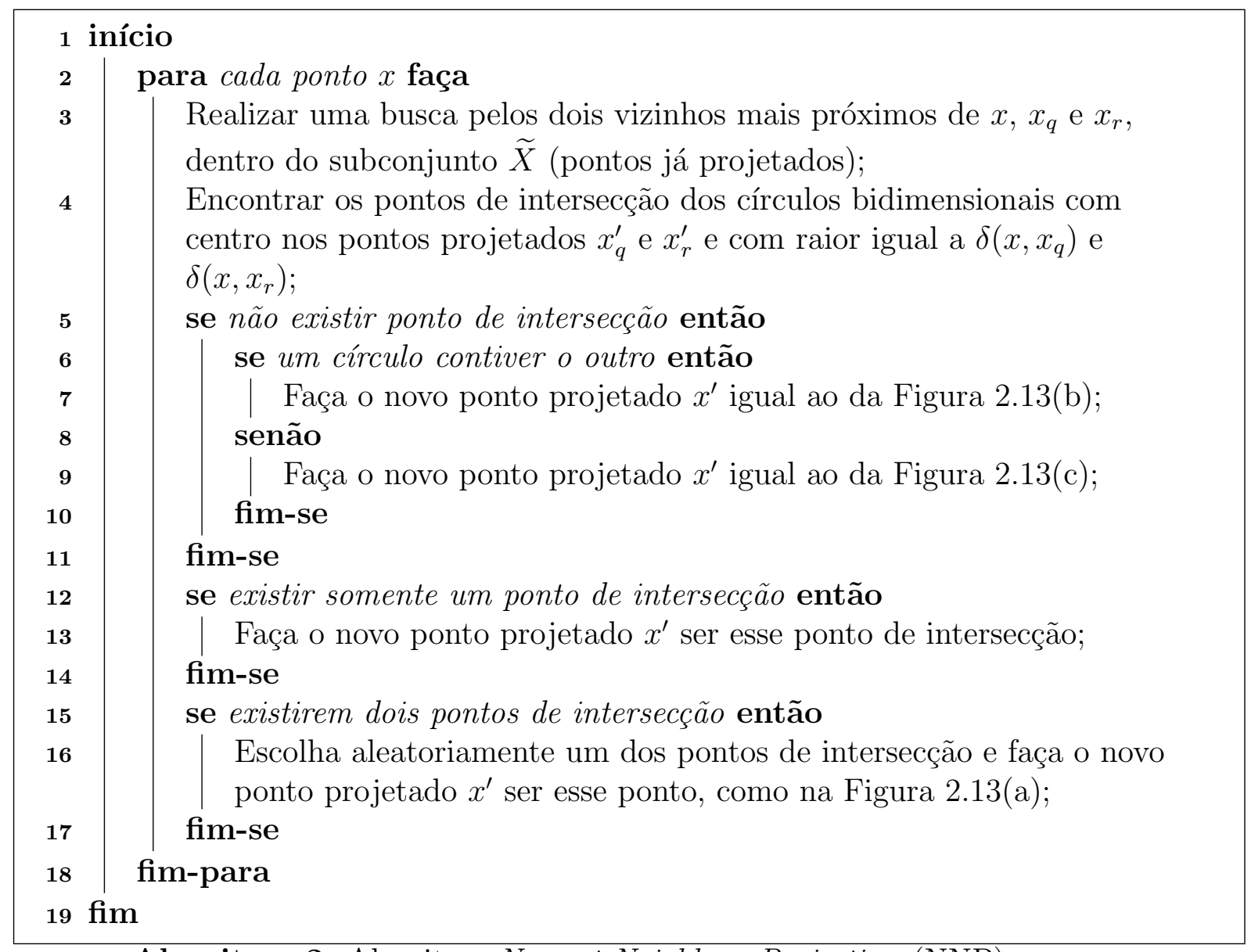

Algoritmo 2: Algoritmo Nearest Neighbors Projection (NNP). 


\subsubsection{Aperfeiçoamento da Projeção: Force Scheme}

A técnica chamada Force Scheme (Tejada et al., 2003) para melhorar as projeções por meio de uma métrica para avaliar a qualidade da projeção. Essa abordagem busca estabelecer uma relação constante entre as distâncias no espaço original e no espaço projetado para todos os pares de pontos $\left(x_{i}, x_{j}\right)$, usando forças de atração e repulsão entre os pontos.

A base para essa abordagem é a seguinte: para cada ponto projetado $x_{i}^{\prime}$, calcula-se um vetor $\vec{v}_{i j}=\left(x_{j}^{\prime}-x_{i}^{\prime}\right), \forall x_{j}^{\prime} \neq x_{j}^{\prime}$. Então, uma pertubação em $x_{j}^{\prime}$ é aplicada na direção de $\vec{v}_{i j}$. A força dessa pertubação depende da relação entre as distâncias no espaço original e no espaço projetado para o par de pontos $\left(x_{i}^{\prime}, x_{j}^{\prime}\right)$, e é expressa pela Equação 2.4:

$$
\Delta=\frac{\delta\left(x_{i}, x_{j}\right)-\delta_{\min }}{\delta_{\max }-\delta_{\min }}-d\left(x_{i}^{\prime}, x_{j}^{\prime}\right)
$$

onde $\delta_{\min }$ e $\delta_{\max }$ representam a máxima e a mínima distância entre os objetos no espaço original. No entanto, é necessário trabalhar com distâncias normalizadas para evitar inconsistências derivadas da diferença entre as faixas de valores do espaço multidimensional original e do espaço projetado. Para melhorar o desempenho, o processo de normalização é aplicado somente uma vez para o espaço original e uma vez para o espaço projetado, para cada iteração. O Algoritmo 3 mostra os passos do Force Scheme.

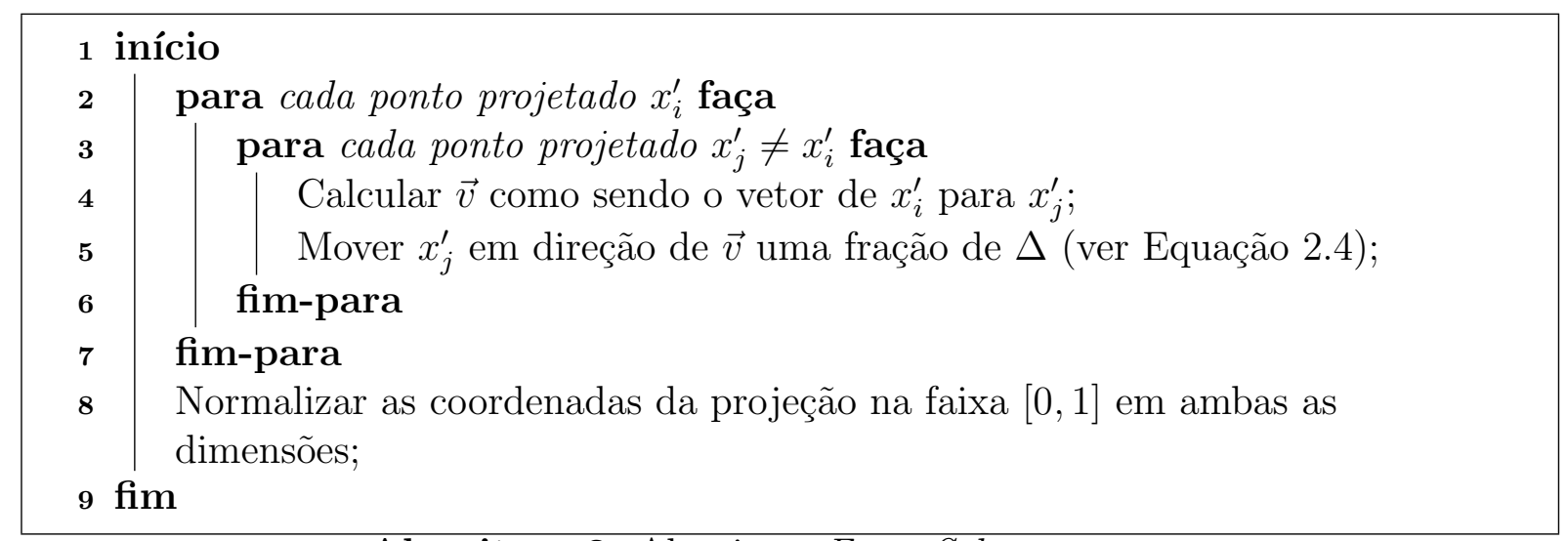

Algoritmo 3: Algoritmo Force Scheme.

A principal desvantagem desse método é sua complexidade $O\left(n^{2}\right)$, pois o posicionamento de cada ponto é alterado $n-1$ vezes. Apesar disso, a abordagem acaba convergindo em um número baixo de iterações, pois os pontos já foram projetados com uma técnica rápida e que busca preservar as distâncias (Fastmap ou NNP). 


\subsubsection{Least Square Projection (LSP)}

Quando conjuntos de dados possuem um agrupamento inerente, considerar relacionamentos entre objetos pertencentes a diferentes grupos no processo de projeção pode distorcer a projeção final. A técnica Least Square Projection (LSP) (Paulovich et al., 2008) busca superar este problema, definindo uma vizinhança para os objetos no espaço $\mathbb{R}^{m}$, a qual é utilizada para projetar um objeto no espaço $\mathbb{R}^{p}$, de modo que ele seja posicionado no centro de gravidade das projeções dos seus vizinhos mais próximos no espaço $\mathbb{R}^{m}$

Essa abordagem é realizada em três passos. Primeiro, define-se uma relação de vizinhança entre os objetos em $\mathbb{R}^{m}$. Depois, uma lista de pontos $S$, chamada de pontos de controle, é projetada em $\mathbb{R}^{p}$ por um método de projeção convencional como o Fastmap. Por fim, constrói-se um sistema linear esparso baseado nas relações de vizinhança e nas coordenadas cartesianas dos pontos de controle projetados. A construção desse sistema linear, bem como a definição dos pontos de controle e da vizinhança dos objetos, são discutidos a seguir.

\subsubsection{Definindo a Vizinhança dos Objetos}

Uma vizinhança $V=\left\{V_{1}, \ldots, V_{n}\right\}$ define uma lista de objetos vizinhos $V_{i}$ para cada objeto $x_{i} \in X$. Cada lista $V_{i}=\left\{x_{i_{1}}, \ldots, x_{i_{k i}}\right\}$ é criada com o algoritmo $k$ vizinhos mais próximos, que busca os $k$ (parâmetro fornecido pelo usuário) objetos mais próximos do objeto $x_{i}$, segundo a função de distância no espaço multidimensional $\delta$. No entanto, é necessário estabelecer a vizinhança dos objetos de forma a assegurar a seguinte condição de sobreposição:

Definição 2.3. Condição de Sobreposição: Seja $X=\left\{x_{1}, \ldots, x_{n}\right\}$ um conjunto de objetos e $V=\left\{V_{1}, \ldots, V_{n}\right\}$ o conjunto de relações de vizinhança dos objetos em $X$. A lista $V$ satisfaz a condição de sobreposição se, para cada par de objetos $x_{i}$ e $x_{j}$ existe uma seqüência de vizinhos $V_{1}^{i j}, \ldots, V_{q}^{i j}$ tal que $V_{1}^{i j}=V_{i}, V_{q}^{i j}=V_{j}$ e $V_{k}^{i j} \cap V_{k+1}^{i j} \neq \emptyset$, $k=1, \ldots, q-1$.

Essa condição assegura propriedades sobre as relações de vizinhança como se a mesma fosse uma malha com um único componente conexo. Se as relações de vizinhança forem examinadas e perceber-se que algum objeto $x_{i}$ está desconexo dos demais, deve-se incluir na sua lista de vizinhos $V_{i}$ um novo vizinho que faça parte do componente conexo principal.

Observa-se que o valor de $k$ não deve ser muito alto, para que objetos distantes não sejam considerados na projeção de um ponto qualquer, contrariando a idéia de vizinhança local adotada pelo LSP 


\subsubsection{Sistema Linear}

Definidas as relações de vizinhança $V$ constrói-se um sistema linear, como segue. Seja $V_{i}=\left\{x_{i_{1}}, \ldots, x_{i_{k i}}\right\}$ um conjunto de $k_{i}$ objetos na vizinhança do objeto $x_{i}$. As coordenadas da projeção de $x_{i}$ em $\mathbb{R}^{p}, \widetilde{x}_{i}$, podem ser calculadas pela seguinte equação:

$$
\widetilde{x}_{i}-\frac{1}{k i} \sum_{x_{j} \in V_{i}} \widetilde{x}_{j}=0
$$

Segundo a Equação 2.5, a projeção de cada objeto $x_{i}$ será o centróide das projeções dos objetos de sua vizinhança $V_{i}$ (outras propriedades podem ser encontradas em Floater (1997)). A equação pode ser expressa como um conjunto de sistemas lineares, cujas soluções são as coordenadas dos objetos projetados:

$$
L x_{i}=0, L x_{2}=0, \ldots, L x_{p}=0
$$

onde $x_{1}, x_{2}, \ldots, x_{p}$ são vetores de tamanho $n$ que contém as coordenadas dos objetos projetados para cada uma das $p$ dimensões, e $L$ é a matriz $n \times n$ cujas entradas são dadas por:

$$
l_{i j}= \begin{cases}1 & i=j, \\ -\frac{1}{k i} & x_{j} \in V_{i}, \\ 0 & \text { caso contrário. }\end{cases}
$$

onde as entradas $l_{i j}$ juntas representam a Equação 2.5 .

No entanto, a matriz $L$ não contém nenhuma informação geométrica, impossibilitando usar soluções do sistema linear para obter as coordenadas dos objetos projetados. De forma a possibilitar esse uso, a informação geométrica é adicionada por meio de pontos de controle. As coordenadas projetadas desses pontos são obtidas por técnicas como o IDMAP.

Os $n c$ (parâmetro definido pelo usuário) pontos de controle $P=\left\{p_{1}, \ldots, p_{n c}\right\}$ são inseridos no sistema como novas linhas na matriz. As coordenadas geométricas da projeção dos pontos de controle são adicionadas do lado direito do sistema, gerando um vetor nãonulo $b$. Dessa forma, reescreve-se a Equação 2.6 na forma da Equação 2.8 .

$$
A x=b
$$


onde $A$ é uma matrix retangular $(n+n c) \times n$ dada por:

$$
A=\left(\begin{array}{c}
L \\
C
\end{array}\right), \quad c_{i j}= \begin{cases}1 & x_{j} \text { é um ponto de controle } \\
0 & \text { caso contrário. }\end{cases}
$$

e $b$ é o vetor não-nulo:

$$
b_{i}= \begin{cases}0 & i \leq n \\ p_{i_{c}} & n<i \leq n+n c\end{cases}
$$

onde $p_{i_{c}}$ é uma das coordenadas da projeção do ponto de controle $p_{i}$.

Esse sistema linear pode ser resolvido aplicando-se a técnica dos mínimos quadrados, que tenta minimizar o valor de $\|A x-b\|^{2}$. A solução que minimiza esse valor é dada por $x=\left(A^{T} A\right)^{-1} A^{T} b$, que é um sistema simétrico e esparso, o que facilita sua solução (Sorkine et al., 2004).

\subsubsection{Pontos de Controle}

A escolha do conjunto dos $n c$ pontos de controle deve ser cuidadosa, pois afeta a qualidade da projeção. Eles devem ser escolhidos de forma a gerar uma boa representação da distribuição dos agrupamentos dos objetos em $\mathbb{R}^{m}$. A escolha pode ser feita de duas formas: aleatória ou baseada em agrupamentos.

A abordagem aleatória é mais rápida, porém não traz bons resultados. Já a outra abordagem divide o conjunto de objetos em $n c$ agrupamentos, e escolhe o medóide (objeto mais próximo do centróide) de cada agrupamento como sendo o ponto de controle. Apesar da maior complexidade, os pontos de controle assim definidos representam melhor os dados. O LSP emprega o método de $k$-medoids (Berkhin, 2002) no agrupamento, que ao contrário do k-means (Tan et al., 2005) não é afetado pela existência de outliers, pois, o agrupamento é representado por um de seus objetos, e não pelo seu centróide. Outra vantagem é que somente as distâncias entre os objetos e os medóides são necessárias, informação já presente na matriz de distância.

Após obter o conjunto de pontos de controle, estes devem ser projetados no espaço $\mathbb{R}^{p}$ para que as coordenadas dessas projeções sejam usadas na construção dos sistema linear. A qualidade da projeção gerada com o LSP é fortemente afetada pelo posicionamento desses pontos de controle, pois as coordenadas das projeções desses pontos serão usadas para projetar os demais objetos. 


\subsubsection{Comparação entre as técnicas IDMAP e LSP}

Nesta seção prossegue-se com a análise do conjunto de dados CBF apresentado na Seção 2.3. para efeito de comparação entre as técnicas IDMAP e LSP. Uma das principais diferenças entre ambas é a formação de agrupamentos. A LSP tende a favorecer a formação de agrupamentos, por projetar os dados com base em relações de vizinhança locais e pontos de controle, que evidenciam a distribuição dos dados. Já a IDMAP não evidencia as fronteiras entre possíveis agrupamentos nos dados, o que a torna mais indicada para dados que não estão necessariamente divididos em grupos. A Figura 2.14 exemplifica a tendência da LSP de formar agrupamentos.

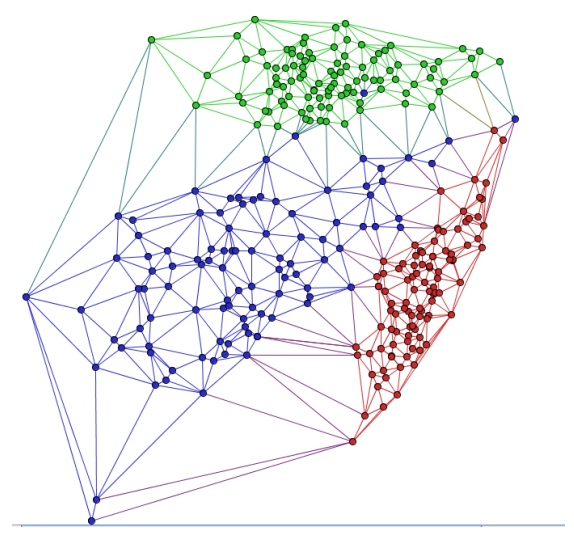

(a) Projeção com a técnica IDMAP

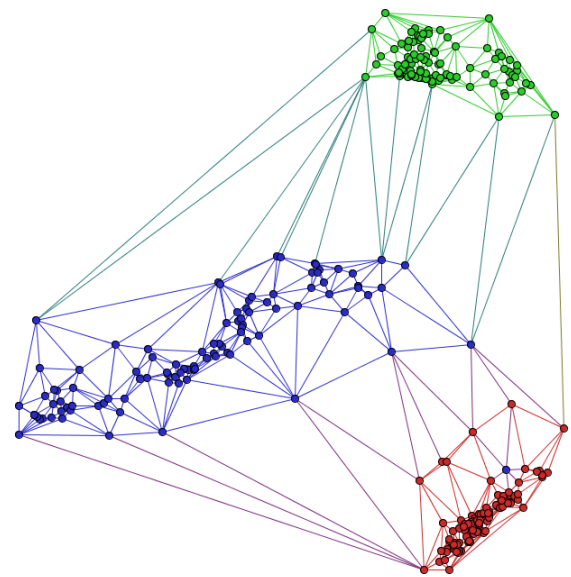

(b) Projeção com a técnica LSP

Figura 2.14: Formação de agrupamentos: projeção multidimensional para o conjunto de séries $\mathrm{CBF}$

As técnicas também se diferenciam no tratamento outliers, que são instâncias que apresentam uma grande distância em relação às demais. A Figura 2.15(c), mostra uma série que apesar de classificada como sendo da classe cylinder, não apresenta o comportamento típico deste tipo de classe. A técnica IDMAP (ver Figura 2.15(a) mostrou-se sensível a este outlier, ao contrário da técnica LSP (ver Figura 2.15(c)). A tolerância a presença de outliers pela LSP se explica pelo uso de relações de vizinhança locais e pontos de controle no processo de projeção, pois dessa forma esse outlier só é comparado aos seus vizinhos mais próximos.

A tendência de formar agrupamentos e a tolerância a outliers torna a LSP superior na maioria das aplicações de projeções. No entanto, a IDMAP é mais indicada quando o usuário não busca identificar agrupamentos nos dados. Quanto a velocidade, a técnica LSP é superior, pois a técnica IDMAP possui complexidade $O\left(n^{2}\right)$. 


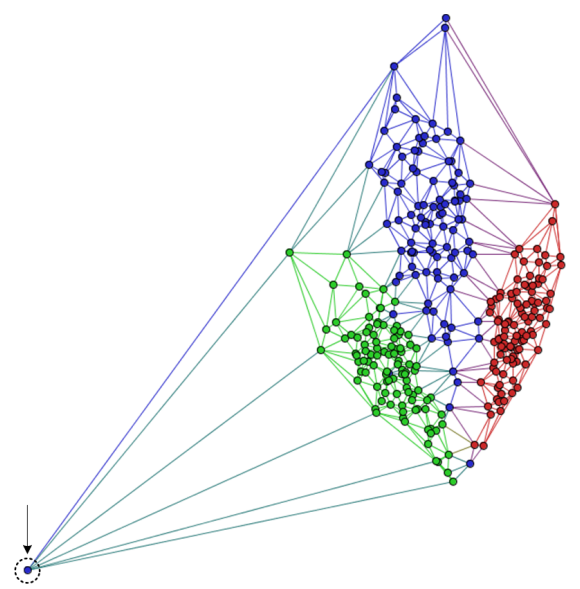

(a) Projeção com a técnica IDMAP

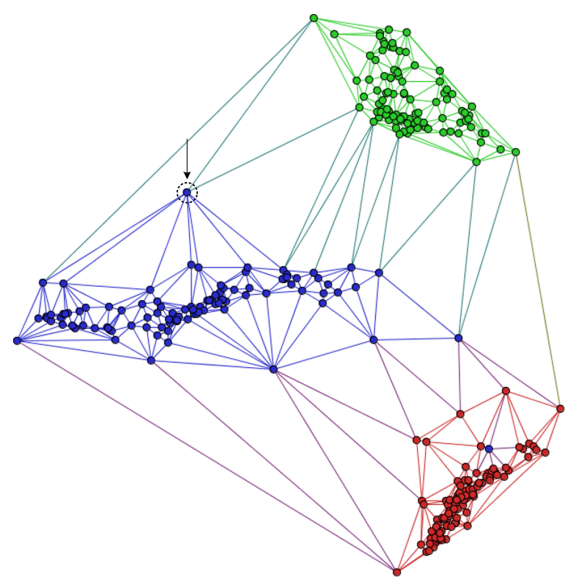

(b) Projeção com a técnica LSP

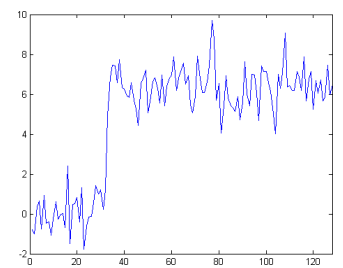

(c) Outlier

Figura 2.15: Projeção multidimensional para o conjunto de séries CBF com presença de outlier. 


\subsection{Considerações Finais}

Este capítulo fornece uma introdução à área de Visualização de Informação aplicada à análise de séries temporais. Também é apresentada a abordagem de projeções multidimensionais adotada neste projeto para gerar visualizações de conjuntos de séries. No próximo capítulo, será apresentada a análise de séries temporais sob o enfoque de Mineração de Dados. 


\subsection{Considerações Iniciais}

Séries temporais podem ser entendidas como uma coleção de observações seqüenciadas no tempo. Elas são extremamente comuns, podendo ser encontrados em diversos domínios, como na biologia, finanças, geologia, robótica, e outras áreas. No entanto, existem várias dificuldades em se tratando de manipular séries temporais (Keogh, 2003):

- Alta dimensionalidade: Séries temporais possuem uma dimensionalidade inerente, equivalente ao seu tamanho. Quanto mais longa uma série, mas difícil é a sua análise, principalmente se o usuário está interessado em analisar um grande número de séries longas.

- Grandes conjuntos de dados: Séries temporais também são conhecidas por seu volume. Conjuntos de séries com vários gigabytes são comuns. Como um exemplo típico, considere o projeto de astrofísica MACHCO (Welch e Quinn, 1999), que contém mais de um terabyte de dados, e é atualizado a uma taxa de vários gigabytes por dia.

- Subjetividade: Como será discutido, a definição de similaridade entre séries temporais distintas depende do usuário, do domínio e da tarefa em questão, e deve ser possível lidar com essa subjetividade. 
- Diversidade: Séries temporais podem ser encontradas em diferentes formatos, registradas com diferentes taxas de amostragem, com ruído, valores ausentes, etc. Essas características as tornam bastante diversas, dificultando a manipulação.

Em vista destas dificuldades, a mineração de séries temporais tem sido largamente empregada para extrair conhecimento de tais tipos de dados. Neste capítulo serão apresentados conceitos, tarefas e aplicações em mineração de séries temporais. Na Seção 3.2 . é apresentada a grande área chamada Mineração de Dados (MD). Introduzida a grande área, as seções seguintes são dedicadas a especificar a aplicação de MD para séries temporais. Desta forma, na Seção 3.3 são apresentados conceitos referentes a séries temporais. Já na Seção 3.4 são descritas operações de pré-processamento típicas. Na Seção 3.5 são apresentadas diferentes métricas para quantificar a similaridade entre séries. Por fim, na Seção 3.6 são descritas algumas tarefas de MD para extração de padrões em séries.

\subsection{Mineração de Dados}

Dados provenientes de vários domínios são freqüentemente gravados, capturados e armazenados, esperando-se que algum conhecimento possa ser obtido deles, seja procurando por estruturas, características, padrões, anomalias ou relacionamentos. Devido ao avanço tecnológico que permite armazenar quantidades cada vez maiores de dados, as bases de dados não param de crescer. No entanto, extrair conhecimento é uma tarefa difícil, e se isto não for feito, o armazenamento torna-se inútil (Keim, 2002).

A dificuldade em analisar e compreender grandes quantidades de dados motiva diversos estudos sobre processos automáticos de extração de conhecimento de bases de dados, os quais se inserem na área de pesquisa chamada Mineração de Dados (MD). O processo de descoberta de conhecimento é intensamente interativo e iterativo, e demanda muitas decisões importantes do usuário (Fayyad et al., 1996a). Uma das definições de MD mais aceitas por pesquisadores da área e de Fayyad et al. (1996b): "Extração de conhecimento de bases de dados é o processo de identificação de padrões válidos, novos, potencialmente úteis e compreensíveis embutidos nos dados". Considerando essa definição, Rezende et al. (2003) dividiu este processo em três grandes etapas - pré-processamento, extração de padrões e pós-processamento. Essa divisão também inclui uma fase anterior ao processo de $\mathrm{MD}$, composta pela identificação do problema, e uma fase posterior, composta pela utilização do conhecimento. Essa divisão do processo de MD é mostrada na Figura 3.1 e, como pode ser visto, podem ocorrer múltiplos ciclos envolvendo as três etapas principais, justamente o que confere o caráter iterativo ao processo. 


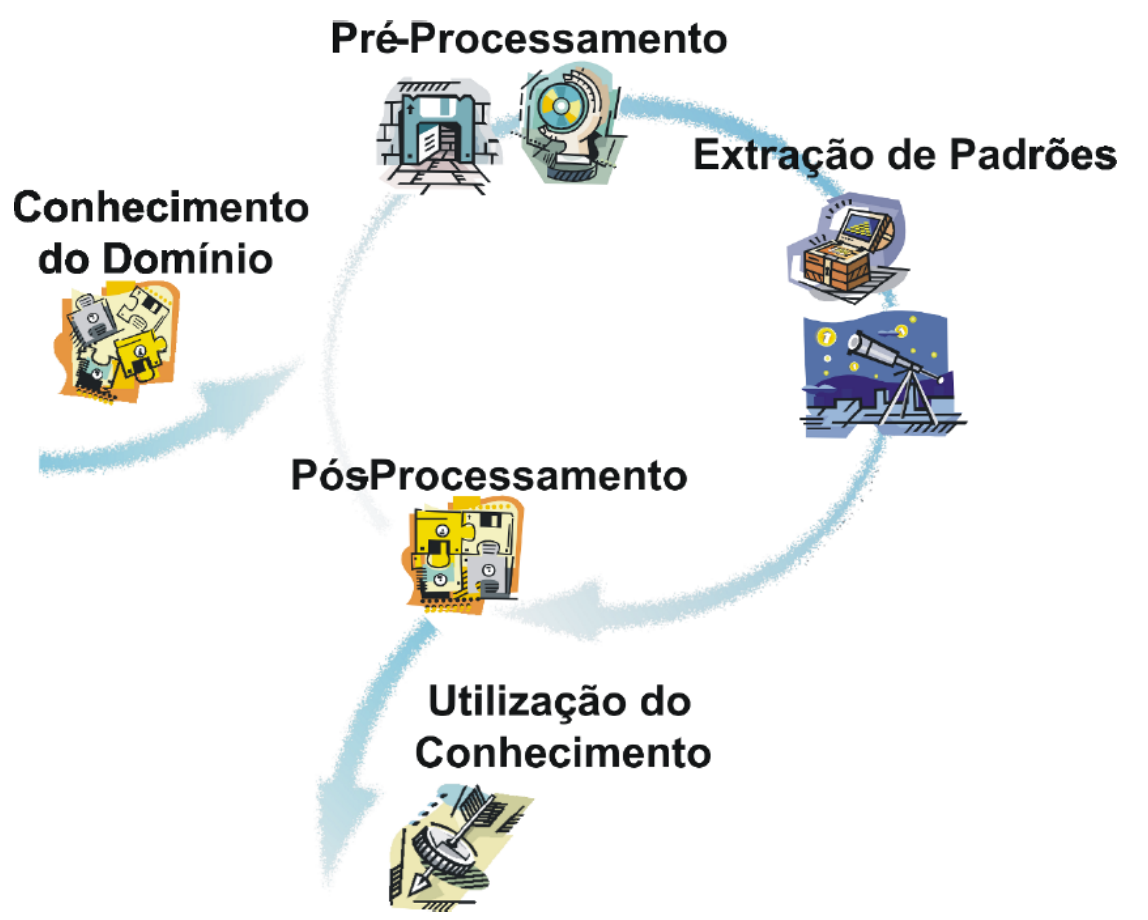

Figura 3.1: Etapas do processo de Mineração de Dados (Rezende et al., 2003).

A fase de identificação do problema requer um estudo do domínio, que é imprescindível a fim de adquirir um conhecimento inicial e subsidiar todas as etapas posteriores do processo de MD. Nesta fase também devem ser definidos os objetivos e metas a serem alcançados no processo de extração de conhecimento.

Já na etapa de pré-processamento os dados devem ser organizados para a extração de conhecimento. Os dados podem prover de diferentes fontes, o que torna necessário a sua unificação em uma única fonte, bem como sua adequação ao formato esperado pelos algoritmos da próxima etapa, a extração de padrões. Outra atividade necessária é a limpeza, para retirar valores incorretos ou ausentes. Os dados também podem conter ruído que deve ser removido, ou pode ser necessário transformá-los para salientar certas características de interesse. Por último, também pode ser necessário escolher um subconjunto representativo, reduzindo o número de instâncias e atributos, de acordo com restrições de espaço em memória ou tempo de processamento. As atividades dessa etapa devem ser realizadas cuidadosamente, pois é fundamental garantir que as informações presentes nos dados brutos se mantenham nos dados amostrados.

A extração de padrões é a principal etapa do processo de $\mathrm{MD}$, e é direcionada ao cumprimento dos objetivos definidos na etapa de identificação do problema. Nesta etapa é realizada a escolha, a configuração e execução de um ou mais algoritmos para a 
extração de conhecimento. Assim, essa etapa é dividida em três atividades: escolha da tarefa de MD a ser executada, escolha do algoritmo e extração dos padrões. A escolha da tarefa é direcionada pelos objetivos do problema. Em seguida é escolhido o algoritmo a ser utilizado, e seus parâmetros configurados, o que deve ser feito de forma bastante criteriosa para garantir a geração de um bom modelo de representação dos dados. A última atividade, extração de padrões, consiste em aplicar o algoritmo de MD escolhido.

Na última etapa, o pós-processamento, os padrões obtidos na etapa anterior são analisados de forma a fornecer ao usuário somente os padrões mais interessantes. Nesta etapa o usuário pode decidir extrair outros padrões, executando novamente o ciclo principal do processo de $\mathrm{MD}$, eventualmente mudando a escolha de algoritmos e parâmetros.

Na fase de utilização do conhecimento, o conhecimento extraído nas etapas anteriores pode ser incorporado a algum Sistema Inteligente, ou ser utilizado diretamente pelo usuário final em algum processo de tomada de decisão.

\subsection{Conceitos Básicos do Domínio de Interesse}

Nesta seção são apresentadas as definições utilizadas ao longo deste trabalho. A seguir tem-se a definição e notação de série temporal, sob um ponto de vista estatístico:

Definição 3.1 . Variável aleatória: Uma variável aleatória $Z$ é definida como uma função mensurável de um espaço de probabilidade para um espaço mensurável, $Z: \Omega \rightarrow \mathbb{R}$, onde $(\Omega, \mathcal{F}, \mathcal{P})$ é um espaço de probabilidade e $\mathbb{R}$ é o espaço mensurável de possíveis valores da variável.

Definição 3.2 . Espaço de probabilidade: Em teoria da probabilidade, o espaço de probabilidade é uma tripla $(\Omega, \mathcal{F}, \mathcal{P})$ na qual:

- O espaço amostral $\Omega$ é um conjunto não vazio de todos os resultados possíveis de um experimento.

- Certos subconjuntos do espaço amostral de um experimento são referidos como eventos. A $\sigma$-álgebra $\mathcal{F}$ é formada por esses eventos, que são conjuntos de resultados sobre os quais é possível definir uma probabilidade.

- A medida de probabilidade $\mathcal{P}$ é uma função definida sobre $\mathcal{F}$, que atribui a cada evento uma probabilidade entre 0 e 1. 
Em termos práticos, uma variável aleatória $Z$ é uma função determinística, que à realização de certo acontecimento aleatório $\omega \in \Omega$ associa um valor numérico $Z(\omega)$. Esse valor numérico adquire assim um caráter aleatório porque depende de uma tiragem aleatória.

Definição 3.3 . Processo estocástico: Um processo estocástico é uma família de variáveis aleatórias $Z=\{Z(t), t \in T\}$ sobre um espaço de probabilidade $(\Omega, \mathcal{F}, \mathcal{P})$, indexada sobre elementos de um conjunto de parâmetros $T$. Quando $T \subset \mathbb{Z}$ diz-se que $Z(t)$ é um processo com parâmetro discreto, por outro lado, quando $T \subset \mathbb{R}$ diz-se que $Z(t)$ é um processo com parâmetro contínuo.

Como, para cada $t \in T$ o processo estocástico $Z(t)$ é uma variável aleatória, trata-se de uma função de dois argumentos, $Z(t, \omega)$, para $\omega \in \Omega$. Essa dependência indica que para cada $t \in T$ fixo, obtém-se uma variável aleatória. Por outro lado, para cada $\omega \in \Omega$ fixo, obtém-se uma função de $T$, ou seja, uma realização ou trajetória do processo, ou ainda, uma série temporal. Na Figura 3.2, ilustra-se três trajetórias estocásticas em $n$ instantes diferentes.

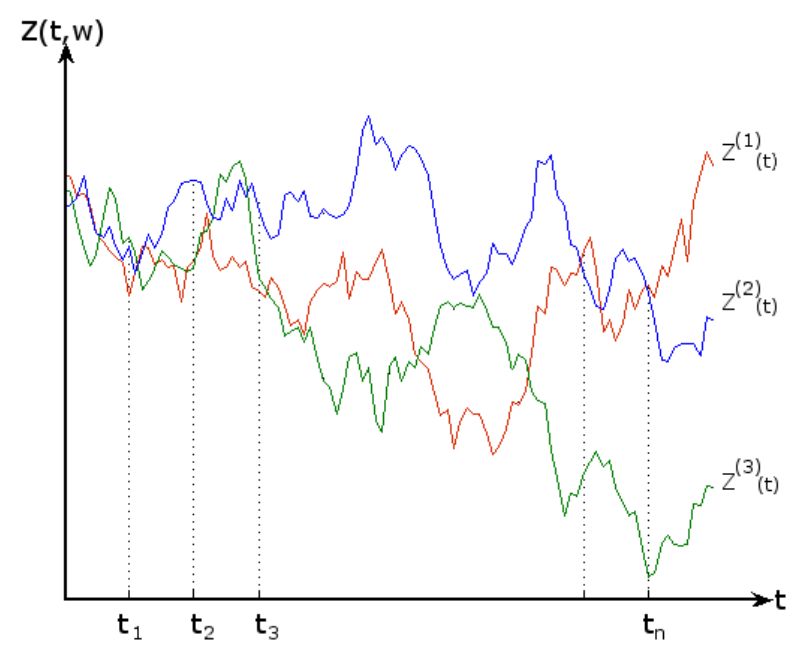

Figura 3.2: Um processo estocástico interpretado como uma família de séries temporais.

Em geral, as observações que caracterizam uma série temporal (realização) são igualmente espaçadas no tempo e assumem valores reais. Essas realizações de $Z(t, \omega)$ são normalmente designadas por $Z^{(1)}(t), Z^{(2)}(t)$, etc. Porém, utilizaremos a notação $Z=$ $\left(Z_{1}, \ldots, Z_{n}\right)$ para especificar uma série temporal discreta de tamanho $n$, por questão de simplicidade. 
No entanto, o interesse em mineração de séries temporais geralmente não está em propriedades globais das séries, mas em subseções locais, conhecidas como subseqüências. Abaixo tem-se a definição de subseqüências segundo Keogh et al. (2005):

Definição 3.4 . Subseqüência: Dada uma série temporal $Z$ de tamanho $n$, uma subseqüência $C_{p}^{m}$ de $Z$ é uma amostragem de tamanho $m<n$ de posições contíguas de $Z$, ou seja, $C_{p}^{m}=\left(Z_{p}, Z_{p+1}, \ldots, Z_{p+m-1}\right)$ para $1 \leq p \leq n-m+1$. O offset de $C_{p}^{m}$ é $p$, que é a posição inicial de $C_{p}^{m}$ dentro de $Z$.

Para extrair todas as subseqüências de uma série temporal, utiliza-se uma janela de deslizamento, definida por Keogh et al. (2003):

Definição 3.5 . Janela de Deslizamento: Dada uma série temporal $Z$ de tamanho $n$, e o tamanho $m$ das subseqüências a serem extraídas, todas as possíveis subseqüências podem ser extraídas pelo deslizamento de uma janela de tamanho $m$ ao longo de $Z$, obtendo-se um conjunto de subseqüências cujos offsets variam de 1 até $m-n+1$.

A Figura 3.3 ilustra as três últimas definições.

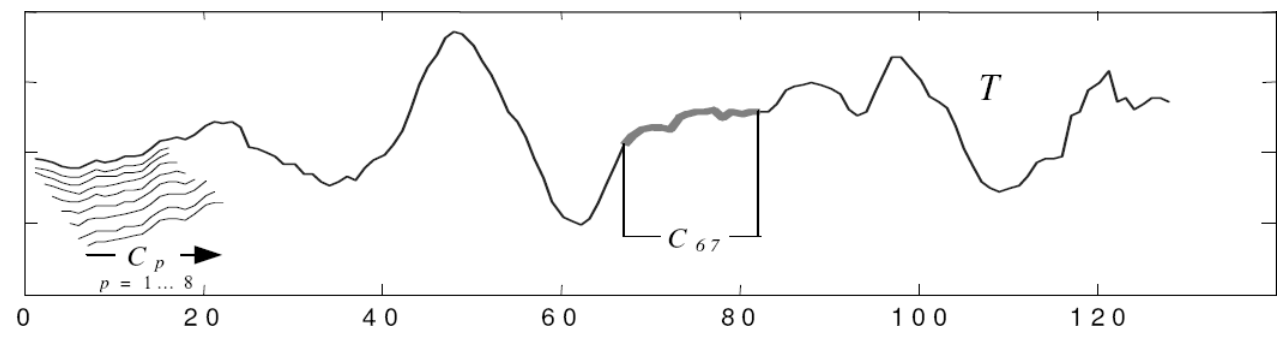

Figura 3.3: Uma série temporal $T$ de tamanho 128, uma subseqüência $C_{67}^{16}$ de tamanho $n=16$ e offset $=67$ sendo extraída pela janela de deslizamento, e as primeiras 8 subseqüências extraídas pela janela. Note que as subseqüências extraídas se sobrepõem (Keogh et al., 2003).

A necessidade de quantificar a similaridade entre séries temporais ou subseqüências é bastante recorrente em várias tarefas de mineração, e requer uma medida de dissimilaridade. Medidas de dissimilaridade também são referenciadas na literatura como função de distância, definida a seguir:

Definição 3.6 . Medida de dissimilaridade: $D$ é uma função que tem como parâmetros $C$ e $M$, duas séries temporais ou duas subseqüências, e retorna um valor não-negativo $R$, que quantifica a dissimilaridade (ou distância) de $M$ para $C$. Quanto menor o valor de $R$, maior a similaridade entre $C$ e $M$. Para as próximas definições é necessário que a função $D$ seja simétrica, ou seja, $D(C, M)=D(M, C)$. 
Existem vários tipos de medidas de dissimilaridade. A mais clássica é a distância Euclidiana. Esta medida exige que as duas séries $C$ e $M$ possuam o mesmo tamanho. No entanto, outros tipos de distância permitem o cálculo da dissimilaridade entre séries de diferentes tamanhos. Esta e outras funções são melhores apresentadas na Seção 3.5 .

A função de distância permite identificar exatamente que subseqüência é similar a outra subseqüência, idéia expressa na definição de casamento elaborada por Lin et al. (2002):

Definição 3.7 . Casamento (match): Dado um número real positivo $\varepsilon$ (chamado tolerância) e uma série temporal $T$ contendo uma subseqüência $C$ começando na posição $p$ e uma subseqüência $M$ começando em $q$, se $D(C, M) \leq \varepsilon$ então $M$ é chamado de casamento da subseqüência $C$.

\subsection{Pré-Processamento}

Ao medir a distância entre duas séries temporais em sua forma original, sem um préprocessamento, pode-se obter resultados não-intuitivos, devido à presença de distorções nos dados. No entanto, para a maioria dos problemas essas distorções não são significativas, e devem ser removidas por meio de um pré-processamento. Nesta seção são discutidas três operações de pré-processamento para séries temporais.

\subsubsection{Suavização}

Séries temporais podem oscilar tão rapidamente que tendências e outras características, se existirem, não são visíveis. Técnicas de suavização são utilizadas para reduzir irregularidades (ruído) evidenciando o comportamento da série. Uma das formas mais simples de suavização chamada Médias Móveis Simples (MMS) (Morettin e Toloi, 2004) suaviza uma observação na série temporal calculando uma média aritmética da observação e das observações vizinhas:

$$
Z^{\prime}=\frac{Z_{t}+Z_{t-1}+\cdots+Z_{t-r+1}}{r}, \quad t=r, \ldots, N
$$

onde $Z^{\prime}$ é denominado valor exponencialmente suavizado.

Na prática, o método de móveis simples não é utilizado freqüentemente. A MMS aplica pesos iguais às observações - independente delas serem recentes ou não - e requer a definição dos limites da vizinhança (parâmetro $r$ ). Este método também reduz o tamanho da série a ser suavizada em $r$ observações. 
A Suavização Exponencial Simples (SES) (Gardner, 1985) é um método de suavização que aplica pesos exponencialmente decrescentes. A atribuição de pesos a observações passadas decresce exponencialmente, atribuindo mais importância para observações recentes, sem descartar por completo observações antigas. A Suavização Exponencial Simples (SES) pode ser descrita matematicamente pela Equação refeq:ses:

$$
Z^{\prime}=\alpha Z_{t}+(1-\alpha) Z_{t-1}^{\prime}, Z_{0}^{\prime}=Z_{1}, \quad t=1, \ldots, N
$$

onde $Z^{\prime}$ é denominado valor exponencialmente suavizado, e $\alpha$ é a constante de suavização, $0 \leq \alpha \leq 1$

Quanto menor o valor de $\alpha$, maior será a suavização da série, pois um baixo valor de $\alpha$ implica em atribuir pesos maiores às observações passadas, e qualquer função aleatória, no presente, exercerá um peso menor no cálculo da série suavizada (Morettin e Toloi, 2004). A Figura 3.4 mostra o efeito da aplicação deste método, com $\alpha=0.3$.

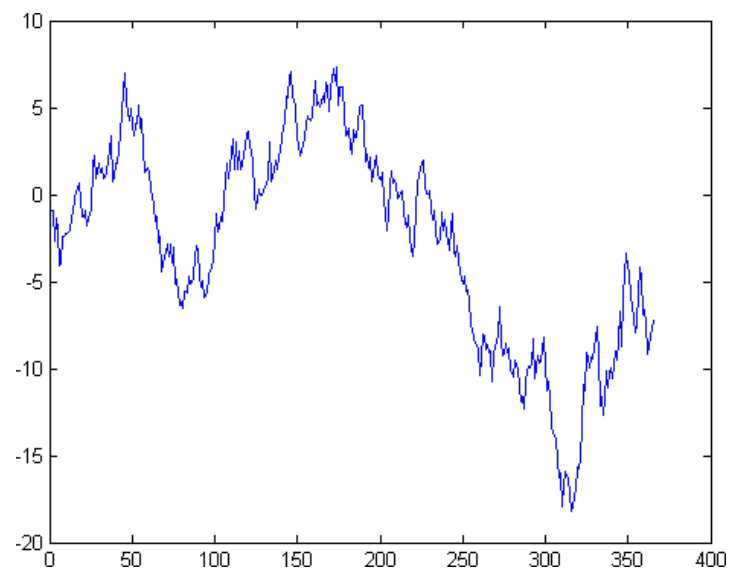

(a) Série Original

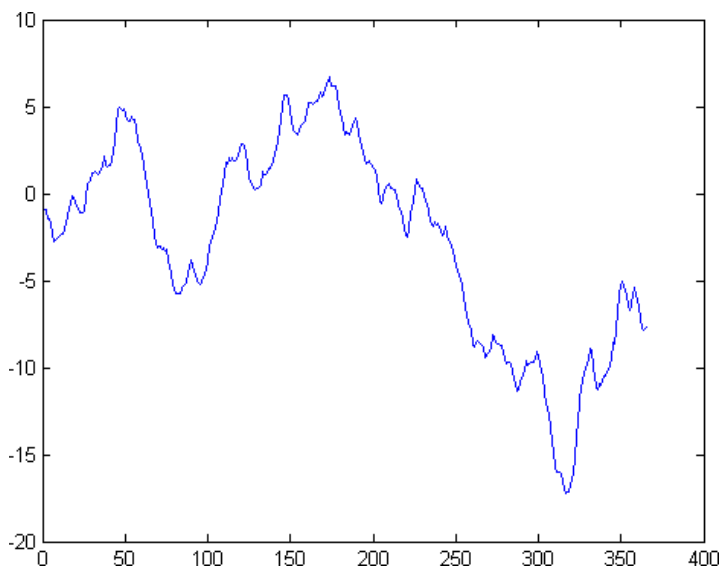

(b) Série Suavizada

Figura 3.4: Suavização Exponencial Simples (SES), $\alpha=0.3$.

A SES é muito utilizada, pois é de fácil entendimento; tem complexidade linear; oferece grande flexibilidade pela variação da constante de suavização $\alpha$; e requer armazenar somente $Z_{t}, Z_{t-1}^{\prime}$ e $\alpha$.

\subsubsection{Normalização}

A normalização é uma das tarefas de pré-processamento mais necessárias utilizadas, pois medidas de distância entre séries não-normalizadas produzir resultados errôneos. A Figura 3.5 mostra uma intuição visual da necessidade de normalizar as séries temporais 
antes de medir a distância entre elas. As séries $Q$ e $C$ são similares em formato, mas possuem diferentes offsets no eixo $y$. Dessa forma, pequenas variações no offset rapidamente ofuscam qualquer informação sobre o formato das séries. A distância computada entre séries não-normalizadas (ver Figura 3.5(b) compara somente a média entre elas. Já a distância computada entre séries normalizadas (ver Figura 3.5(c) compara a similaridade entre o formato das séries.

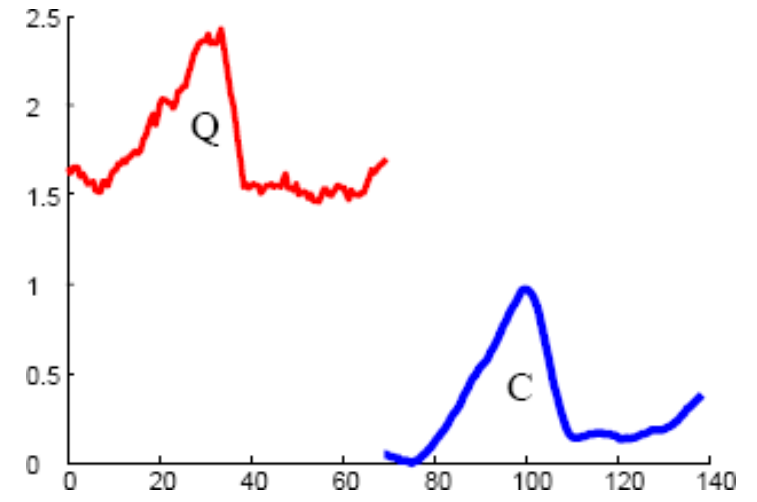

(a) Séries Temporais

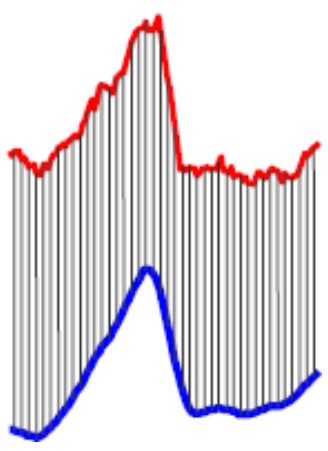

(b) Distância Nãonormalizada

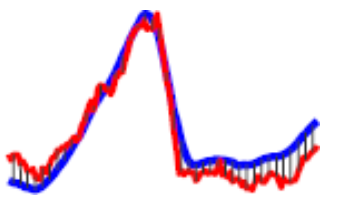

(c) Distância Normalizada

Figura 3.5: Normalização de séries temporais. As linhas em cinza representam a distância Euclidiana (Keogh e Kasetty, 2002).

A normalização de uma série temporal consiste em subtrair de cada observação da série a sua média, e dividir pelo seu desvio padrão (ver Equação 3.3). Após o que, a distribuição de freqüência terá média zero e desvio padrão igual a 1.

$$
Z^{\prime}=\frac{Z_{t}-\bar{Z}}{\widehat{\sigma}}, \quad t=1, \ldots, N
$$

A média de uma série temporal é estimada pela Equação 3.4:

$$
\bar{Z}=\frac{1}{N} \sum_{i=1}^{N} Z_{i}=\frac{Z_{i}+Z_{2}+\cdots+Z_{N}}{N}
$$

Já o desvio padrão é estimado pela Equação 3.5 .

$$
\widehat{\sigma}=\sqrt{\frac{1}{N-1} \sum_{i=1}^{N}\left(Z_{i}-\bar{Z}\right)}
$$




\subsubsection{Remoção da Sazonalidade}

Um conceito importante sobre séries temporais é a sazonalidade, que pode ser definida da seguinte maneira: os dados de uma série apresentam padrões de comportamento que se repetem periodicamente. Um exemplo é o aumento de temperatura nos meses de verão em uma série que registra temperaturas mensais. O aumento de temperatura, neste caso, provavelmente vai se repetir em todos os meses de verão, independente do ano, refletindo a sazonalidade do clima. A remoção dessa sazonalidade muitas vezes é um procedimento necessário, pois a presença de movimentos sazonais ofusca outros padrões não-sazonais importantes.

O Método dos Momentos Sazonais (Andrade, 2004) é um método não paramétrico para estimar e remover a componente sazonal de uma série. Neste método os dados são arranjados em uma tabela, onde cada linha corresponde às observações de um ciclo sazonal e as colunas são as observações dentro daquele ciclo, como ilustrado na Tabela 3.1. supondo observações mensais de uma série com ciclo anual.

Tabela 3.1: Estimação não paramétrica da sazonalidade.

\begin{tabular}{|c|c|c|c|c|c|}
\hline Anos $\backslash$ Meses & Janeiro & Fevereiro & Março & $\ldots$ & Dezembro \\
\hline 1 & $Z_{1,1}$ & $Z_{1,2}$ & $Z_{1,3}$ & $\ldots$ & $Z_{1,12}$ \\
\hline 2 & $Z_{2,1}$ & $Z_{2,2}$ & $Z_{2,3}$ & $\ldots$ & $Z_{2,12}$ \\
\hline$\vdots$ & $\vdots$ & $\vdots$ & $\vdots$ & $\ldots$ & $\vdots$ \\
\hline$n$ & $Z_{n, 1}$ & $Z_{n, 2}$ & $Z_{n, 3}$ & $\ldots$ & $Z_{n, 12}$ \\
\hline Médias Mensais & $\bar{Z}_{1}$ & $\bar{Z}_{2}$ & $\bar{Z}_{3}$ & $\ldots$ & $\bar{Z}_{12}$ \\
\hline
\end{tabular}

A partir da notação da Tabela 3.1 estima-se as médias mensais $\bar{Z}_{j}$ e os desvios padrões mensais $\widehat{\sigma}_{j}$, da seguinte forma:

$$
\begin{gathered}
\bar{Z}_{j}=\frac{1}{n} \sum_{i=1}^{n} Z_{i, j} \quad, \quad j=1, \ldots, 12 \\
\widehat{\sigma}_{j}=\sqrt{\frac{1}{n} \sum_{i=1}^{n}\left(Z_{i, j}-\bar{Z}_{j}\right)^{2}} \quad, \quad j=1, \ldots, 12
\end{gathered}
$$

Para obter a série livre de sazonalidade $Z^{\prime}$ deve-se subtrair de cada observação da série a sua média mensal, e dividir pelo desvio padrão mensal:

$$
Z_{i, j}^{\prime}=\frac{Z_{i, j}-\bar{Z}_{j}}{\widehat{\sigma}_{j}}
$$


A série $Z^{\prime}$ apresenta, aproximadamente, média zero e variância unitária. Dessa forma, esse método também promove a normalização das séries. A Figura 3.6 ilustra a aplicação desse método a uma série sazonal que representa a vazão média mensal da usina hidrelétrica de Furnas.

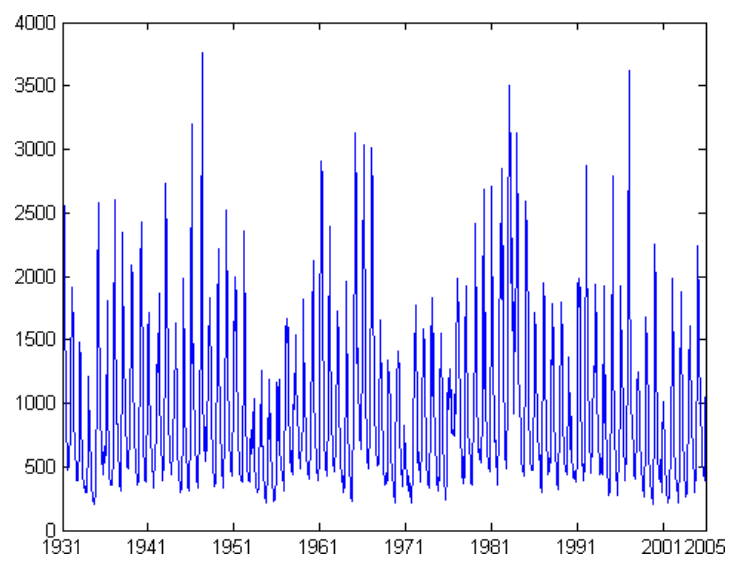

(a) Série original

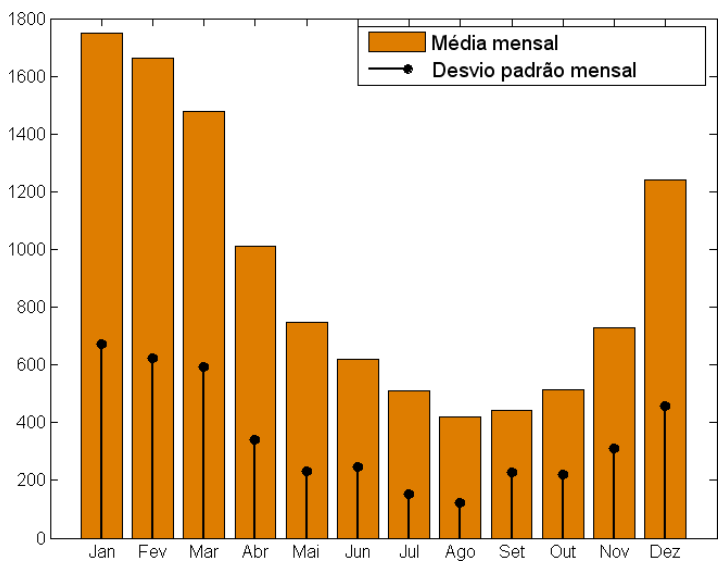

(c) Média e Desvio Padrão Mensal

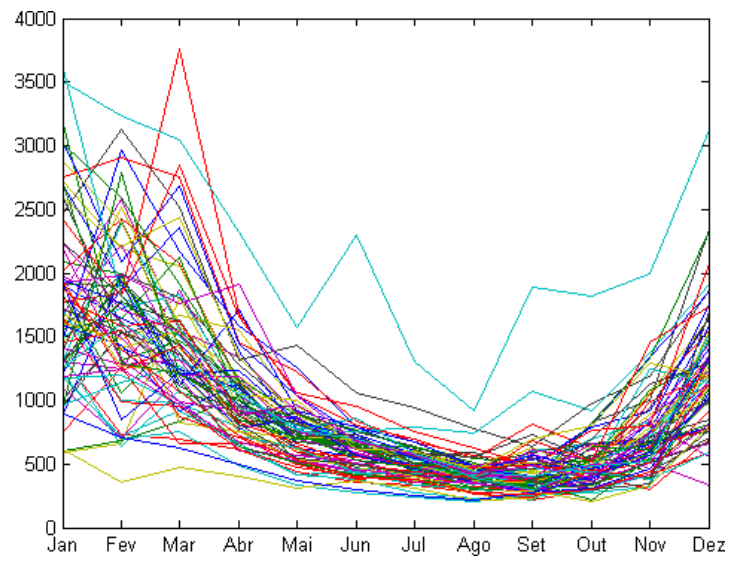

(b) Sazonalidade anual

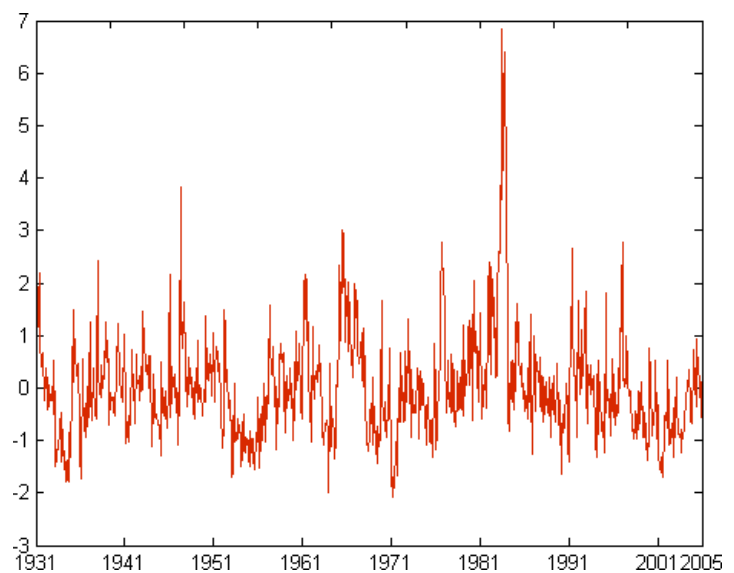

(d) Série sem sazonalidade

Figura 3.6: Método de Momentos Sazonais.

\subsection{Métricas de Dissimilaridade entre Séries Temporais}

A maioria das tarefas de mineração em séries temporais envolve quantificar a semelhança entre séries temporais e subseqüências, o que requer uma função para medir a (dis)similaridade entre duas seqüências, de acordo com a Definição 3 . A seguir são apresentadas duas métricas de dissimilaridade muito utilizadas por pesquisadores da área: a distância Euclidiana e o Dynamic Time-Warping (DTW). Também é apresentada uma 
terceira métrica, chamada Compression-based Dissimilarity Measure (CDM), utilizada para identificar similaridades estruturais.

\subsubsection{Distância Euclidiana}

Muitos trabalhos em séries temporais adotam a distância Euclidiana como medida de dissimilaridade. A distância Euclidiana só pode ser medida em séries do mesmo tamanho, consistindo no cálculo da distância entre pares de pontos das duas seqüências, como ilustrado na Figura 3.7 .

Definição 3.8 . Distância Euclidiana: Dadas duas séries temporais $Q=\left(Q_{1}, \ldots, Q_{n}\right)$ e $C=\left(C_{1}, \ldots, C_{n}\right)$ de mesmo tamanho $n$, a distância Euclidiana entre elas é definida como:

$$
D_{\text {euclidiana }}(Q, C)=\sqrt{\sum_{i=1}^{n}\left(Q_{i}-C_{i}\right)^{2}}
$$

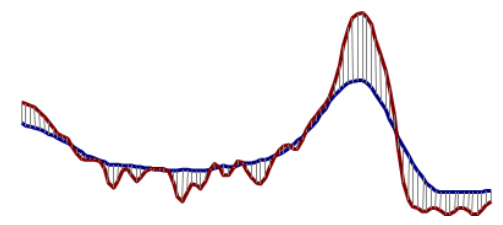

Figura 3.7: Noção intuitiva da distância Euclidiana, que pode ser vista como a soma das linhas cinzas entre os pares de pontos.

O cálculo da distância Euclidiana tem complexidade $O(n)$, mas pode ser acelerado. Quando ela é utilizada como sub-rotina em algoritmos de mineração como o de classificação, por exemplo, o interesse pode estar em conhecer a verdadeira distância entre duas séries somente quando ela é menor do que alguma tolerância $\varepsilon$. Neste caso, pode-se acelerar o cálculo praticando o "abandono prematuro" (ver Figura 3.8), como definido por Keogh et al. (2006a):

Definição 3.9 . Abandono Prematuro: Durante o cálculo da distância Euclidiana, se a soma atual das diferenças quadradas entre os pares de observações exceder o valor de $\varepsilon^{2}$, então é possível abandonar o cálculo da distância, com a certeza de que o valor exato da distância excederia $\varepsilon$. 




Figura 3.8: Abandono prematuro do cálculo da distância Euclidiana (Keogh et al. 2006a).

\subsubsection{Dynamic Time-Warping}

Apesar de ser simples de calcular, a distância Euclidiana produz resultados errôneos para séries temporais que são similares, mas que apresentam distorções no eixo do tempo. DTW (Berndt e Clifford, 1994) é uma medida de dissimilaridade mais eficiente nesse caso. Ao contrário da distância Euclidiana, o $\mathrm{DTW}$ é baseado na idéia de alinhamentos não-lineares entre séries, como ilustrado na Figura 3.9. Alinhamentos não-lineares há muito são utilizados pelas comunidades de bioinformática e reconhecimento de fala.

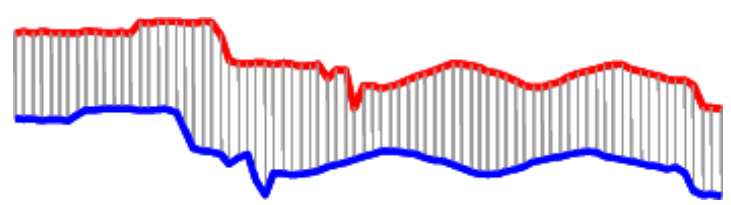

(a) Euclidiana

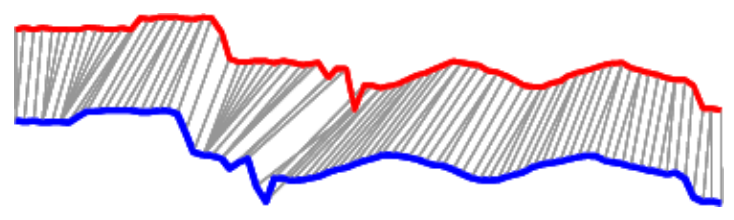

(b) DTW

Figura 3.9: Apesar das duas séries terem formas similares, elas não estão alinhadas no eixo do tempo. A distância Euclidiana gera uma medida de dissimilaridade pessimista, já o DTW produz uma medida de dissimilaridade mais intuitiva devido aos alinhamentos não-lineares (Keogh e Ratanamahatana, 2005).

A seguir é apresentada uma breve revisão da idéia do DTW. Dadas duas séries temporais, $Q$ de tamanho $n$, e $C$ de tamanho $m$ :

$$
\begin{aligned}
& Q=\left(Q_{1}, Q_{2}, \ldots, Q_{i}, \ldots, Q_{n}\right) \\
& C=\left(C_{1}, C_{2}, \ldots, C_{j}, \ldots, C_{m}\right)
\end{aligned}
$$

Para alinhar essas duas séries usando o DTW, constrói-se uma matriz de tamanho $n \times m$ na qual o elemento de índice $(i, j)$ contém a distância entre as observações $Q_{i}$ e 
$C_{j}, d(i, j)=\left|Q_{i}-C_{j}\right|$. Cada célula da matriz $(i, j)$ corresponde ao alinhamento entre as observações $Q_{i}$ e $C_{j}$, como ilustrado na Figura 3.10 .

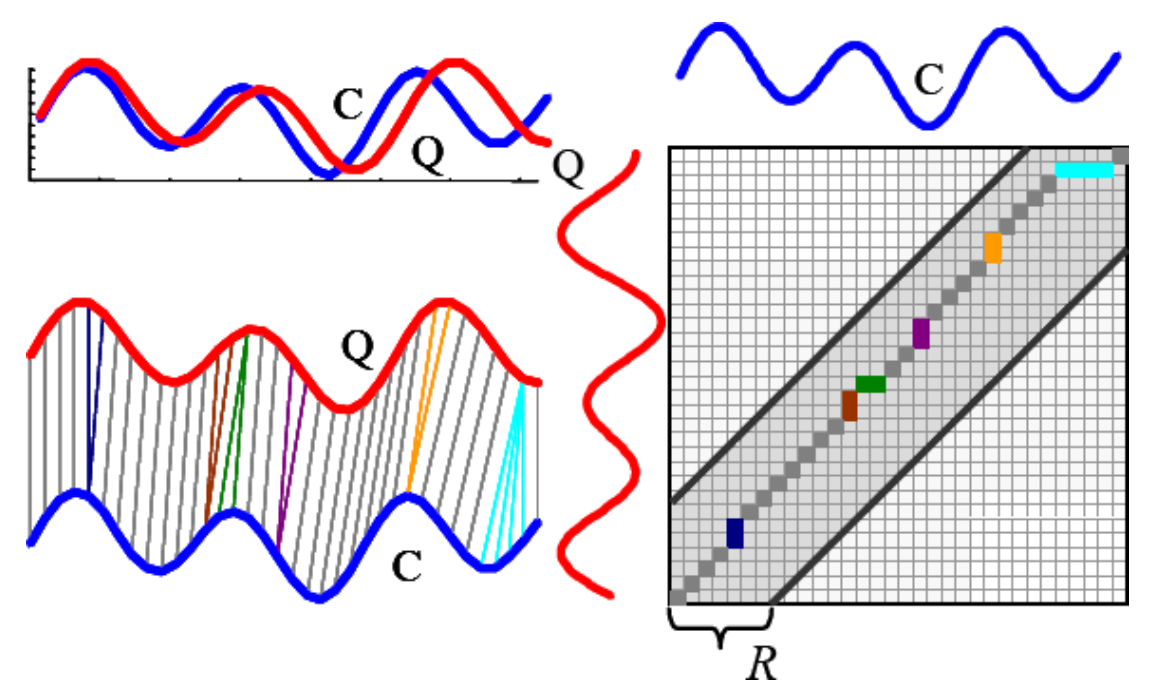

Figura 3.10: Matriz de alinhamento para o cálculo do DTW. A área em cinza mostra uma janela de alinhamento (Keogh e Ratanamahatana, 2005).

Dada essa matriz, o interesse é achar um caminho de alinhamento, como definido abaixo:

Definição 3.10 . Caminho de alinhamento: O caminho de alinhamento $P$ é um conjunto de elementos contíguos da matriz que definem um mapeamento entre $Q$ e $C$. O k-ésimo elemento de $P$ é definido como $p_{k}=(i, j)_{k}$.

$$
P=p_{1}, p_{2}, \ldots, p_{k}, \ldots, p_{t}, \quad \max (m, n) \leq t<m+n-1
$$

Este caminho de alinhamento está sujeito a diversas restrições:

1. Monotonicidade - Dado $p_{k}=(a, b)$, então $p_{k-1}=\left(a^{\prime}, b^{\prime}\right)$, no qual $a^{\prime} \leq a$ e $b^{\prime} \leq b$. O caminho de alinhamento não pode 'voltar'.

2. Continuidade - Dado $p_{k}=(a, b)$, então $p_{k-1}=\left(a^{\prime}, b^{\prime}\right)$, no qual $a-a^{\prime} \leq 1 \mathrm{e}$ $b-b^{\prime} \leq 1$. Os elementos do caminho devem ser células adjacentes (incluindo células diagonalmente adjacentes) 
Como conseqüência dessas duas restrições, a seguinte relação entre dois elementos consecutivos $p_{k}=(a, b)$ e $p_{k-1}=\left(a^{\prime}, b^{\prime}\right)$ é assegurada:

$$
p_{k-1}=\left(a^{\prime}, b^{\prime}\right)= \begin{cases}(a, b-1) & \text { ou, } \\ (a-1, b-1) & \text { ou } \\ (a-1, b) & \end{cases}
$$

3. Restrição de limite $-p_{1}=(1,1)$ e $p_{t}=(m, n)$. Esta restrição garante que o caminho de alinhamento comece e termine nas células dos cantos diagonalmente opostos da matriz.

Além dessas restrições, uma prática comum é limitar o quanto o caminho de alinhamento pode se afastar da diagonal.

Definição 3.11 . Janela de alinhamento: É o subconjunto de elementos da matriz, que o caminho de alinhamento é permitido visitar.

O uso de janelas de alinhamento considera o fato de que distorções no eixo do tempo usualmente não são muito excessivas. Existem várias razões para o seu uso, uma é que elas aceleram o cálculo do DTW. No entanto, a mais importante é prevenir alinhamentos patológicos, nos quais uma pequena porção de uma série é mapeada para uma grande porção da outra série. A Figura 3.11 mostra as duas janelas de alinhamento mais utilizadas, a Banda de Sakoe-Chiba (Sakoe e Chiba, 1978) e o Paralelogramo de Itakura (Itakura, 1975).

A janela Banda de Sakoe-Chiba restringe os índices do caminho de alinhamento $p_{k}=$ $(i, j)$ tal que $j-R \leq i \leq j+R$, em que $R$ é uma constante que define o alcance da janela de alinhamento. Autores como Keogh e Ratanamahatana (2005) recomendam que o valor de $R$ seja de $10 \%$ do tamanho da série mais longa. Na Figura 3.10, a área cinza da matriz representa a janela de alinhamento de Sakoe-Chiba.

Já o Paralelogramo de Itakura estabelece a região que o caminho de alinhamento pode visitar como sendo aquela formada pelas relações:

$$
\begin{aligned}
\frac{(j-1)}{E_{M A X}}+1 \leq i \leq E_{M A X}(j-1)+1, & \text { para } i+j<\frac{(N+M)}{2}+1 \\
E_{M A X}(j-M)+N \leq i \leq \frac{(j-M)}{E_{M A X}}+N, & \text { caso contrário }
\end{aligned}
$$


onde $E_{M A X}$ (geralmente igual a 2) é a expansão máxima da diagonal do paralelogramo. Assim o alcance da janela de alinhamento formada pelo Paralelogramo de Itakura é uma função de $i$ baseada nas Equações 3.14 e 3.15, sendo denotada por $R_{i}$.

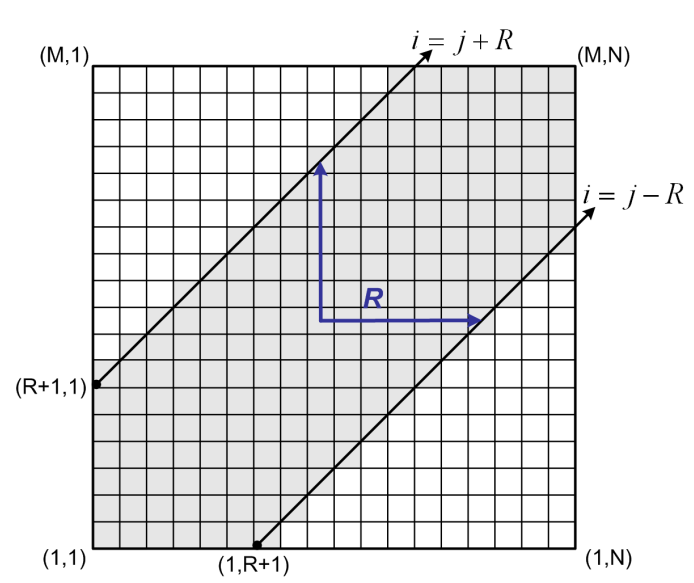

(a) Banda de Sakoe-Chiba

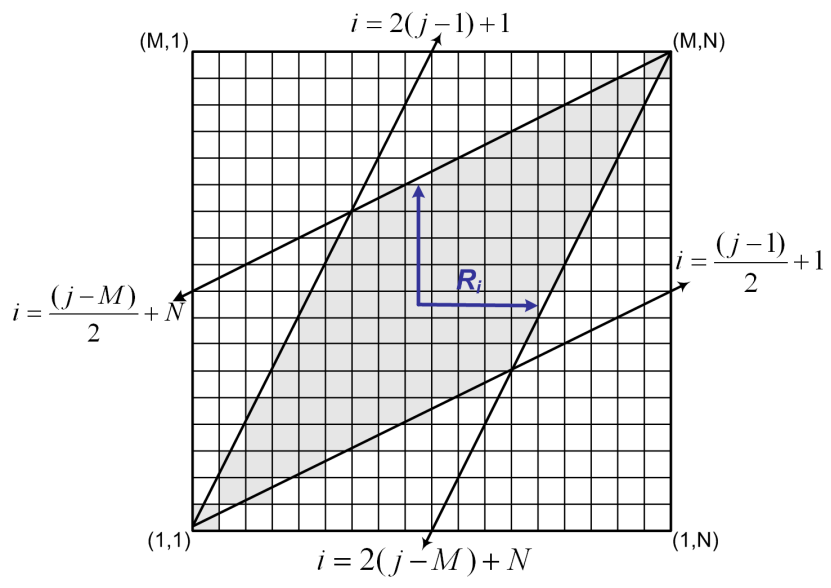

(b) Paralelogramo de Itakura

Figura 3.11: Janelas de alinhamento. Em (b), $E_{M A X}=2$

Existe um número exponencial de caminhos que obedecem as restrições e as janelas de alinhamento mencionadas acima. No entanto, o interesse é achar apenas o caminho ótimo, $P_{0}$, que minimize o total cumulativo da distância entre as séries:

Definição 3.12 . Distância DTW: Dadas duas séries temporais $Q$ e $C$, a distância DTW entre elas é o custo mínimo de todos os caminhos de alinhamento:

$$
D_{D T W}(Q, C)=\min \left\{\sqrt{\sum_{k=1}^{K} p_{k}}\right\}
$$

Esse caminho ótimo pode ser encontrado usando programação dinâmica, que estabelece uma relação de recorrência baseada na Equação 3.13. Essa relação define que a distância cumulativa $\gamma(i, j)$ é a soma da distância $d(i, j)$ da célula atual e distância mínima cumulativa das células adjacentes:

$$
\gamma(i, j)=d(i, j)+\min \{\gamma(i, j-1), \gamma(i-1, j-1), \gamma(i-1, j)\}
$$

Além de detectar séries similares com distorções no eixo do tempo, o DTW também é capaz de calcular a distância entre séries de diferentes tamanhos. No entanto, sua grande exatidão tem um preço. Dependendo do tamanho das séries, o DTW pode ser centenas 
ou milhares de vezes mais lento que a distância Euclidiana, devido à sua complexidade computacional quadrática. O custo computacional para o cálculo do DTW, sem o uso de janelas de alinhamento é de $O(N . M)$ para duas séries temporais de tamanho $N$ e $M$. Devido ao custo elevado muitos trabalhos visam obter uma estimativa para a distância DTW, cujo cálculo não seja demorado, questão abordada na próxima seção.

\subsubsection{Limite Inferior para o DTW}

Vários autores, como Kim et al. (2001) e Yi et al. (1998), buscam maneiras de estimar a distância DTW de uma forma eficiente. No entanto, qualquer estimativa para uma medida de similaridade deve atender duas características fundamentais:

1. Deve ser fácil de calcular. Uma estimativa que leva mais tempo para calcular do que a medida original obviamente não tem utilidade.

2. Deve obedecer a propriedade chamada limite inferior, que é extremamente importante e garante a qualidade da estimativa.

Definição 3.13 . Limite Inferior: A estimativa para uma medida de similaridade entre duas séries temporais deve ser menor e o mais próxima possível da verdadeira distância entre as mesmas séries.

$$
D_{\text {estimada }}(A, B) \leq D_{\text {original }}(A, B)
$$

A relação apresentada pela Equação 3.18 garante a inexistência de falsos dissimilares no processo de busca. Falsos dissimilares são séries que se qualificariam como similares segundo a distância original, mas que são distantes segundo a medida estimada. Falsos dissimilares não são aceitáveis, pois ignoram séries possivelmente similares, comprometendo a qualidade do resultado. No entanto, o limite inferior não garante a inexistência de falsos alarmes, que ocorrem quando séries indicadas como sendo similares segundo a medida estimada estão, na verdade, distantes. Como falsos alarmes podem ser removidos posteriormente, eles podem ser tolerados, contanto que não sejam muito freqüentes. Quanto mais próxima for a estimativa da medida original (desde que inferior à ela), menor o número de falsos alarmes.

Resumindo (ver Figura 3.12), para buscar uma série de consulta $Q$ em uma base de séries de acordo com uma tolerância $\varepsilon$ usando uma estimativa da distância, realiza-se uma pré-seleção para obter um conjunto de possíveis resultados (sem falsos dissimilares). 


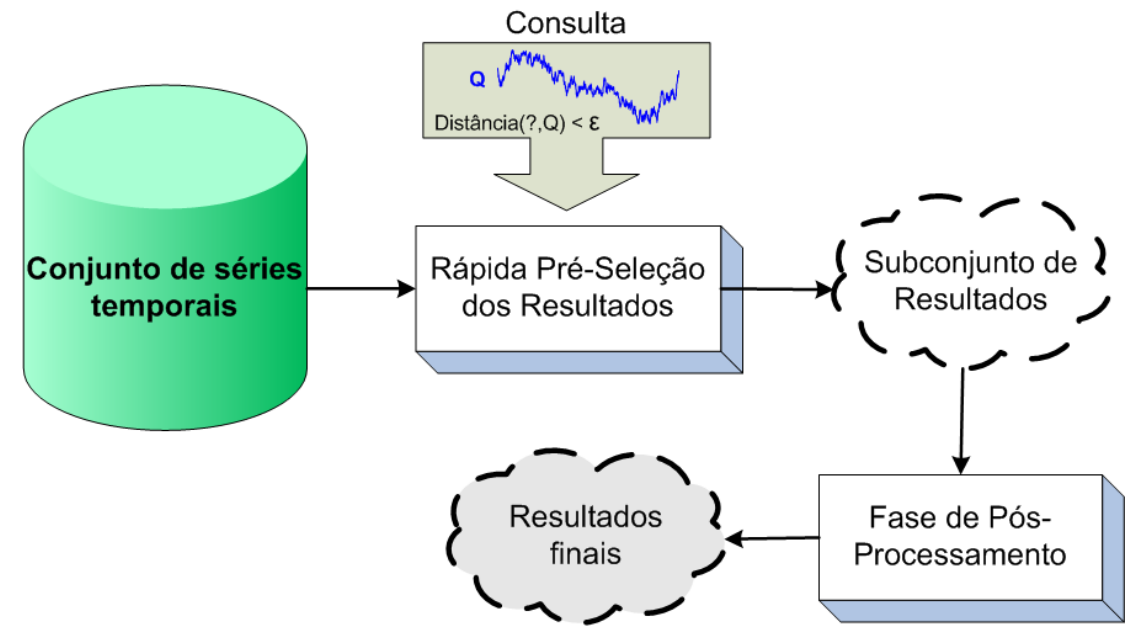

Figura 3.12: Uso de medidas de limite inferior para buscar séries similares a uma série de consulta $Q$ dentro de uma base de dados.

Falsos alarmes são eliminados em uma fase de pós-processamento, na qual sua distância exata será calculada. Portanto, um significativo aceleramento é alcançado calculado a distância exata (de cálculo demorado) somente para um subconjunto dos dados.

Com essa idéia em mente, Keogh e Ratanamahatana 2005) definiram uma estimativa para o DTW, chamada $L B \_K e o g h$, e comprovaram matematicamente que essa estimativa obedece à propriedade de limite inferior. Os autores também comprovaram, por meio de avaliações em bases de dados, que essa estimativa se aproxima mais da distância DTW exata do que outras publicadas anteriormente. Devido a essas características ela foi adotada neste trabalho. A seguir é apresentada uma breve revisão da estimativa $L B_{-} K e o g h$.

Dada uma série $Q=\left(Q_{1}, \ldots, Q_{N}\right)$, são calculadas duas séries temporais definidas por:

$$
\begin{aligned}
U_{i}=\max \left(Q_{i-R}: Q_{i+R}\right), & i=1, \ldots, N \\
L_{i}=\min \left(Q_{i-R}: Q_{i+R}\right), & i=1, \ldots, N
\end{aligned}
$$

onde $R$ é o alcance estabelecido por janelas de alinhamento (ver Seção 3.5.2). No caso da banda de Sakoe-Chiba, $R$ é uma constante. Já no caso do Paralelogramo de Itakura, $R$ é uma função de $i$ baseada nas relações descritas pelas Equações 3.14 e 3.15 . Dessa forma, as séries $U$ e $L$ podem ser construídas com base em uma dessas janelas de alinhamento (ver Figura 3.13), e devem obedecer a propriedade $U_{i} \geq Q_{i} \geq L_{i}$ para $\forall i$, criando um envelope para a série $Q$. 


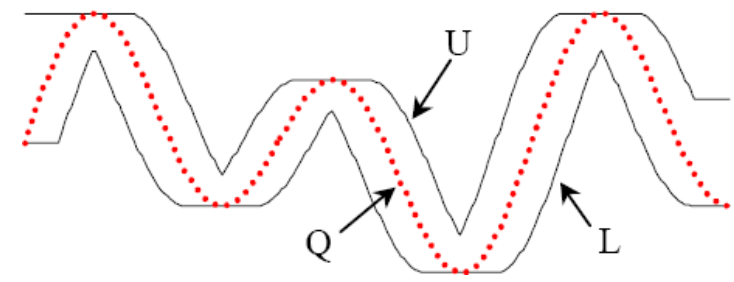

(a) Envelope criado com a Banda de SakoeChiba

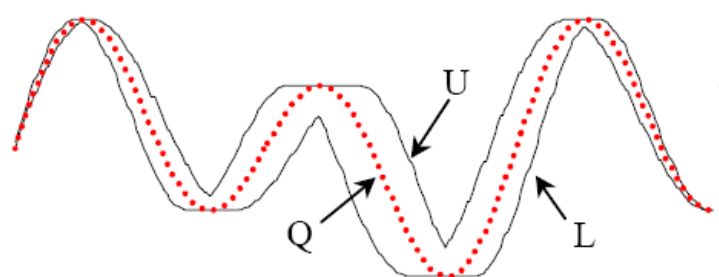

(b) Envelope criado com o Paralelogramo de Itakura

Figura 3.13: Envelopes para cálculo da estimativa $L B \_K e o g h($ Keogh e Ratanamahatana, 2005).

Definidos $U$ e $L$, a estimativa de limite inferior $L B_{-} K e o g h$ é definida da seguinte forma:

$$
L B \_K \operatorname{eogh}(Q, C)=\sqrt{\sum_{i=1}^{N} \begin{cases}\left(C_{i}-U_{i}\right)^{2} & \text { se } C_{i}>U_{i} \\ \left(C_{i}-L_{i}\right)^{2} & \text { se } C_{i}<L_{i} \\ 0 & \text { caso contrário }\end{cases} }
$$

Esta função pode ser visualizada como a distância Euclidiana entre partes da série $C$ e o envelope de $Q$, definido por $U$ e $L$. Essa distância Euclidiana só será calculada para partes da série $C$ que não se encontrem dentro do envelope, como ilustrado na Figura 3.14 ,

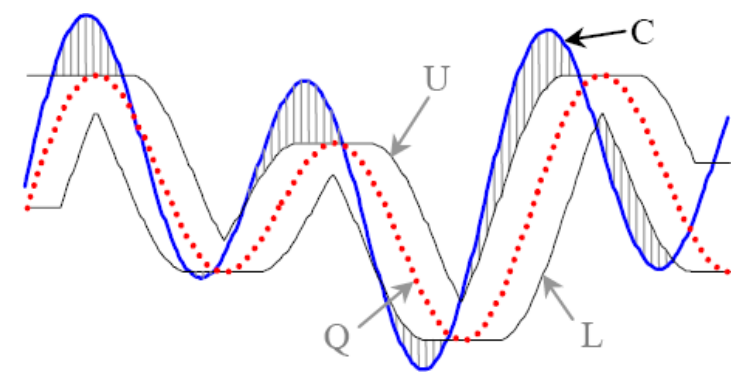

(a) LB_Keogh com a Banda de Sakoe-Chiba

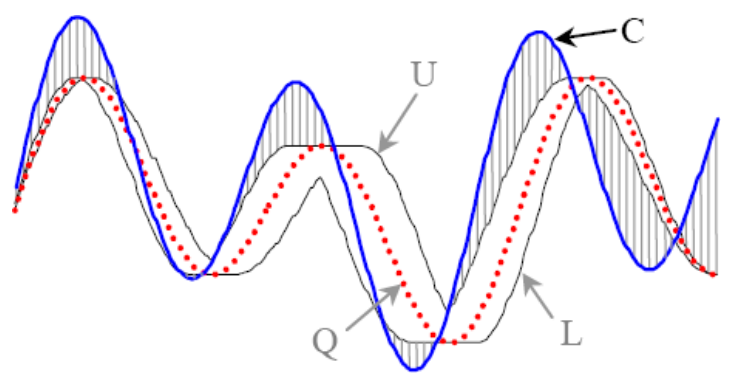

(b) LB_Keogh com o Paralelogramo de Itakura

Figura 3.14: Função de Limite Inferior $L B_{-} K \operatorname{Keogh}(Q, C)$ Keogh e Ratanamahatana, 2005).

\subsubsection{Compression-based Dissimilarity Measure}

Métricas de dissimilaridade como a distância Euclidiana e o DTW não conseguem tratar todas as aplicações de séries temporais, pois detectam diferenças entre os formatos locais das séries. Existem aplicações em que o interesse é em similaridades estruturais, que se 
manifestam nos padrões globais das séries. Métricas de dissimilaridade estruturais, como o CDM (Keogh et al., 2007), são adequadas para esse tipo de aplicação.

A medida CDM é baseada na complexidade de Kolmogorov (Kolmogorov, 1965), que busca quantificar a complexidade (quantidade de informação) de strings e outros objetos de forma objetiva e absoluta. No entanto, a complexidade de Kolmogorov não é uma função computável. Para definir a distância CDM, Keogh et al. baseiam-se no fato de que algoritmos de compressão são capazes de fornecer um limite superior para a verdadeira complexidade. Além de um algoritmo de compressão, para calcular essa medida entre duas séries é necessário, primeiramente, convertê-las para uma representação discreta. A representação sugerida pelos autores é conhecida como Symbolic Aggregate approXimation (SAX), que converte uma série temporal em uma seqüência de caracteres. O SAX será apresentado na Seção 3.6, e assumindo um algoritmo de compressão e essa representação, define-se a seguir a medida de dissimilaridade CDM. Dado um algoritmo de compressão $C, C(s)$ é definido como o tamanho em bytes da compressão da string s. Denotando como $x$ e $y$ a string da representação SAX das séries temporais $Q$ e $C$, respectivamente, a distância CDM entre elas é definida como:

$$
D_{C D M}(Q, C)=\frac{C(x y)}{C(x)+C(y)}
$$

onde $x y$ é $x$ concatenado com $y$.

Essa distância é próxima de 1 quando $Q$ e $C$ são dissimilares, e próxima de 0 quando $Q$ e $C$ são similares. Note que $D_{C D M}(Q, Q)$ não é zero. Quanto melhor o algoritmo de compressão, melhor a aproximação de $D_{C D M}$ para a verdadeira complexidade de Kolmogorov.

A distância CDM tem a vantagem de ser extremamente rápida, mas requer séries temporais longas (dimensionalidade maior ou próxima de 1.000) para produzir bons resultados. Outra vantagem é que essa métrica é livre de parâmetros.

\subsection{Tarefas de Mineração de Séries Temporais}

Nas seções seguintes são apresentadas algumas tarefas de mineração em séries temporais utilizadas neste projeto: representações de séries temporais, classificação e consulta por conteúdo. Essas tarefas são muito utilizadas no processo de descoberta de conhecimento, como validação experimental ou como componentes em algoritmos complexos. 


\subsubsection{Representações de Séries Temporais}

Alguns algoritmos e estruturas de mineração de dados escalam pobremente para dados com alta dimensionalidade. Esse é o caso de séries temporais, cuja dimensionalidade é igual ao número de pontos amostrados no tempo (tamanho da série). Tamanhos muito grandes tornam impraticável, em teoria, a aplicação de muitos algoritmos de mineração de dados.

Para resolver este problema muitas vezes gera-se uma representação de alto nível da série, de dimensionalidade menor do que a original, mas que suporte a execução das demais tarefas de mineração. Uma definição formal encontra-se abaixo:

Definição 3.14 . Representação de séries temporais: Dada uma série temporal $Q$ contendo $n$ pontos, constrói-se um modelo $\bar{Q} \operatorname{com} w$ segmentos $(w \ll n)$ tal que $\bar{Q}$ é uma boa aproximação de $Q$.

O principal objetivo é obter um modelo de representação, de menor dimensionalidade, mas que preserve as características da série original. Como $w$ geralmente é bem menor do que $n$, as representações são mais fáceis de armazenar, transmitir e analisar. A escolha da representação afeta fortemente a eficiência das tarefas de mineração, de modo que um grande número de representações já foi proposto na literatura. Uma visualização e breve descrição das principais representações para séries temporais podem ser vistas na Figura 3.15 e na Tabela 3.2 .

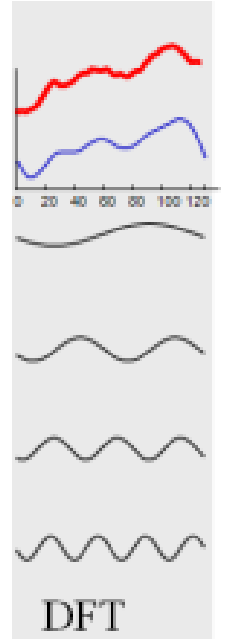

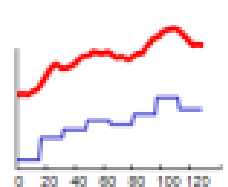
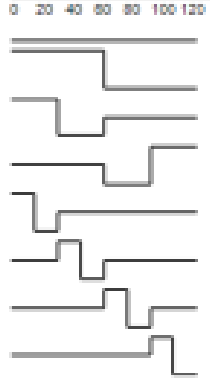

DWT
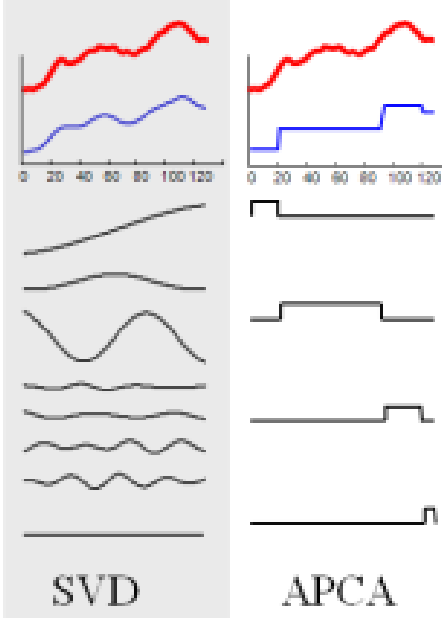

APCA
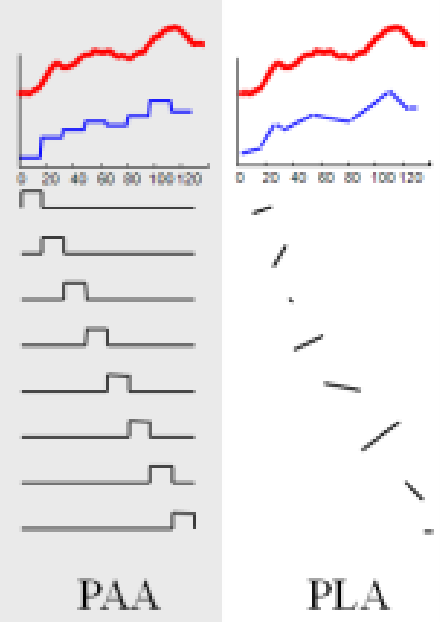

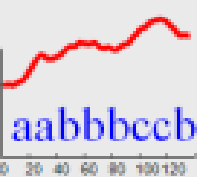

a

$a_{\text {b }}$

b

b
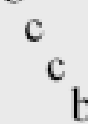

SAX

Figura 3.15: Representações de séries temporais. A série original está em azul, e a representação em vermelho.

A maioria das representações apresentadas na Tabela 3.2 fornece valores contínuos, o que limita os algoritmos, estruturas de dados e definições aplicáveis. Por exemplo, em 
Tabela 3.2: Principais representações de séries temporais.

\begin{tabular}{|c|c|}
\hline Nome & Descrição \\
\hline $\begin{array}{l}\text { Discrete Fourier Trans- } \\
\text { form (DFT) }\end{array}$ & $\begin{array}{l}\text { Representa a série como uma soma de funções seno e coseno multiplicadas } \\
\text { por coeficientes (amplitude e fase). (Agrawal et al. }, 1993) \text {. }\end{array}$ \\
\hline $\begin{array}{l}\text { Discrete Wavelet Trans- } \\
\text { form (DWT) }\end{array}$ & $\begin{array}{l}\text { Representa a série como uma combinação linear de funções base de Wavelet, } \\
\text { mantendo somente os primeiros } N \text { coeficientes (Chan e Fu, 1999). }\end{array}$ \\
\hline $\begin{array}{l}\text { Singular Value Decompo- } \\
\text { sition } \text { SVD }\end{array}$ & $\begin{array}{l}\text { Representa a série como uma combinação linear de formatos (neste traba- } \\
\text { lho, eigenwaves)(Korn et al., 1997). }\end{array}$ \\
\hline $\begin{array}{l}\text { Piecewise Aggregate Ap- } \\
\text { proximation } \sqrt{\mathrm{PAA})}\end{array}$ & $\begin{array}{l}\text { Representa a série como uma seqüência de segmentos de igual tamanho, } \\
\text { que representam a média da série naquele intervalo (Keogh et al., 2000). }\end{array}$ \\
\hline $\begin{array}{l}\text { Adaptive } \quad \text { Piecewise } \\
\text { Constant Approxima- } \\
\text { tion APCA }\end{array}$ & $\begin{array}{l}\text { Generalização do Piecewise Aggregate Approximation, que admite segmen- } \\
\text { tos de tamanhos arbitrários, de acordo com a atividade da série temporal. } \\
\text { O APCA coloca vários segmentos em áreas de alta atividade, e poucos } \\
\text { segmentos em áreas de baixa atividade (Chakrabarti et al. } 2002) \text {. }\end{array}$ \\
\hline $\begin{array}{l}\text { Piecewise Linear Appro- } \\
\text { ximation (PLA) }\end{array}$ & $\begin{array}{l}\text { Representa a série como uma seqüência de linhas retas, que podem estar } \\
\text { conectadas ou não (Morinaka et al., 2001). }\end{array}$ \\
\hline $\begin{array}{l}\text { Symbolic Aggregate ap- } \\
\text { proXimation (SAX) }\end{array}$ & $\begin{array}{l}\text { Converte as séries temporais em uma seqüência de caracteres (Lin et al. } \\
\text { 2003). }\end{array}$ \\
\hline
\end{tabular}

detecção de anomalias não é possível definir a probabilidade de observar uma determinada ocorrência, já que a probabilidade de observar qualquer número real é zero. Tais limitações incentivam pesquisadores a considerar o uso de representações simbólicas para séries temporais, discretizando-as (Lin et al., 2003).

A representação discreta $\mathrm{SAX}$ é apresentada em detalhes a seguir. Ela foi utilizada neste trabalho para calcular a medida de dissimilaridade CDM (ver Seção 3.5.3).

\subsubsection{Symbolic Aggregate approXimation (SAX)}

O SAX é um método de representação simbólica de séries temporais proposto por Lin et al. (2003). Essa representação transforma as séries, que possuem valores reais, em seqüências de caracteres, preservando as características da série original. O SAX permite que uma série de tamanho arbitrário $n$ seja reduzida a uma string de tamanho $w$, com $w \ll n$.

A representação simbólica é obtida por meio de três etapas: normalização, $[\mathbf{P A A}$ e discretização.

A etapa de normalização consiste em aplicar a operação de pré-processamento discutida na Seção 3.4.2, obtendo-se séries temporais com média igual a 0 e desvio padrão igual a 1 .

Já a segunda etapa, chamada PAA (Keogh et al., 2000), é de fato outro algoritmo de representação de séries. É nesta representação intermediária que acontece a redução 
de dimensionalidade. A idéia básica é dividir uma série temporal de tamanho $n$ em $w$ segmentos de igual tamanho, reduzindo dimensionalidade de $n$ para $w$. Então, é calculada a média aritmética dos valores da série que estão dentro de cada segmento, e o vetor dessas médias torna-se a representação $\overline{\mathrm{PAA}}$. Para calcular o vetor de $w$ segmentos, $\bar{X}=\left\{\bar{x}_{1}, \ldots, \bar{x}_{w}\right\}$ para uma série temporal $X=\left\{x_{1}, \ldots, x_{n}\right\}$ usa-se a Equação 3.23 .

$$
\overline{x_{i}}=\frac{w}{n} \sum_{j=\frac{n}{w}(i-1)+1}^{\frac{n}{w} i} x_{j} \quad, \quad i=1, \ldots, w
$$

A escolha do valor de $w$ é extremamente importante, pois determina o grau da redução de dimensionalidade. Como uma série que antes tinha dimensão $n$ terá uma representação de tamanho $w$, tem-se um fator de agregação $n / w$. Quanto menor o valor de $w$, maior o fator de agregação e maior a redução de dimensionalidade.

Tendo transformado uma série na representação $\mathrm{PAA}$, aplica-se a etapa de discretização para obter uma representação discreta, a representação do $S A X$. Nesta etapa, cada segmento da representação PAA é transformado numa letra equiprovável.

Para gerar dessas letras equiprováveis deve-se escolher o tamanho $a$ do alfabeto, que determina quais letras serão usadas no processo de discretização. O tamanho do alfabeto é um inteiro arbitrário, com $a>2$. Para $a=4$, por exemplo, as letras do alfabeto serão $\{$ 'a', 'b' 'c', 'd' $\}$. Para determinar que segmentos serão mapeados em que letras criase uma lista de breakpoints, de acordo com a Definição 3|15. Dado que séries temporais normalizadas têm uma curva de distribuição de probabilidade Gaussiana, é possível definir $a$ áreas de igual tamanho sob a curva de distribuição.

Definição 3.15 . Breakpoints: é uma lista ordenada de números $\beta=\beta_{1}, \ldots, \beta_{a-1}$, tal que a área sob a curva Gaussiana $N(0,1)$ de $\beta_{i}$ até $\beta_{i+1}$ seja igual a $1 / a$, de forma a gerar símbolos equiprováveis ( $\beta_{0}$ e $\beta_{a}$ são definidos como $-\infty$ e $\infty$, respectivamente).

A Tabela 3.3 mostra os valores da lista de breakpoints, para tamanhos de $a$ entre 3 e 10.

Uma vez obtidos os breakpoints determina-se o mapeamento de segmentos em símbolos, como ilustrado na Figura 3.16. Os breakpoints dividem o eixo $y$, e os segmentos contidos antes do primeiro breakpoint $\beta_{1}$ serão mapeados para a letra 'a'. Já os segmentos que ocorrem após $\beta_{1}$, mas antes que $\beta_{2}$, são mapeados para a letra 'b', e assim por diante. 
Tabela 3.3: Tabela de breakpoints para a etapa de discretização, com o tamanho do alfabeto variando de 3 a 10.

\begin{tabular}{|c|c||c|c|c|c|c|c|c|c|}
\hline \multicolumn{2}{|c||}{} & \multicolumn{10}{c|}{$a$} \\
\cline { 2 - 9 } \multicolumn{2}{|c||}{} & 3 & 4 & 5 & 6 & 7 & 8 & 9 & 10 \\
\hline \hline \multirow{6}{*}{$\beta$} & $\beta_{1}$ & -0.43 & -0.67 & -0.84 & -0.97 & -1.07 & -1.15 & -1.22 & -1.28 \\
& $\beta_{2}$ & 0.43 & 0 & -0.25 & -0.43 & -0.57 & -0.67 & -0.76 & -0.84 \\
& $\beta_{3}$ & - & 0.67 & 0.25 & 0 & -0.18 & -0.32 & -0.43 & -0.52 \\
& $\beta_{4}$ & - & - & 0.84 & 0.43 & 0.18 & 0 & -0.14 & -0.25 \\
& $\beta_{5}$ & - & - & - & 0.97 & 0.57 & 0.32 & 0.14 & 0 \\
& $\beta_{6}$ & - & - & - & - & 1.07 & 0.67 & 0.43 & 0.25 \\
& $\beta_{7}$ & - & - & - & - & - & 1.15 & 0.76 & 0.52 \\
& $\beta_{8}$ & - & - & - & - & - & - & 1.22 & 0.84 \\
& $\beta_{9}$ & - & - & - & - & - & - & - & 1.28 \\
\hline
\end{tabular}

A concatenação das letras obtidas por este processo de discretização dos segmentos é chamada de 'palavra'. Segue uma definição formal deste processo:

Definição 3.16 . Palavra $(\widehat{X})$ : Uma representação $P A A$ com $w$ segmentos pode ser representada por uma "palavra", $\widehat{X}=\left\{\widehat{x}_{1}, \ldots, \widehat{x}_{w}\right\}$, como segue. Seja $\alpha_{i}$ o i-gésimo elemento do alfabeto, ou seja, $\alpha_{1}=\mathrm{a}, \alpha_{2}=\mathrm{b}, \alpha_{3}=\mathrm{c}$, e assim por diante. Então a transformação da representação PAA, $\bar{X}$, para uma "palavra", $\widehat{X}$, é obtida de acordo com a Equação 3.24

$$
\widehat{c}_{i}=\alpha_{j} \text {, se e somente se } \beta_{j-1} \leq \bar{c}_{i}<\beta_{j} \quad, \quad i=1, \ldots, w
$$

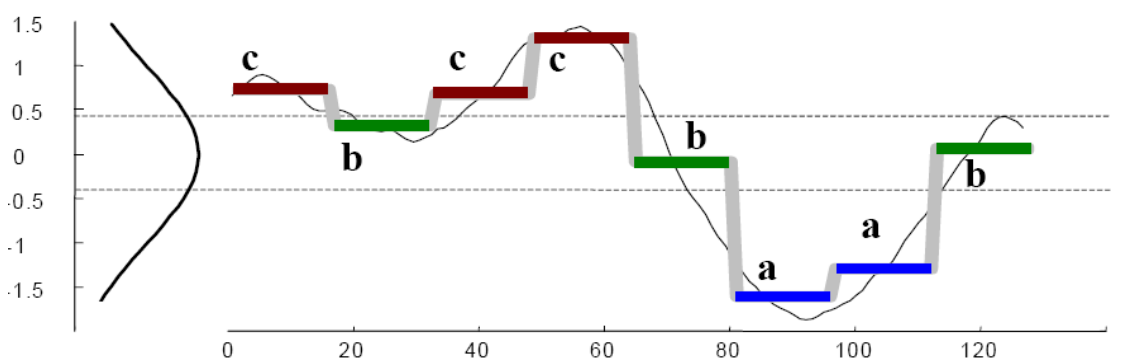

Figura 3.16: A série temporal (linha preta), já normalizada, é discretizada, obtendo-se uma representação PAA (linha cinza grossa). Depois uma lista de breakpoints é usada para mapear os coeficientes PAA em letras (em negrito). Neste exemplo, $n=128, w=8$ e $a=3$, a série é discretizada para a string cbccbaab (Keogh et al., 2005).

A transformação da representação $\mathrm{PAA}$ para uma representação discreta gera uma seqüência de letras para representar a série temporal. A principal vantagem do SAX é obter um modelo de representação, que reduz a dimensionalidade, mas preserva as características da série original. Outra motivação para ter uma representação discreta 
é que ela permite aplicar algoritmos para dados discretos originários das comunidades de processamento de texto e biológica. As comunidades da área biológica, por exemplo, algoritmos para o tratamento e manipulação de seqüências de DNA, que nada mais são do que seqüências de caracteres.

\subsubsection{Classificação}

A tarefa de mineração de dados chamada classificação pode ser definida como segue:

Definição 3.17 . Classificação: Dado um conjunto de dados $X=\left\{x_{1}, \ldots, x_{n}\right\}$, cujas classes são conhecidas $y, y=\{1, \ldots, J\}$, o objetivo da classificação é o aprendizado de uma função $f: X \rightarrow Y$ que mapeie um objeto $x \in X$ para a sua classe $y \in Y$.

A função $f$ é conhecida como modelo de classificação. Uma abordagem geral para o aprendizado deste modelo consiste, primeiramente, em fornecer dados de treinamento, cujas classes são conhecidas. Os dados de treinamento são, então, usados para gerar o modelo de classificação, que é posteriormente aplicado aos dados de teste, cujas classes são desconhecidas. O objetivo é criar um modelo capaz de categorizar corretamente tanto os dados utilizados em seu treinamento, como dados nunca vistos antes, ou seja, um modelo com boa capacidade de generalização (Tan et al., 2005).

O interesse principal na classificação está na precisão do resultado obtido, cuja avaliação é baseada na contagem do número de objetos classificados corretamente (acurácia) ou incorretamente (taxa de erro). A velocidade e o consumo memória do processo são dois aspectos importantes, além de uma boa generalidade. Se dados de treinamento impróprios (insuficientes, ausentes ou incorretos) forem fornecidos, o modelo resultante poderá ter uma boa precisão para o conjunto de treinamento, mas um desempenho ruim para novos exemplos. Diz-se, então, que o modelo é específico para o conjunto de treinamento, ocorrendo o overfitting.

Existem muitos domínios de aplicação da classificação de séries temporais: reconhecimento de fala, análise de sinais médicos, reconhecimento de gestos, entre outros, e muitos algoritmos têm sido propostos. Em Rodríguez e Alonso (2004), por exemplo, o foco é a produção de um modelo de classificação mais compreensível, baseado em árvores de decisão. Mas ,quando o foco é a acurácia, a simples combinação do algoritmo do vizinho mais próximo com o DTW apresenta ótimos resultados. Este algoritmo atribui a um objeto não-classificado a classificação do objeto mais próximo (similar) dentro de um conjunto de objetos previamente classificados. Mas devido ao uso do DTW, tal abordagem é muito lenta computacionalmente para aplicações reais. No entanto, o cálculo pode ser acelerado 
utilizando a estimativa $L B_{-} K e o g h$ (apresentada na Seção 3.5.2.1) como explicado pelo Algoritmo 4.

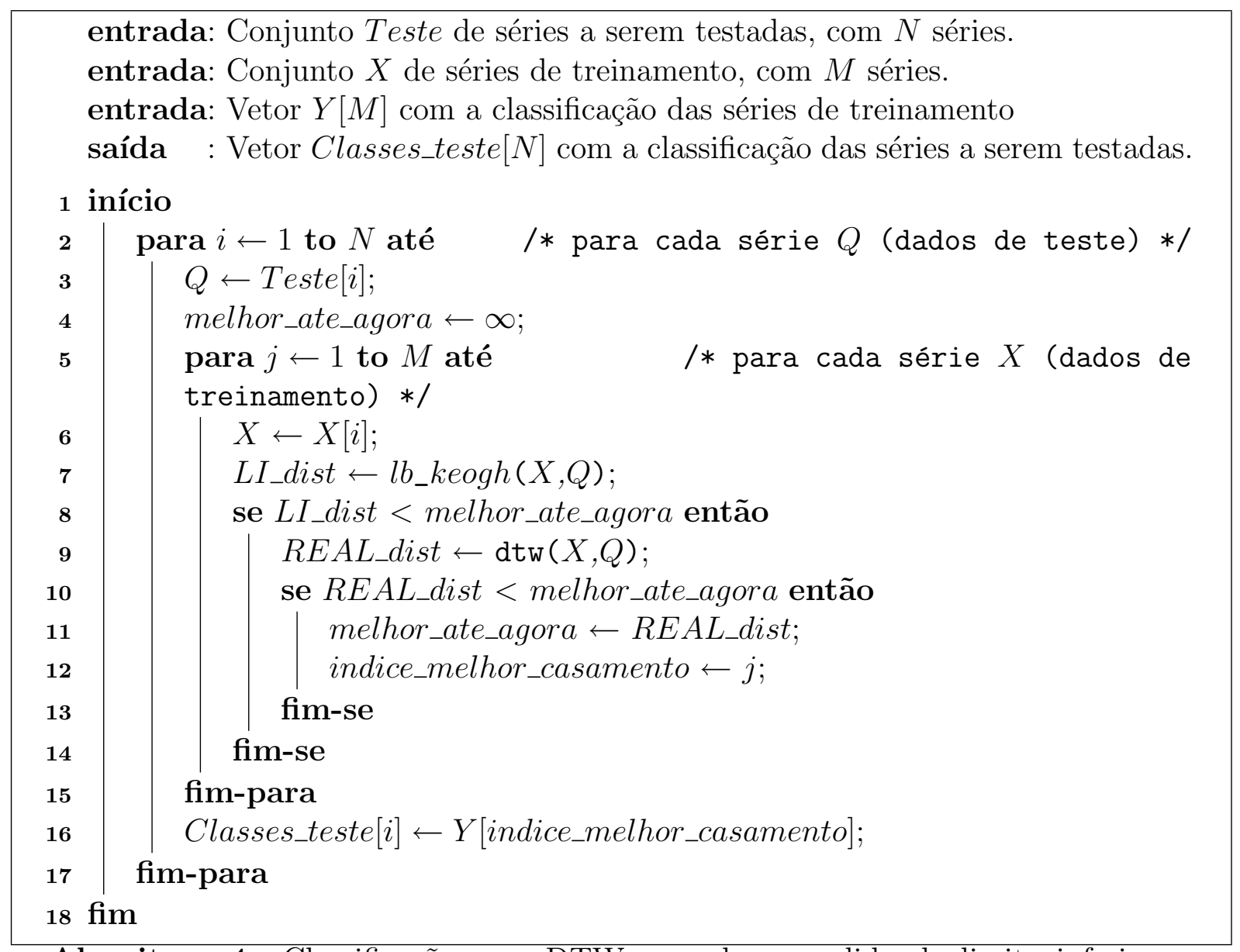

Algoritmo 4: Classificação com DTW, usando a medida de limite inferior LB_Keogh.

Neste algoritmo, a verdadeira distância DTW somente é calculada para as séries que possuírem uma estimativa $L B_{-}$Keogh inferior a menor distância computada até o momento entre a série temporal que está sendo testada e as séries de treinamento. Para ilustrar a velocidade e acurácia deste algoritmo é usado o conjunto de dados CBF, cujas séries são classificadas em três classes (ver Figura 3.17): cylinder, bell e funnel. O conjunto de teste possui 900 séries, e o de treinamento, possui 30 séries. Todas as séries possuem tamanho 128.

A Tabela 3.4 mostra o tempo, em segundos, e a taxa de erro, para a classificação do conjunto $\mathrm{CBF}$, segundo diferentes medidas de dissimilaridade. Os tempos foram calculados em um computador com processador Intel Pentium IV 3.2 GHz e 1GB de RAM. A 


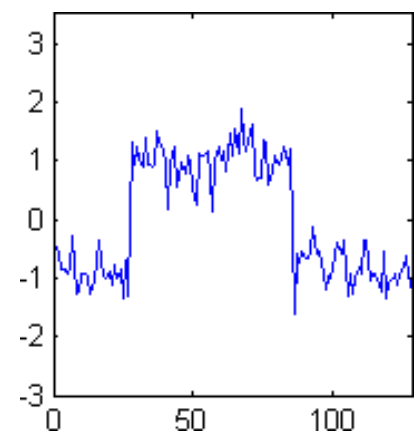

(a) Cylinder

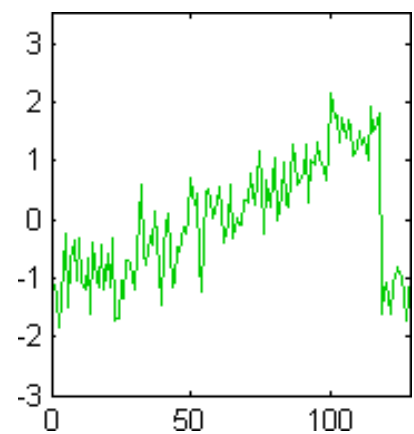

(b) Bell

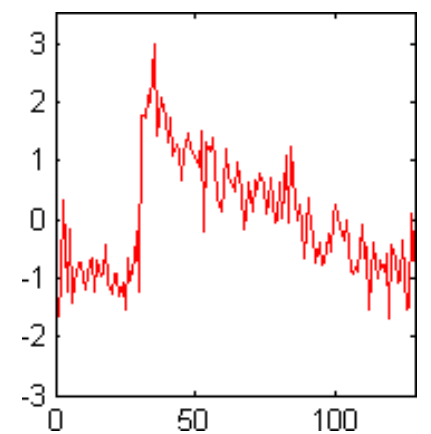

(c) Funnel

Figura 3.17: Exemplo das classes do conjunto de dados Cylinder-Bell-Funnel (CBF).

abordagem de classificação que apresenta melhores resultados é aquela apresentada pelo Algoritmo 4, que apresenta melhor combinação de taxa de erro e tempo de processamento.

Tabela 3.4: Comparação de Medidas de Similaridade para Classificação.

\begin{tabular}{|l|c|c|}
\hline Método & Tempo (segundos) & Taxa de erro \\
\hline \hline $\begin{array}{l}\text { Vizinho mais próximo com distância Euclidi- } \\
\text { ana }\end{array}$ & 0,578 & $\approx 0,148$ \\
\hline $\begin{array}{l}\text { Vizinho mais próximo com DTW sem janela } \\
\text { de alinhamento }\end{array}$ & 70,031 & $\approx 0,004$ \\
\hline $\begin{array}{l}\text { Vizinho mais próximo com DTW com janela } \\
\text { de alinhamento }(R=10 \%)\end{array}$ & 24,427 & $\approx 0,004$ \\
\hline $\begin{array}{l}\text { Vizinho mais próximo com DTW janela de } \\
\text { alinhamento }(R=10 \%) \text { e limite inferior } \\
L B \_ \text {Keogh (Algoritmo 44) }\end{array}$ & 17,828 & $\approx 0,004$ \\
\hline
\end{tabular}

\subsubsection{Consulta por Conteúdo}

A partir das medidas de dissimilaridade apresentadas na Seção 3.5, uma tarefa interessante chamada consulta por conteúdo é achar, em um conjunto de séries temporais, quais se assemelham a uma série de consulta $Q$, de acordo com alguns parâmetros definidos pelo usuário. Existem dois métodos de busca adequados para realizar consulta por conteúdo em um conjunto de séries temporais: busca por alcance e busca pelos k-vizinhos mais próximos. A definição desses métodos, segundo Vlachos (2004), é apresentada a seguir.

Definição 3.18 . Busca por alcance: Dado um conjunto de séries temporais $S$ e uma série de consulta $Q$, uma busca por alcance irá retornar um subconjunto $T \subset S$, tal que $D\left(Q, T_{j}\right)<\varepsilon$, onde $D$ é uma medida de dissimilaridade e $\varepsilon$ é uma tolerância (alcance) definidos pelo usuário. 
A escolha do valor da tolerância $\varepsilon$ pode ser um problema, já que esse parâmetro afeta o resultado da busca. Em Buono et al. (2005), os autores contornam este problema definindo a tolerância como uma porcentagem de erro máxima permitida, depois de normalizar as distâncias obtidas para que seus valores fiquem entre 0 e 1.

Definição 3.19 . K-Vizinhos Mais Próximos: Dado um conjunto de séries temporais $S$, uma série de consulta $Q$ e uma medida de dissimilaridade $D$, uma busca pelos $k$ vizinhos mais próximos irá retornar um subconjunto $T \subset S$ com cardinalidade $k$, tal que, se $\max \left(T_{j}, Q\right)=\rho$ para $j=1, \ldots, k, T^{\prime} \subset S$, e $T^{\prime} \cap T=\emptyset$, então $D\left(Q, T_{i}^{\prime}\right) \geq \rho$.

Ainda existem duas variações dos métodos acima:

- Casamento Inteiro: Todas as séries de $S$ a serem comparadas tem o mesmo tamanho da série de consulta $Q$.

- Casamento de Subseqüências: A série de consulta $Q$ possui um tamanho menor do que as séries em $S$. Dessa forma, a consulta é feita deslizando-se e comparando-se $Q$ contra as subseqüências das séries em $S$ (ver Figura 3.18).

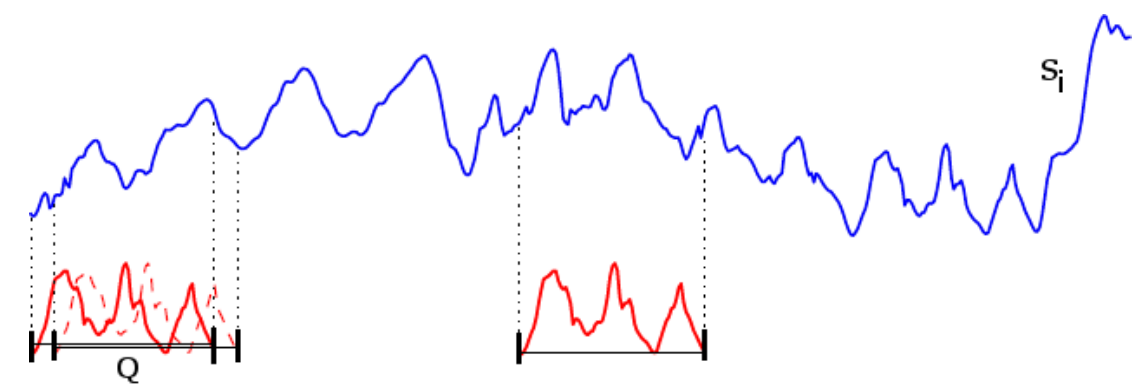

Figura 3.18: Casamento de subseqüências (Vlachos, 2004).

No entanto, um importante fenômeno é observado no casamento de subseqüências. Como abordado em Keogh et al. (2003), quando procura-se por subseqüências similares em um conjunto de dados, tipicamente os melhores casamentos para uma subseqüência $C_{p}$ tendem a ser as subseqüências ..., $C_{p-2}, C_{p-1}, C_{p+1}, C_{p+2}, \ldots$ Em outras palavras, os melhores casamentos tendem a ser versões levemente deslocadas da subseqüência de interesse, conhecidas como casamentos triviais. Uma definição mais exata de casamento trivial foi fornecida por Keogh et al. (2003):

Definição 3.20 . Casamento Trivial (trivial match): Dada uma série temporal $T$, contendo uma subseqüência $C$ começando na posição $p$, e uma subseqüência $M$ que casa com $C$, começando em $q$, diz-se que $M$ é um casamento trivial de $C$ se $p=q$, ou se não existe 
uma subseqüência $M^{\prime}$ começando em $q^{\prime}$ tal que $D\left(C, M^{\prime}\right)>D(C, M)$, e $q<q^{\prime}<p$ ou $p<q^{\prime}<q$.

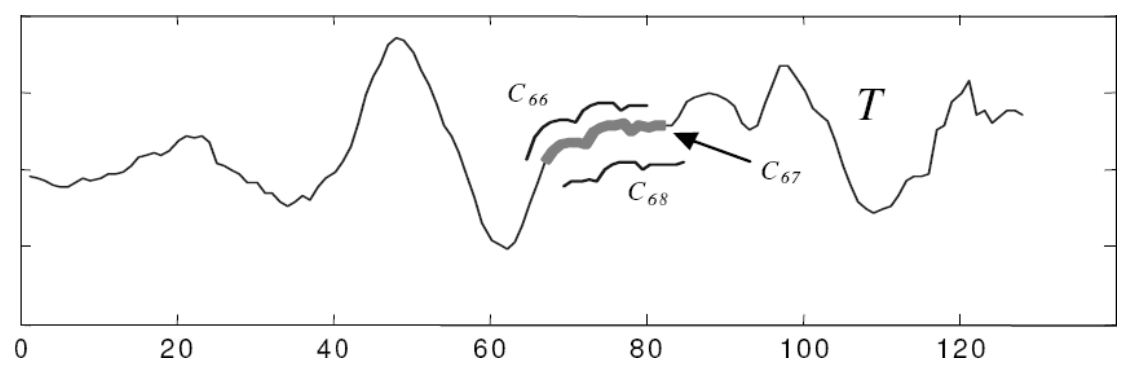

Figura 3.19: Para quase toda subseqüência $C$ em uma série temporal, as subseqüências mais similares são as subseqüências imediatamente à esquerda e à direita de $C$ (Keogh et al., 2003).

Esses casamentos triviais devem ser excluídos quando realiza-se casamento de subseqüências. Essa exclusão é crítica, pois como discutido no trabalho de Keogh et al. (2003), casamentos triviais não têm sentido e podem levar a interpretações erradas.

Definidos os interesses em cada uma das buscas surge a questão em como resolver estas consultas. A abordagem bruta seria uma busca seqüencial, que requer a comparação da série temporal de consulta $Q$ contra todas as séries ou subseqüências no conjunto de dados, mantendo-se um registro dos melhores casamentos. No entanto, tal abordagem é inapropriada para grandes conjuntos de dados.

Uma abordagem mais eficiente é utilizar uma estrutura de indexação. Esses índices são estruturas hierárquicas que direcionam a busca para a parte mais promissora do conjunto de dados, eliminando a necessidade de examinar uma grande porção dos objetos. Existem vários tipos dessas estruturas, sendo que as mais usadas são as árvores-R Guttman, 1984), uma variação das árvores-B para dados multidimensionais, e suas variantes. No entanto, a maioria dessas estruturas degrada rapidamente para um número maior do que 8 dimensões, passando a fazer busca seqüencial. Para resolver este problema adotase uma etapa anterior de segmentação para reduzir a dimensionalidade dos dados de um valor $n$ para um valor $N$, que possa ser eficientemente manipulado pela estrutura de indexação escolhida. Tal abordagem, que usa uma técnica de redução de dimensionalidade para representar as séries e indexa essas representações em uma estrutura, foi explorada eficientemente no arcabouço GEMINI (GEneric Multimedia INdexIng) Faloutsos et al., 1994). 


\subsection{Considerações Finais}

Neste capítulo discutiu-se a aplicação de mineração para séries temporais, focando nas diferentes etapas deste processo: estudo do domínio de interesse, as atividades de préprocessamento, definição medidas de dissimilaridade necessárias a tarefas clássicas de mineração para séries temporais. No próximo capítulo será apresentada a ferramenta desenvolvida durante este projeto, que utiliza parte dos conceitos apresentados até o momento. Também serão apresentados os resultados obtidos. 


\section{Temporal-PEx: Ferramenta e Resultados}

\subsection{Considerações Iniciais}

Uma vez definidas medidas de dissimilaridade apropriadas é possível aplicar técnicas de projeção multidimensional para gerar representações visuais de grandes coleções de dados. Essas representações fornecem uma visão geral dos dados que favorece a identificação de elementos com padrões similares/dissimilares, provendo um ponto de partida para uma exploração mais detalhada. A aplicação de tarefas de mineração de dados que extraiam automaticamente informações úteis dos dados é outro campo promissor. Desta forma, estudamos a aplicação de técnicas de projeção multidimensional em conjunto com tarefas de mineração para a mineração visual de conjuntos de séries temporais. Com este intuito, propomos e desenvolvemos uma ferramenta que implementasse recursos de mineração visual de séries: a ferramenta Temporal-Projection Explorer (Temporal-PEx).

$\mathrm{Na}$ Seção 4.2 são apresentadas as características e funcionalidade da Temporal-PEx. Já na Seção 4.3 são apresentados alguns cenários de análise de conjuntos de séries, e os resultados correspondentes obtidos. A Seção 4.4 exibe uma visão geral das técnicas de projeção e das medidas de dissimilaridade disponíveis, estabelecendo suas vantagens e desvantagens. Por fim, a Seção 4.5 fornece os tempos de processamento necessários para a geração das projeções exibidas na seção de resultados. 


\subsection{A Ferramenta Temporal-PEx}

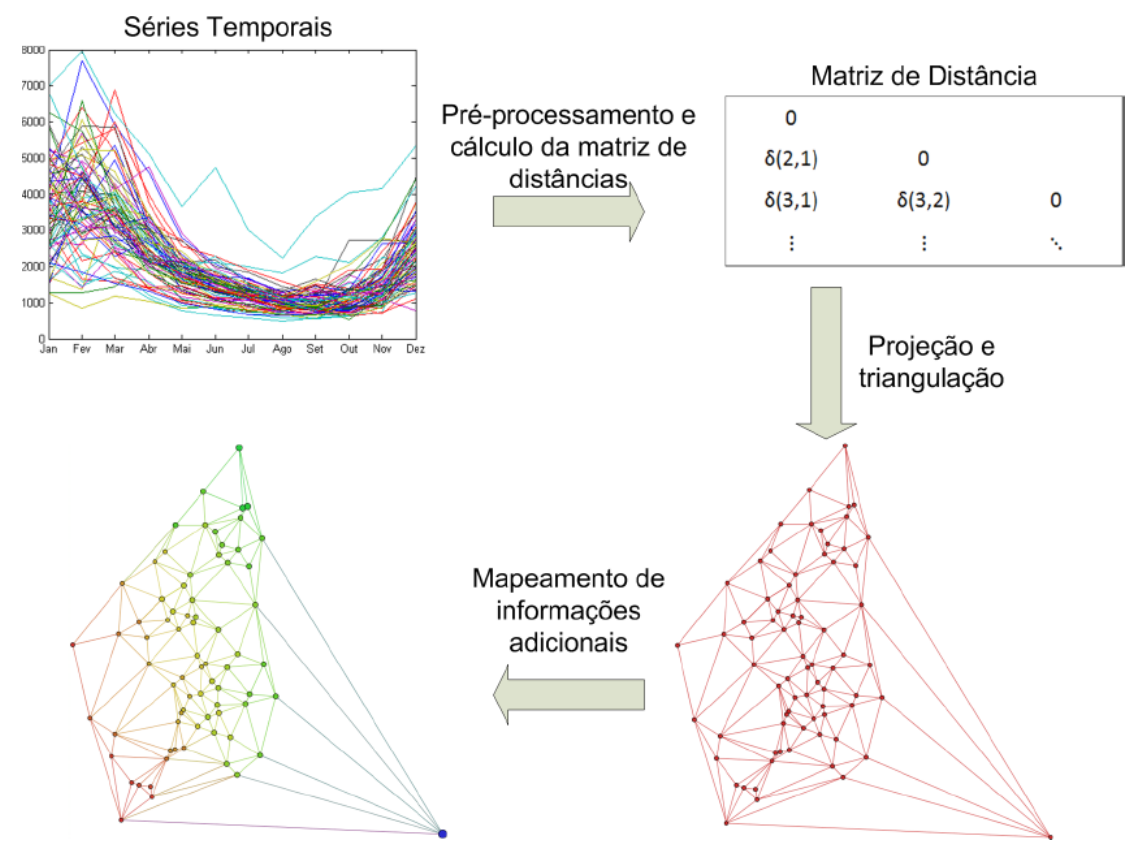

Figura 4.1: Visão geral do processo para projeção de séries temporais aplicado pela ferramenta Temporal-PEx.

O processo geral para criar uma projeção de séries temporais utilizando o TemporalPEx é composto por cinco etapas principais, ilustradas na Figura 4.1.

1. Especificação do Arquivo Fonte de Séries Temporais - O formato de entrada das séries para a ferramenta Temporal-PEx chama-se TSD. Este formato assemelhase ao formato Comma-Separated Values (CSV) com algumas informações adicionais no cabeçalho: a descrição do conjunto de séries; o número de séries temporais; presença ou não de sazonalidade, e o tamanho do ciclo sazonal; possível classificação prévia das séries; e eixo temporal no qual elas ocorrem. Após este cabeçalho, as séries são fornecidas usando-se um rótulo seguido pelos valores da série. A descrição formal da construção de arquivos nesse formato encontra-se disponível juntamente com a distribuição da ferramenta. A Tabela 4.1 mostra um exemplo do uso desse formato para descrever o conjunto de séries Cylinder-Bell-Funnel, que foi apresentado na Seção 2.3. Nesse formato, o caractere \# é usado para indicar comentário.

2. Pré-processamento - Se tentarmos medir a similaridade entre duas séries temporais em sua forma original, sem um pré-processamento, podem-se obter resultados 
Tabela 4.1: Exemplo do formato TSD.

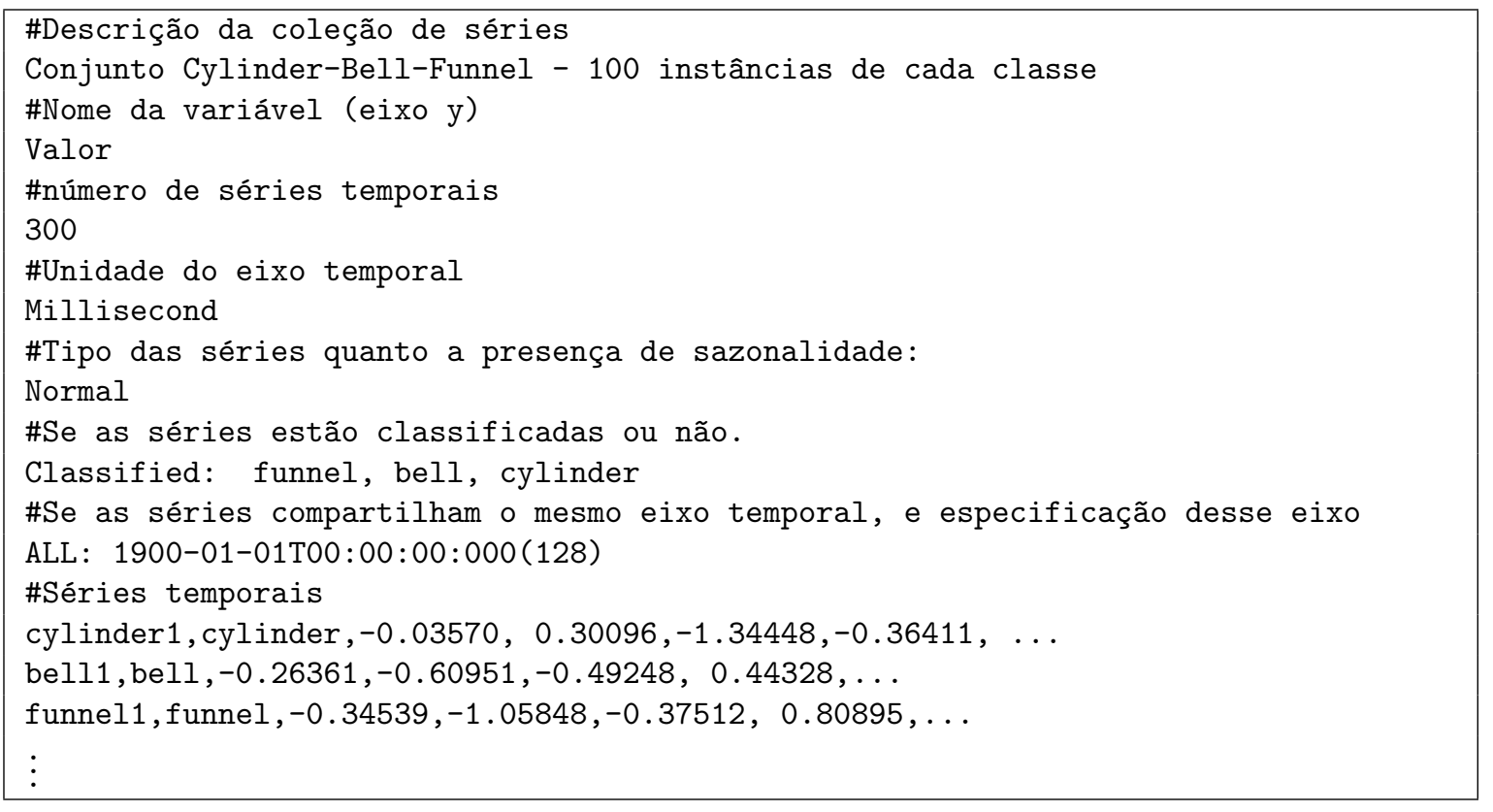

não intuitivos devido a distorções nos dados. Foram implementadas três funcionalidades de pré-processamento, que podem ser utilizadas a critério do usuário (ver Seção 3.4): normalização, suavização e remoção de sazonalidade.

3. Cálculo da Matriz de Distâncias - Dado um conjunto de $N$ séries, $S=\left\{S_{1}, \ldots, S_{N}\right\}$, uma matriz de distância contém as distâncias entre todos os pares de séries (ver Tabela 4.2). Na Tabela 4.2 a expressão $\delta\left(S_{i}, S_{j}\right)$ representa a distância entre as séries temporais de índices $i$ e $j$, segundo alguma medida de dissimilaridade. A matriz de distância é a base para a projeção de um conjunto de dados, como discutido no Capítulo 2, A ferramenta Temporal-PEx incorpora três medidas de dissimilaridade (ver Seção 3.5): a distância Euclidiana, o DTW e o CDM.

Tabela 4.2: Matriz de distância.

\begin{tabular}{|ccccc|}
\hline 0 & & & & \\
$\delta\left(S_{2}, S_{1}\right)$ & 0 & & & \\
$\delta\left(S_{3}, S_{1}\right)$ & $\delta\left(S_{3}, S_{2}\right)$ & 0 & & \\
$\vdots$ & $\vdots$ & $\vdots$ & $\ddots$ & \\
$\delta\left(S_{N}, S_{1}\right)$ & $\delta\left(S_{N}, S_{2}\right)$ & $\delta\left(S_{N}, S_{3}\right)$ & $\cdots$ & 0 \\
\hline
\end{tabular}

4. Projeção e Conexão entre Pontos - OTemporal-PEx incorpora duas técnicas de projeção multidimensional, que eram originalmente da ferramenta PEX (ver Seção 2.3): IDMAP e LSP. A IDMAP não necessita de parâmetros. Já no caso da LSP 
é necessário fornecer dois parâmetros: o número de pontos de controle $(n c)$; e o número de vizinhos $(k)$. A ferramenta sugere valores para ambos os parâmetros, baseando-se no número de séries. O número sugerido de pontos de controle $(n c)$ é igual a 10\% do número de séries. E o valor sugerido para o número de vizinhos $(k)$ é igual a 10 para coleções com menos de 1500 séries, ou 15 caso contrário.

Uma vez projetadas as séries é possível gerar um grafo ou uma triangulação, ambas representações convenientes para ressaltar a percepção de vizinhança (proximidade) entre os pontos. Três tipos de conexão entre os pontos estão disponíveis, que também foram incorporados da ferramenta $\mathrm{PEX}$

- Triangulação de Delaunay - Gera uma triangulação entre os pontos $X^{\prime}$, $T\left(X^{\prime}\right)$, de tal forma que nenhum ponto de $X^{\prime}$ esta dentro do circuncírculo de qualquer triângulo de $T\left(X^{\prime}\right)$ (ver Figura 4.2). A triangulação de Delaunay maximiza o ângulo mínimo de todos os ângulos de todos os triângulos na triangulação, evitando ao máximo triângulos com ângulos pequenos. Essa triangulação foi inventada em 1934 por Boris Delaunay (Delaunay, 1934).

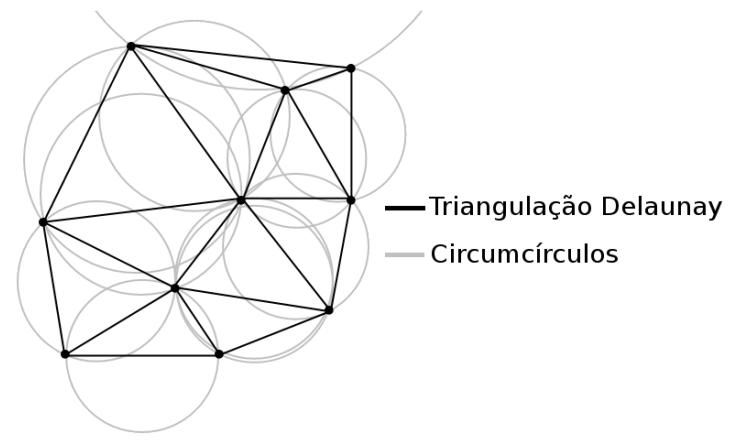

Figura 4.2: Triangulação de Delaunay.

- KNN-RM-1 - Arestas do grafo representam conexões entre os vizinhos mais próximos no espaço original, $\mathbb{R}^{m}$.

- KNN-R2-1 - Arestas do grafo representam conexões entre os vizinhos mais próximos no espaço projetado, $\mathbb{R}^{2}$.

5. Mapeamento de Informações Adicionais - Apesar de opcional, esta etapa fornece recursos visuais interessantes que representam características dos dados. Informações das séries podem ser mapeadas para a cor e/ou tamanho dos círculos que as representam: a média, a variância, o valor mínimo, o valor máximo. Se existir uma classificação das séries, também é possível mapear a classe. 


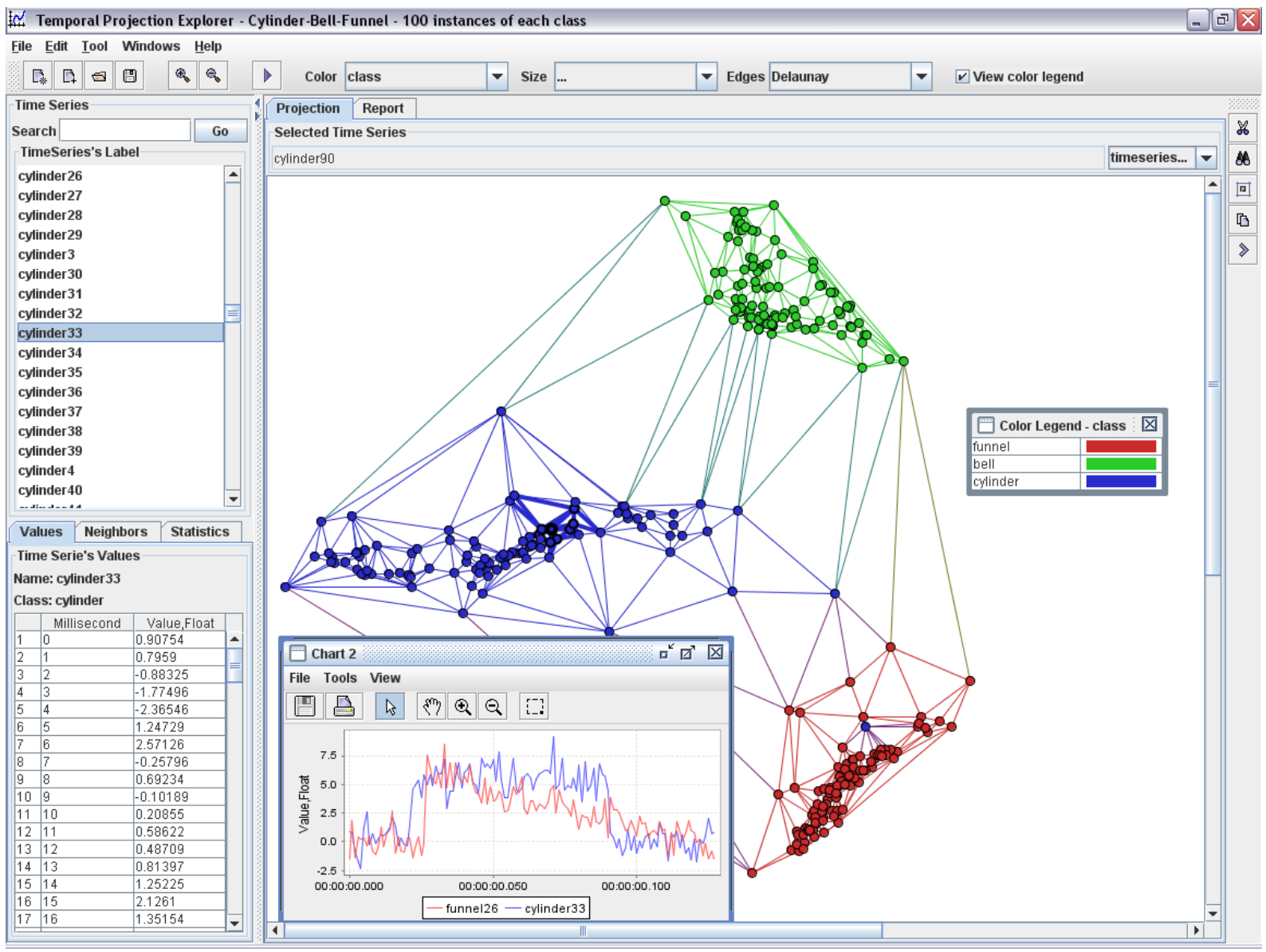

Figura 4.3: Janela principal da ferramenta Temporal-PEx. O conjunto de dados exibido é o Cylinder-Bell-Funnel discutido na Seção 2.3 
A ferramenta embute um assistente de criação de projeções que guia o usuário nas etapas do processo. Também possui outras funcionalidades, referentes a interações sobre três painéis complementares à projeção com recursos para auxiliar a descoberta de padrões nos dados:

- Painel de projeção (central) - Esse painel exibe a projeção, na qual cada círculo representa uma única série. Um clique duplo sobre um círculo irá abrir uma janela que mostra o gráfico correspondente àquela série. Um clique com o botão direito do mouse sobre outro ponto faz com que o gráfico desta série seja anexado à outra janela existente, permitindo a comparação entre múltiplas séries, como ilustrado na Figura 4.3 .

- Painel dos rótulos das séries (lado esquerdo superior) - Esse painel mostra os rótulos descritivos associados a cada uma das séries no conjunto de dados, e que foram informados juntamente com o arquivo fonte.

- Painel detalhes-sob-demanda (lado esquerdo inferior) - Já esse painel mostra em suas abas três tipos de informação relativos às séries: os valores da série, a relação de vizinhança entre os círculos, ou seja, quais são as séries mais similares a uma determinada série selecionada, e informações estatísticas (média, variância, valor mínimo e valor máximo).

Esse três painéis são altamente integrados: a seleção de um círculo na projeção causa a seleção do rótulo da série temporal correspondente no painel de rótulos (e vice-versa) e a exibição das informações relativas à série no painel de detalhes-sob-demanda.

Outras funcionalidades:

- Salvar e carregar projeções em arquivos no formato eXtensible Markup Language (XML), incluindo os valores das séries temporais.

- Relatório das técnicas e parâmetros usados na projeção.

- Salvar, imprimir e interagir (zoom interativo e pan) com gráficos de séries temporais.

\subsubsection{Tarefas de Mineração de Dados}

A visualização da distribuição das séries no conjunto dá ao usuário um ponto de partida para a busca por padrões de interesse. Para auxiliar na busca por esses padrões estão disponíveis na ferramenta duas atividades de mineração, que são descritas nas seções seguintes. 


\subsubsection{Casamento de Subseqüências}

Dado um conjunto de séries temporais, uma tarefa interessante é achar quais séries contém subseqüências que se assemelham a uma subseqüiência de consulta $Q$ (ver Seção 3.6.3), ou seja, realizar uma busca por padrões internos às séries, considerando que a projeção já fornece uma visão comparativa dos padrões globais.

Para executar essa busca, primeiramente é necessário selecionar uma subseqüência $Q$, contida em uma série de interesse selecionada, pela qual estamos procurando. Os usuários especificam essa subseqüência de consulta desenhando interativamente, com o mouse, uma caixa que a delimite no gráfico da série (ver Figura 4.4). Selecionada a subseqüência de consulta é necessário definir dois parâmetros: a porcentagem de diferença permitida e se uma normalização deve ser aplicada. A porcentagem de diferença indica o quão similares à original (alvo) as subseqüências devem ser, ou seja, uma definição de tolerância. Quanto menor este valor, maior a similaridade. Se a normalização for aplicada estaremos ignorando diferenças na magnitude das subseqüências, mas buscando similaridade em seu formato. Definidos esses parâmetros, a execução do casamento de subseqüências retorna uma janela de resultados, que contém todas as subsequiências do conjunto de dados que são similares a $Q$ e atendem aos parâmetros especificados. As subseqüências similares são listadas por ordem decrescente de similaridade.

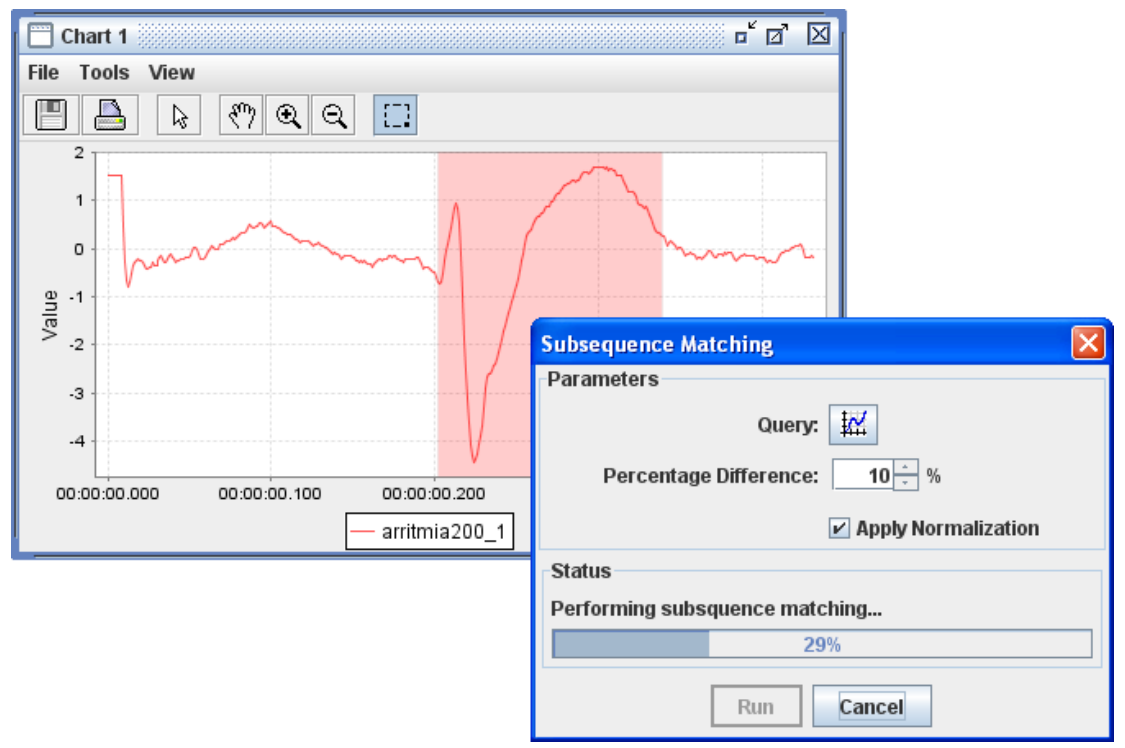

Figura 4.4: Casamento de subseqüências interativo. Subseqüência de consulta selecionada interativamente por meio do mouse, e destacado em vermelho. Porcentagem de diferença máxima $=10 \%$. Com normalização. 
Casamentos triviais (ver Definição 320) são excluídos, incluindo casamentos triviais entre os próprios resultados para não se obter subseqüências levemente deslocadas que representam o mesmo padrão. Salienta-se que a distância Euclidiana foi empregada para esta atividade. A Seção 4.3.4.1 ilustra uma aplicação deste tipo de busca, mostrando inclusive como os resultados são mostrados.

\subsubsection{Classificação}

A classificação de séries no Temporal-PEx adota o paradigma baseado em exemplos(ver Seção 3.6.2), que classifica séries nunca vistas antes a partir de séries similares cujas classes são conhecidas (conjunto de treinamento). Esta tarefa compreende em três etapas:

1. Definição do conjunto de treinamento - Também deve ser fornecido no formato TSD. É importante que o conjunto de treinamento seja representativo em relação à distribuição dos dados. O usuário também pode aplicar atividades de pré-processamento ao conjunto de treinamento.

2. Escolha da medida de dissimilaridade - São disponibilizadas duas medidas de dissimilaridade para classificação das séries:

- Distância Euclidiana - Apesar de simples, essa medida pode ser eficaz para alguns conjuntos de dados, especialmente se estes estiverem pré-processados devidamente. O conceito de "abandono prematuro" (ver Definição 3|9p foi empregado para acelerar ainda mais a classificação com essa medida.

- DTW - Essa medida é altamente eficaz na classificação de séries pela capacidade de lidar com desvios no eixo do tempo. No entanto, ela possui um custo computacional quadrático. Para superar essa limitação, o limite inferior $L B \_K e o g h$ (ver Seção 3.5.2.1) foi usado para acelerar a classificação, como apresentado no Algoritmo 4 da Seção 3.6.2.

3. Resultados - Os resultados incluem o tempo de processamento necessário para realizar a classificação. Se as séries possuírem uma classificação prévia, a taxa de erro e a matriz de confusão da classificação obtida por este processo em comparação a classificação prévia, supondo que esta última estava correta, também são disponibilizadas.

Uma barra de progresso informa o andamento da classificação, já que, dependendo do tamanho do conjunto de séries, esse processo pode ser lento. Após o término da 
classificação, os círculos das séries na projeção são coloridos segundo a nova classificação obtida. Um exemplo prático do uso da classificação é dado na Seção 4.3.2.

\subsection{Resultados}

As próximas seções são dedicadas a apresentar alguns cenários de análise de conjuntos de séries temporais de diferentes domínios utilizando a ferramenta Temporal-PEx e os resultados obtidos.

\subsubsection{Synthetic Control Chart}

Esse conjunto de dados contém 600 séries temporais geradas sinteticamente pelo processo descrito por Alcock e Manolopoulos (1999), as quais estão classificadas em seis classes (ver Figura 4.5): Normal,Cyclic, Increasing trend, Decreasing trend, Upward shift e Downward shift. Cada classe é representada por 100 séries temporais, cada uma com 60 observações. O conjunto de dados encontra-se disponível em Hettich e Bay (1999).

Abordagens convencionais de classificação e clustering demonstram dificuldade em agrupar essas séries com precisão, pois os pares de classes Normal/Cyclic, Decreasing trend/Downward shift e Increasing trend/Upward shift tendem a se misturar.

A Figura 4.6 mostra as projeções geradas para esse conjunto de dados com a técnica de projeção IDMAP. Nessas projeções as cores dos círculos estão mapeando as classes., usando a mesma referência de cores da Figura 4.5. Na Figuras 4.6(a) percebe-se a dificuldade da distância Euclidiana em separar corretamente as classes, pois os pares de classes encontram-se misturados. O DTW gera uma projeção maisprecisa, exibida na Figura 4.6(b), tendo sido capaz de promover uma melhor separação entre os pares de classes.

Esse exemplo foi incluído com o objetivo de ilustrar o potencial da ferramenta TemporalPEx em apresentar um visão geral do conteúdo do conjunto de séries, que reflete a similaridade no comportamento de seus conjuntos de séries.

\subsubsection{Gun-Point}

O conjunto de dados Gun-Point pertence ao domínio de vídeo vigilância, e encontra-se disponível em Keogh et al. (2006c). Os dados foram gerados utilizando dois atores, e rastreando o centróide da mão direita dos atores no eixo $Y$, gerando séries de tamanho igual a 150. Esse conjunto possui duas classes: 

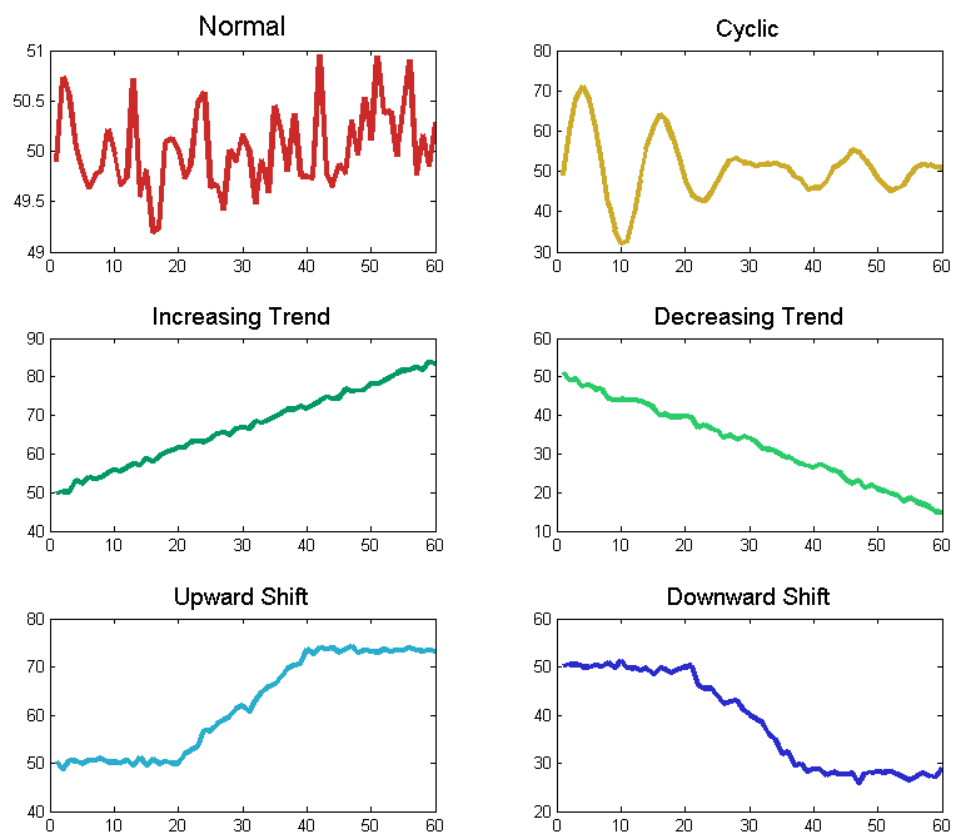

Figura 4.5: Classes do conjunto de dados Synthetic Control Chart. Cada classe é representada na figura por sua série temporal média.

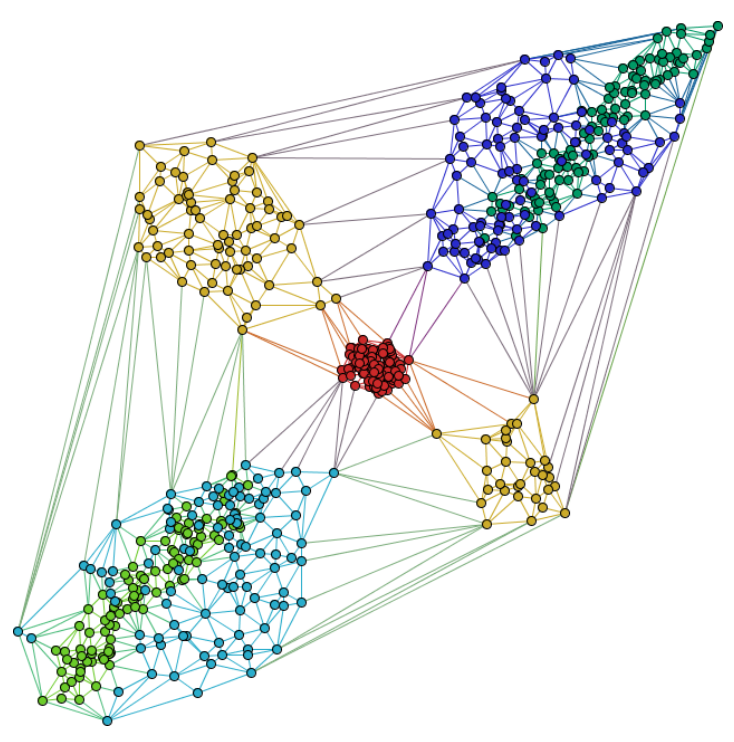

(a) Distância Euclidiana.

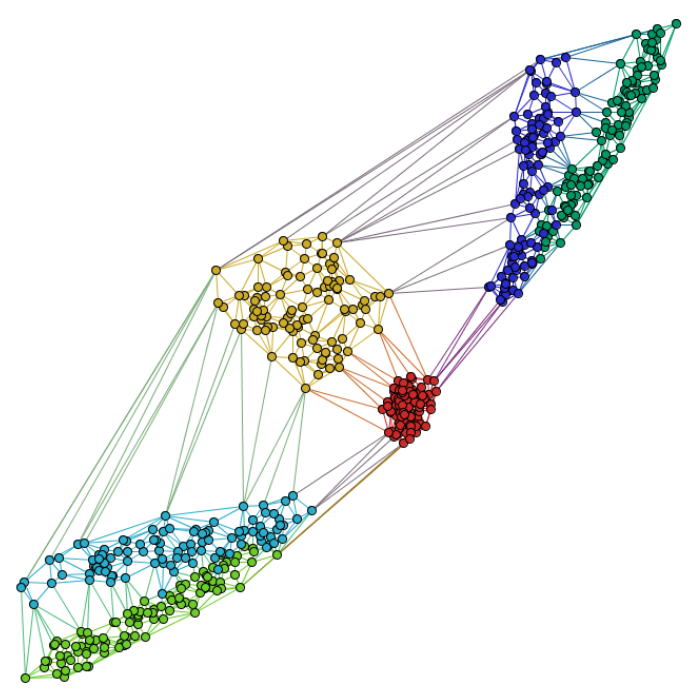

(b) DTW

Figura 4.6: Conjunto de dados Synthetic Control Chart projetado com a técnica IDMAP. 
- Point - Os atores têm inicialmente suas mãos ao lado de seus corpos. Eles então apontam seus dedos indicadores para um alvo por aproximadamente um segundo, e depois retornam as mãos para a posição inicial. Essa classe contém 74 séries. Ver Figura 4.7(a),

- Gun - Os atores estão com suas mãos ao lado de seus corpos. Eles então tiram uma réplica de uma arma de um coldre preso à cintura, e apontam para um alvo por aproximadamente um segundo, e então retornam a arma para o coldre, e depois mãos para a posição inicial. Essa classe contém 76 séries. Ver Figura 4.7(b).
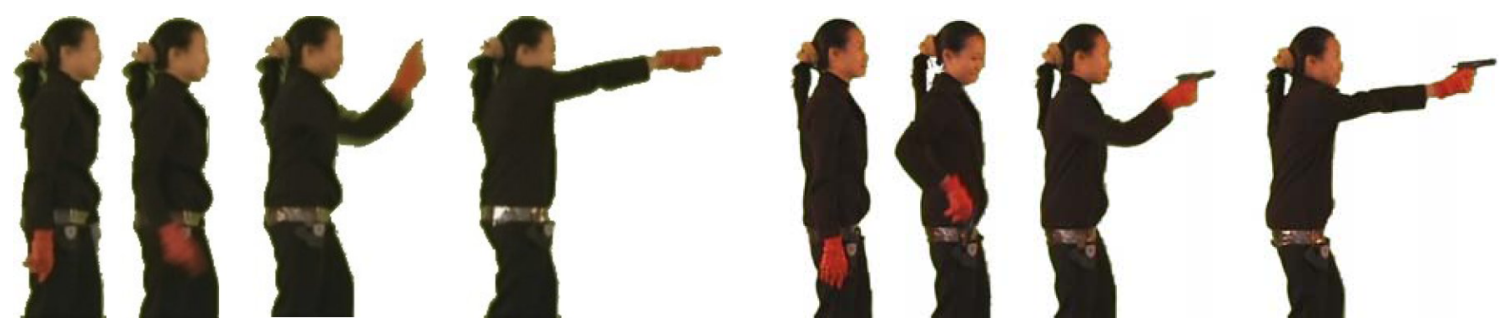

(a) Point.

(b) Gun
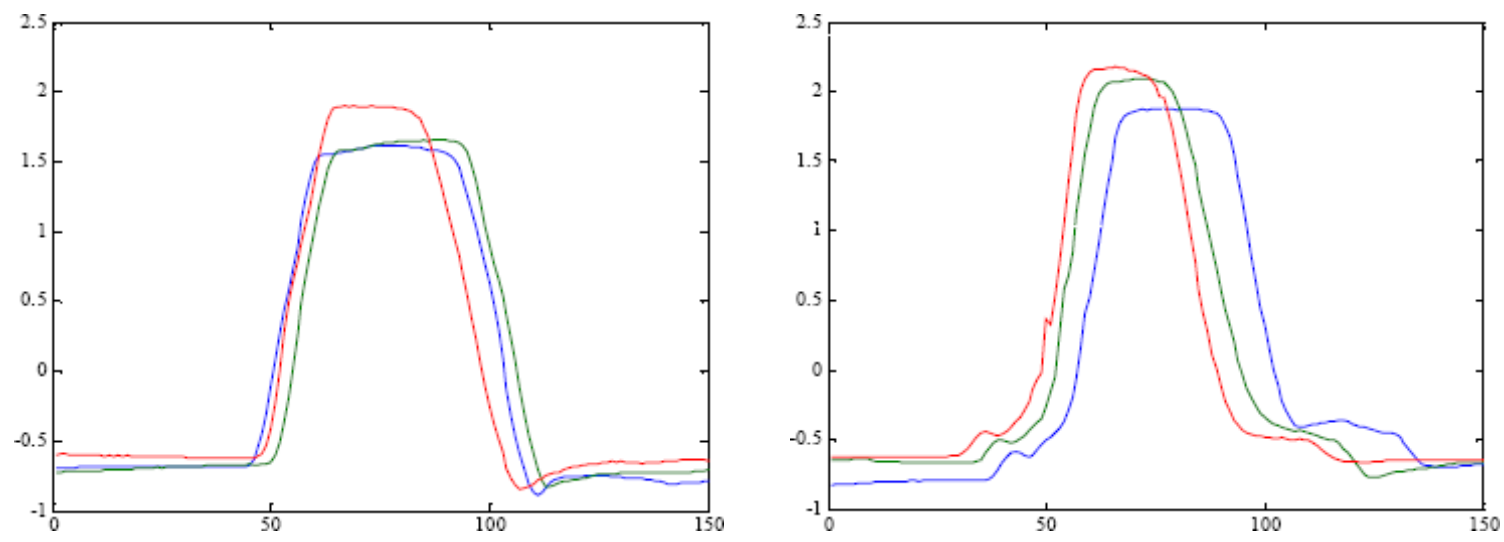

(c) Série Point.

(d) Série Gun

Figura 4.7: Conjunto de dados Gun-Point.

As duas classes de séries obtidas possuem comportamento similar. No entanto, é possível classificar as séries visualmente com grande acurácia, notando-se que o ator deve levantar sua mão acima do coldre quando pega a arma. Tal fato cria uma leve distinção no começo e no fim dos picos das classes (ver Figuras 4.7(c) e 4.7(d).

A combinação da medida de dissimilaridade DTW e da técnica de projeção LSP foi escolhida para gerar a projeção dos dados. O DTW é mais indicado nesse caso, pois os atores podem levantar suas mãos em momentos diferentes. Foi utilizada a janela de alinhamento Sakoe-Chiba com $R=10 \%$ (ver Seção 3.5.2 para melhorar o desempenho e 
a acurácia do DTW. Já a LSP foi escolhida por sua tendência de ressaltar a formação de agrupamentos. Na etapa de pré-processamento, aplica-se a normalização para compensar a diferença de altura entre os atores. A projeção resultante é apresentada na Figura 4.8 .

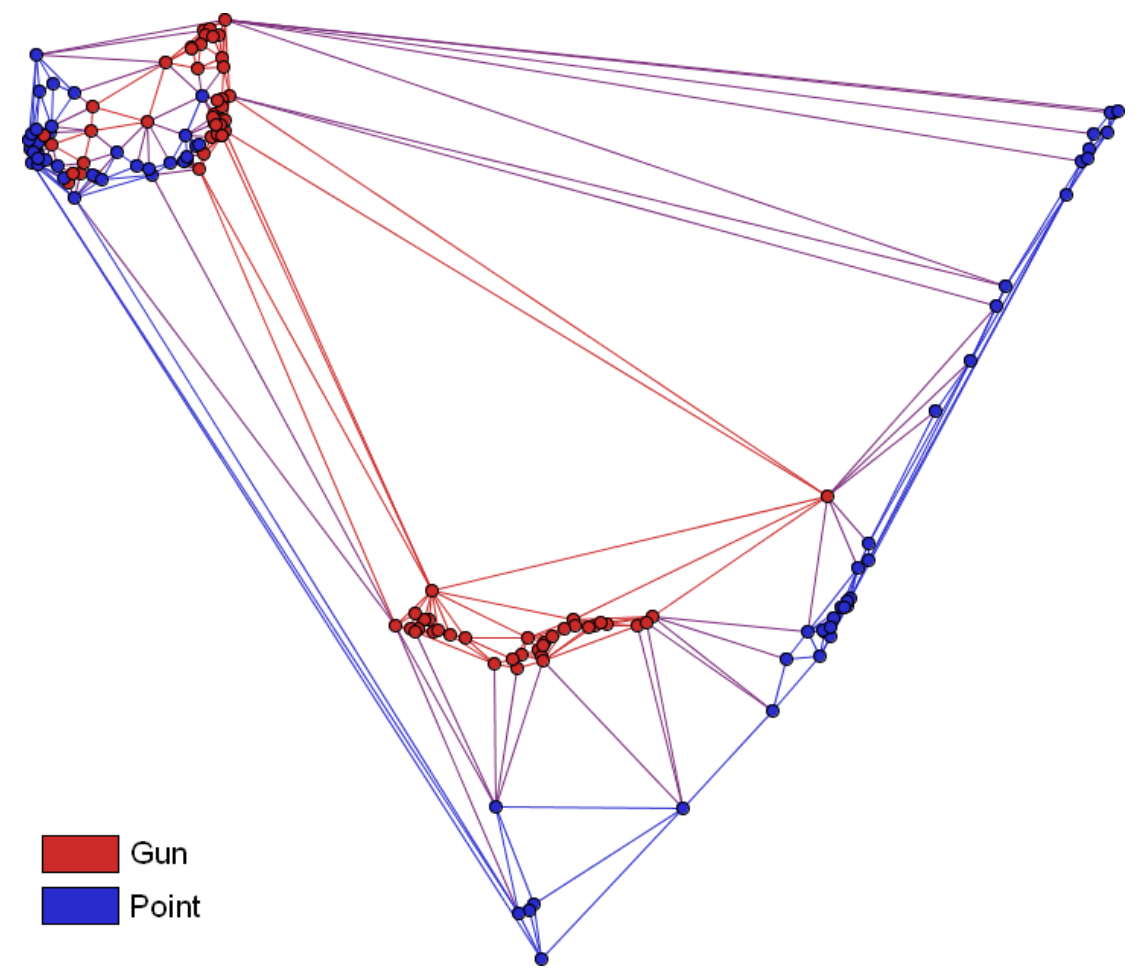

Figura 4.8: Projeção do conjunto de dados Gun-Point com a técnica LSP e a medida de dissimilaridade DTW. Classe point em azul, e classe gun em vermelho.

A projeção desse conjunto de dados gerou duas áreas na projeção: uma região inferior em que a separação das classes foi maior; e outra superior em que o nível de separação foi menor. A menor separação das classes em uma das áreas foi causada por um movimento mais sutil do ator, quando ele retira a arma do coldre para a classe gun.

Outra tarefa interessante nesse domínio é a classificação desses dados, pois detectar se uma pessoa representa uma ameaça séria à segurança de um local é de extrema importância. Entretanto a classificação errada de uma série em qualquer das classes é grave, ignorando-se uma ameaça grave ou gerando um alerta errado contra uma pessoa. Dessa forma, deseja-se que a taxa de erro seja a menor possível na classificação. Um conjunto de treinamento com 50 séries (24 da classe gun e 26 da classe point) foi fornecido para a classificação. Também foi aplicada a normalização ao conjunto de treinamento, e a medida DTW foi escolhida para quantificar a similaridade entre as séries a serem classificadas (teste) e as de treinamento. 
Tabela 4.3: Comparação de medidas de similaridade para classificação das séries do conjunto gun-point.

\begin{tabular}{|l|c|c|}
\hline Método & Tempo (segundos) & Taxa de erro \\
\hline \hline $\begin{array}{l}\text { Vizinho mais próximo com distância Euclidi- } \\
\text { ana }\end{array}$ & 0,219 & $\approx 8,7 \%$ \\
\hline $\begin{array}{l}\text { Vizinho mais próximo com DTW sem janela } \\
\text { de alinhamento }\end{array}$ & 34,890 & $\approx 9,3 \%$ \\
\hline $\begin{array}{l}\text { Vizinho mais próximo com DTW, janela de } \\
\text { alinhamento }(R=10 \%) \text { e limite inferior } \\
\text { LB_Keogh }\end{array}$ & 17,828 & $6 \%$ \\
\hline
\end{tabular}

A Tabela 4.4 mostra a matriz de confusão para a classificação resultante dessas séries. Esse tipo de matriz é uma medida mais efetiva da classificação obtida, pois mostra o número de classificações corretas versus as classificações preditas para cada classe, sobre o conjunto de dados. Os resultados são dispostos em duas dimensões: classes verdadeiras e classes preditas. Cada elemento $(i, j)$ da matriz representa o número de séries que realmente pertecem à classe $C_{i}$, mas foram classificadas como sendo da classe $C_{j}$. $\mathrm{O}$ número de acertos, para cada classe, localiza-se na diagonal principal da matriz. Os demais elementos, para $i \neq j$, representam erros na classificação.

Tabela 4.4: Matriz de confusão para a classificação dos dados gun-point.

\begin{tabular}{|c|c|c|c|c|c|}
\hline & & \multicolumn{2}{|c|}{ Predita } & & \\
\hline \multicolumn{2}{|c|}{ Classe } & Gun & Point & Taxa de Erro da & Taxa de Erro \\
\hline Verdadeira & $\begin{array}{c}\text { Gun } \\
\text { Point }\end{array}$ & $\begin{array}{c}70 \\
3\end{array}$ & $\begin{array}{c}6 \\
71\end{array}$ & $\begin{array}{l}\approx 7,8 \% \\
\approx 4 \% 0\end{array}$ & $6 \%$ \\
\hline
\end{tabular}

Apesar da taxa de erro para classe Gun ter sido maior $(7,8 \%)$, a taxa de erro total de $6 \%$ indica o bom resultado geral obtido pela classificação.

\subsubsection{Ações de Empresas}

O conjunto de dados apresentado nesta seção refere-se ao preço médio das ações de 1430 empresas registrado durante 52 semanas, e foi apresentado por Hochheiser e Shneiderman (2004). Esse é o mesmo conjunto de séries que foi apresentado na Figura 2.3.

Para a projeção deste conjunto de dados foi utilizada a técnica IDMAP em associação com a distância Euclidiana. A normalização não foi aplicada às séries, pois o interesse reside na diferença de magnitudes entre elas. A Figura 4.9 mostra a projeção das séries, cuja apresentação utiliza a conexão do tipo $K N N-R M-1$ foi utilizada, ou seja, cada ponto 
foi conectado por uma aresta ao seu vizinho mas próximo no espaço original. Um primeiro fator na escolha de uma empresa para se investir pode ser baseado no valor médio das suas ações (ver Figura 4.9(a)), uma vez que altos valores de ações são um forte indicativo de empresas lucrativas. Baseando-se nesse fato, a escolha óbvia seria a empresa chamada BHC Communications Inc, que na projeção da Figura 4.9 é associada a cor verde associada. O valor médio de ações dessa empresa é de aproximadamente U\$153, muito maior do que a média apresentada de U\$ 39,25 para o conjunto inteiro.

No entanto, existem riscos provenientes da oscilação do preço das ações que devem ser considerados na escolha de uma empresa. O valor das ações de uma empresa é reflexo das percepções e estimativas dos investidores sobre o seu desempenho e o desempenho da economia. Dessa forma, não há nenhuma garantia para os valores das ações, existindo chances de que um investimento contabilize tanto ganho como prejuízo. Para calcular o risco de um investimento pode-se utilizar a variância como medida de dispersão. A Figura 4.9(b) exibe a projeção com o uso da variância para mapear a cor dos círculos, na qual percebe-se que a empresa $B H C$ Communications Inc possui alta variância (cor vermelha) -indicativo de alto risco associado. Essa empresa teve uma forte queda na $19^{\mathrm{a}}$ semana (ver Figura 4.9(c)].

Assim, um investidor cauteloso selecionaria uma empresa que tivesse média alta (cor verde), porém uma baixa variância (cor verde-azulada). Já o investidor "corajoso" aplicaria na empresa BHC Communications Inc em sua queda, e venderia as ações nas últimas semanas, quando o valor voltou a subir.

\subsubsection{Eletrocardiogramas}

O trabalho cardíaco produz sinais elétricos que passam para os tecidos vizinhos e chegam à pele, de modo que a colocação de eletrodos no peito, permite gravar as variações de ondas elétricas emitidas pelas contrações do coração. OECG é um exame médico na área de cardiologia no qual é feito o registro da variação dos potenciais elétricos gerados pela atividade elétrica do coração.

O conjunto de séries temporais de eletrocardiogramas a ser estudado nesta seção encontra-se disponível em Keogh (2004), que o construiu a partir do banco de dados PhysioBank (Goldberger et al., 2000). Cada uma das séries temporais foi extraída do eletrocardiograma de quatro pacientes diferentes:

- Primeiro paciente (chf02): Este paciente sofre de Insuficiência Cardíaca Congestiva (ICC) severa, que é uma condição na qual o coração não consegue bombear sangue 


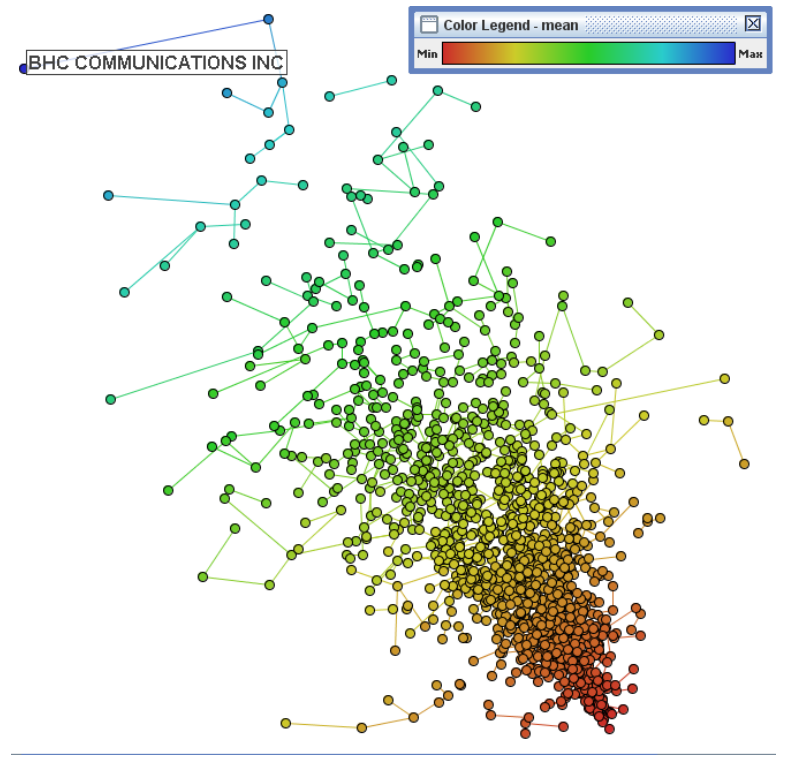

(a) Cor mapeada para média

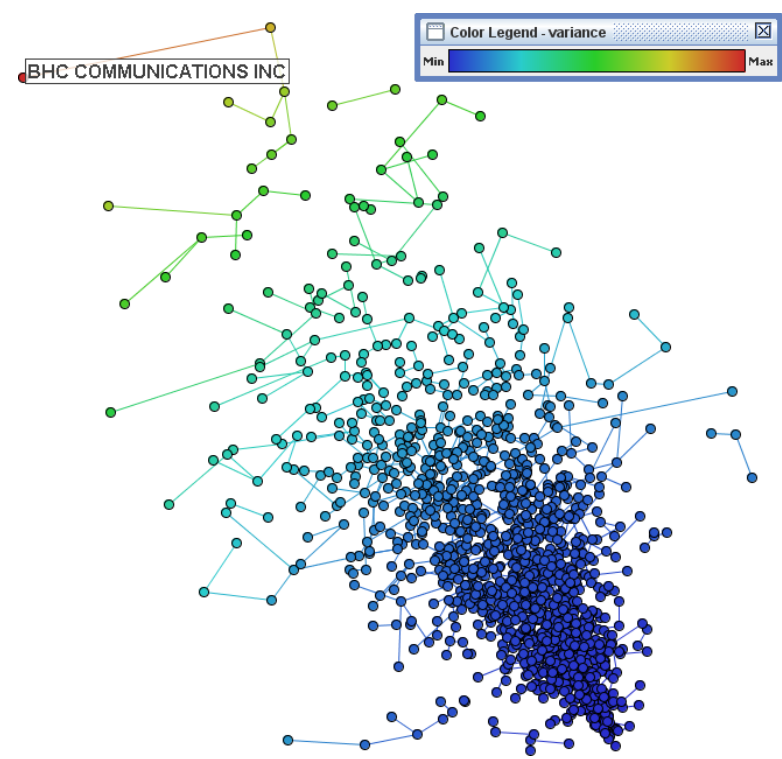

(b) Cor mapeada para variância

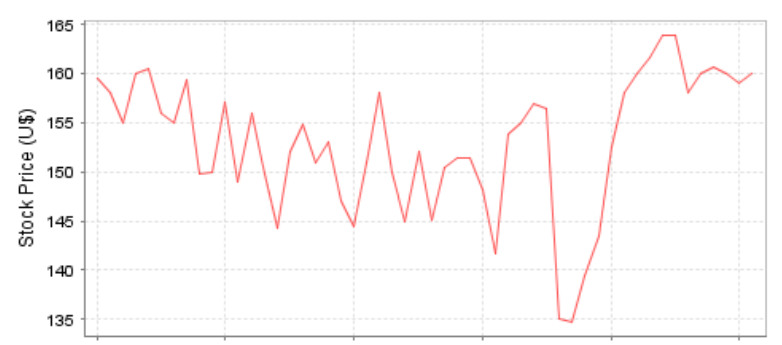

(c) Ações da empresa BHC Communications Inc

Figura 4.9: Séries com valores médios semanais de ações de 1430 empresas durante 26 semanas. Projeção gerada com técnica IDMAP e distância Euclidiana. 
a uma taxa suficiente para os orgãos. O eletrocardiograma completo desse paciente encontra-se na base de dados BIDMC Congestive Heart Failure do PhysioBank.

- Segundo paciente (chf15): Este paciente também sofre de ICC severa. O eletrocardiograma completo desse paciente também encontra-se na base de dados BIDMC Congestive Heart Failure.

- Terceiro paciente (20021): Este paciente possui alterações no segmento ST do eletrocardiograma, que constituem um bom preditor de infarto do miocárdio e morte súbita. O eletrocardiograma completo encontra-se na base de dadosLong Term ST do PhysioBank.

- Quarto paciente (118e6): Este paciente sofre de arritmia, que é um nome genérico para diversas perturbações que alteram a freqüência cardíaca. No entanto, foi adicionando ruído ao eletrocardiograma desse paciente para testar a tolerância de detectores de arritmia a ruído. O eletrocardiograma completo encontra-se na base de dados MIT-BIH Noise Stress Test do PhysioBank.

A partir de cada um desses quatro eletrocardiogramas foram extraídas cinco séries temporais de tamanho 10.000, todas começando nos índices 0, 82, 150, 200 e 250, totalizando 20 séries temporais de tamanho 10.000, oriundas de quatro pacientes diferentes. O interesse aqui é agrupar as séries temporais segundo o paciente da qual elas foram extraídas. A Figura 4.10 mostra exemplos séries temporais de cada um dos pacientes.

A técnica de projeção LSP foi escolhida para projetar esse conjunto de dados, utilizandose 8 pontos e de controle e 5 vizinhos para definição das relações de vizinhança. As séries foram normalizadas na etapa de pré-processamento para evitar influência das diferenças de voltagem entre os pacientes. A Figura 4.11(a) mostra a projeção gerada com a distância Euclidiana, e a Figura 4.11(b) mostra a projeção gerada com a distância CDM. A distância CDM conseguiu agrupar as séries eficientemente, ao contrário da distância Euclidiana. Essa superioridade é devido à alta dimensionalidade dessas séries e suas diferenças estruturais. Os círculos foram conectados com a conexão entre arestas do tipo $K N N-R M-1$, ou seja, a conexão ocorre entre os vizinhos mais próximos no espaço original.

\subsubsection{Busca por batimentos anormais}

Os eletrocardiogramas nesse exemplo também foram retirados do banco de dados PhysioBank, e pertencem à base da dados MIT-BIH Arrhythmia Database, que disponibiliza eletrocardiogramas com episódios de arritmia anotados por especialistas. A contração 
BIDHC Congestive Heart Failure Database (chfdb): paciente chf02
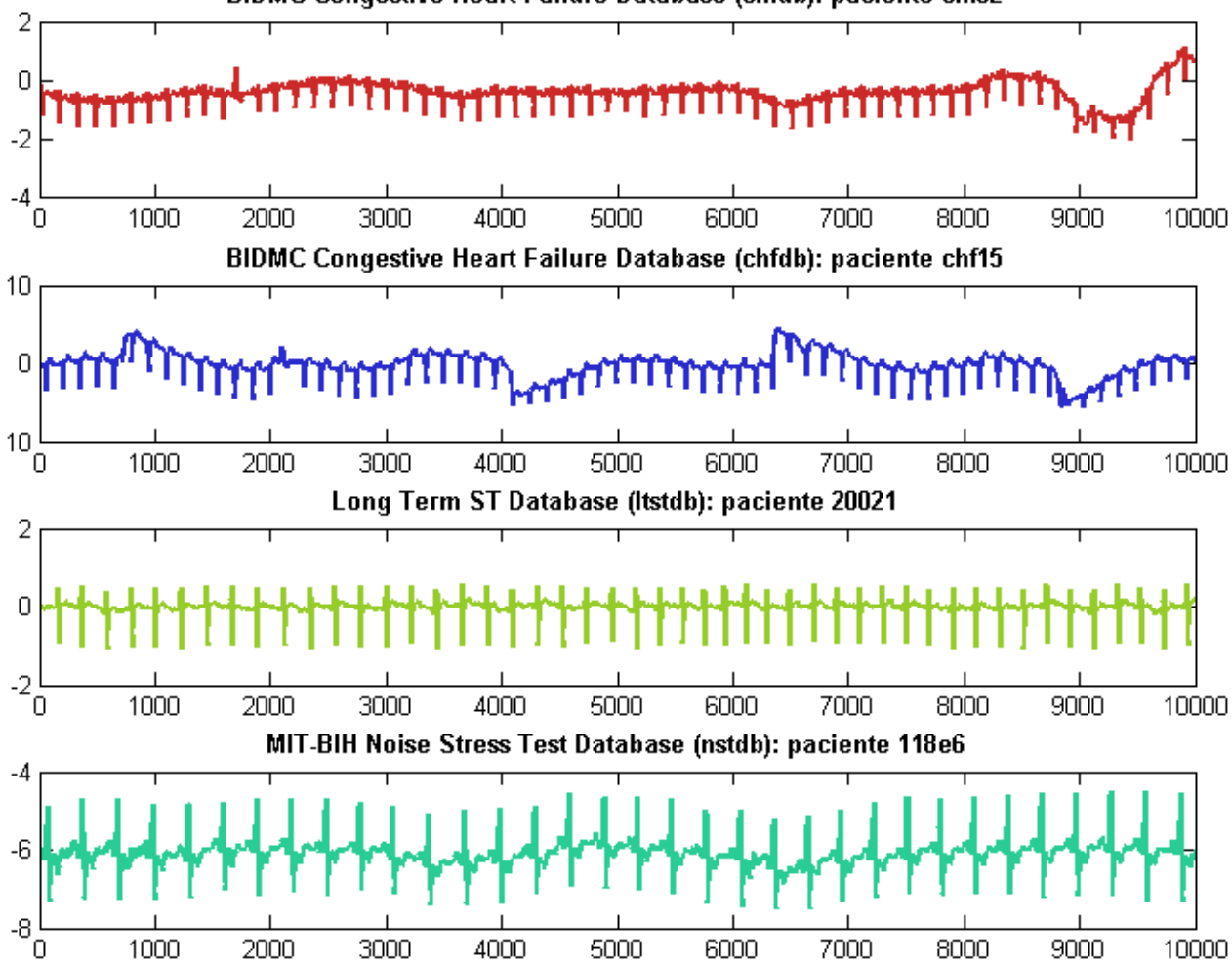

Figura 4.10: Exemplos de séries temporais extraídas de cada um dos quatro pacientes.

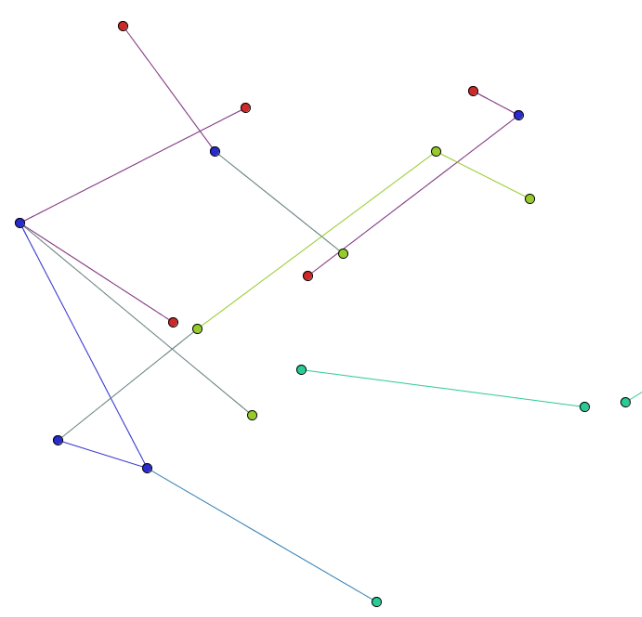

(a) Distância Euclidiana

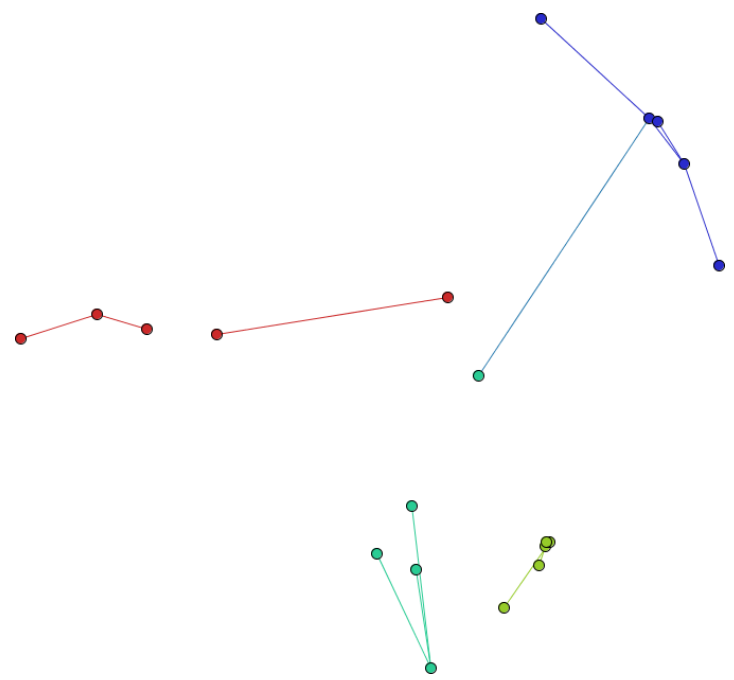

(b) CDM

Figura 4.11: Projeção do conjunto de eletrocardiogramas por meio da técnica LSP. Cada cor indica um paciente 
ventricular prematura (CVP) é um tipo de batimento anormal, no qual o ventrículo contrai prematuramente (ver Figura 4.12). Isto resulta em um "batimento pulado" seguido por um batimento forte. Esse tipo de batimento anormal é comum, e pode ocorrer tanto em pacientes normais como em pacientes com doenças cardíacas. No entanto, contrações ventriculares prematuras podem diminuir a capacidade do coração bombear sangue para os outros órgãos (diminuindo a capacidade cardíaca), resultando em uma baixa pressão sanguínea. Pacientes com mais de três CVP consecutivos têm taquicardia ventricular que pode culminar em uma fibrilação ventricular, que é um ritmo cardíaco fatal.

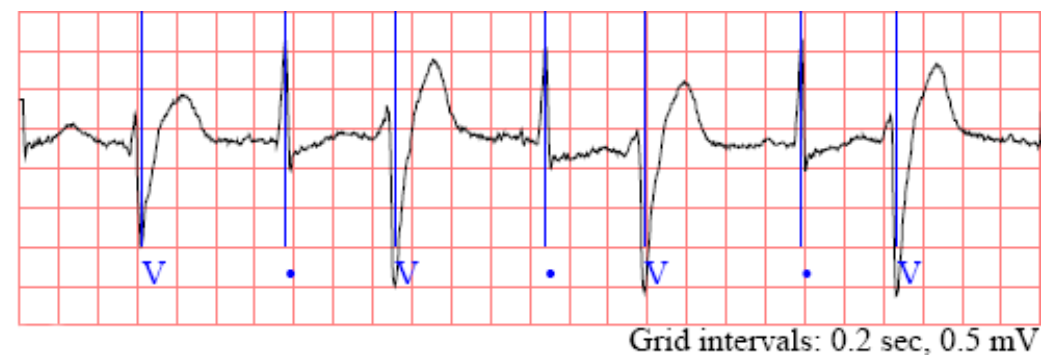

Figura 4.12: Eletrocardiograma de paciente com arritmia. Anotações: V - contração ventricular prematura; • - batimento normal.

Para esta análise selecionou-se o ECG de um homem (número do registro: 200) de 64 anos, com duração de 1 minuto. A taxa de amostragem desse ECG é de 360 valores por segundo, totalizando uma série temporal de tamanho 21.600. Para entrar com este ECG na ferramenta Temporal-PEx a série inteira foi decomposta em 12 séries menores, cada uma contendo 5 segundos e aproximadamente 7 batimentos.

Segundo as anotações fornecidas pelos especialistas, o primeiro batimento registrado é um CVP. Dessa forma, utiliza-se esse batimento como subseqüência de consulta para encontrar as demais ocorrências. Adotando uma tolerância de $30 \%$ e normalizando as subseqüências, a ferramenta localizou corretamente os 27 CVPs existentes no ECG. A Figura 4.13 mostra os resultados obtidos para esta consulta. Na Figura 4.13(a), que contém a tela que mostra simultaneamente os gráficos de todas as subseqüências retornadas, observa-se que os resultados exibem o formato padrão do CVP, e que a Temporal-PEx indentificou inclusive CVPs com diferentes amplitudes.Já a Figura 4.13(b) mostra uma das subseqüências encontradas, em azul, sendo comparada graficamente com a subseqüência de consulta, em vermelho. Também é possível exibir a série a qual pertence a subseqüência sendo analisada, destacando-se sua localização (ver Figura 4.13(c)]. 


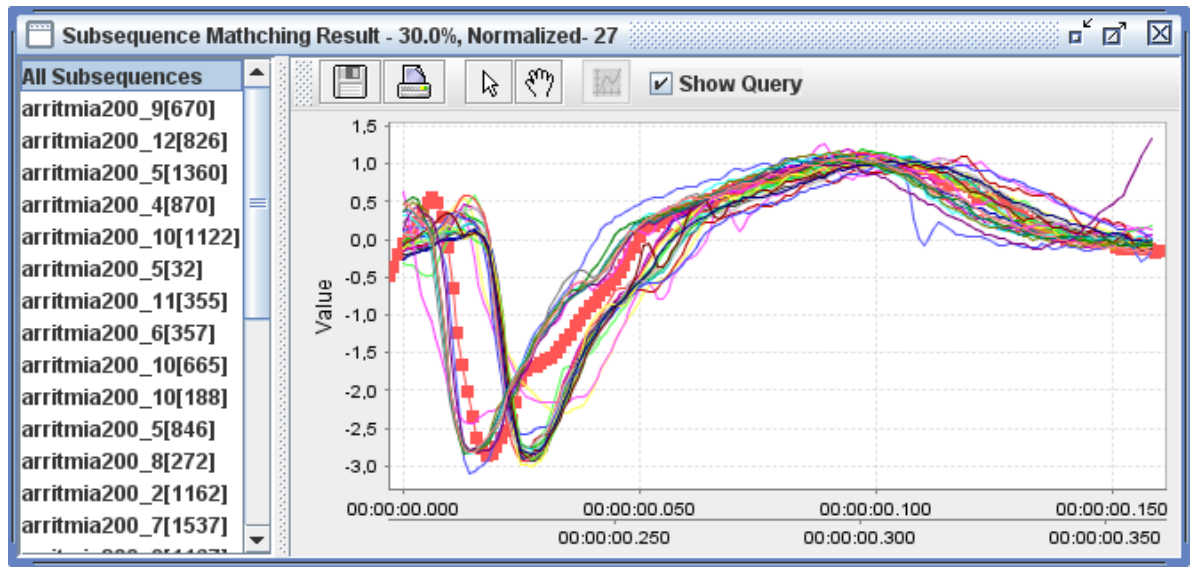

(a) Resultado

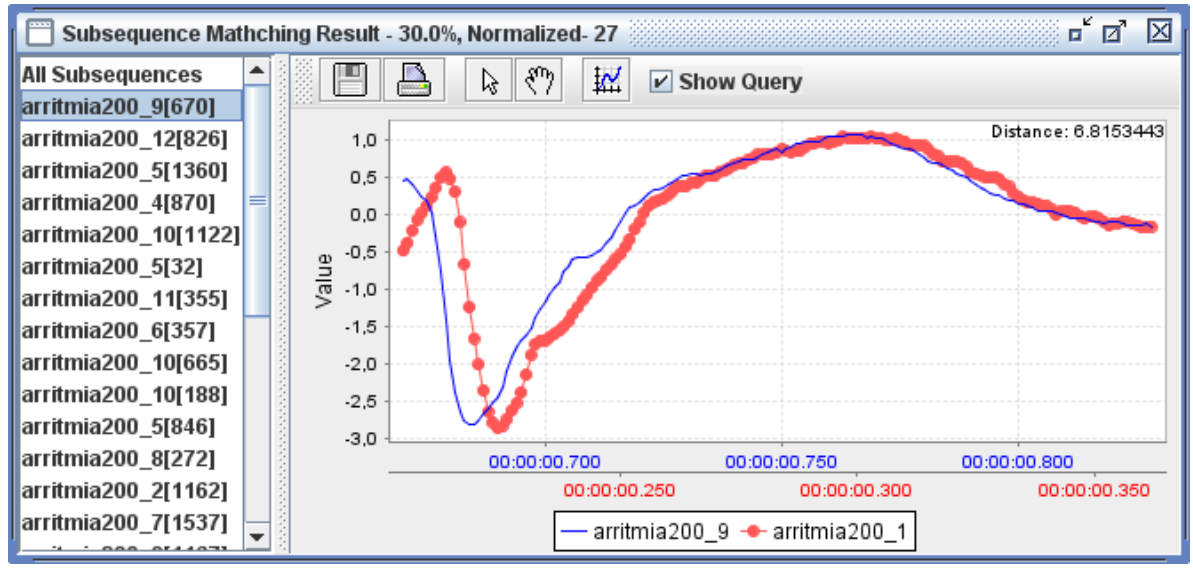

(b) Contração ventricular prematura

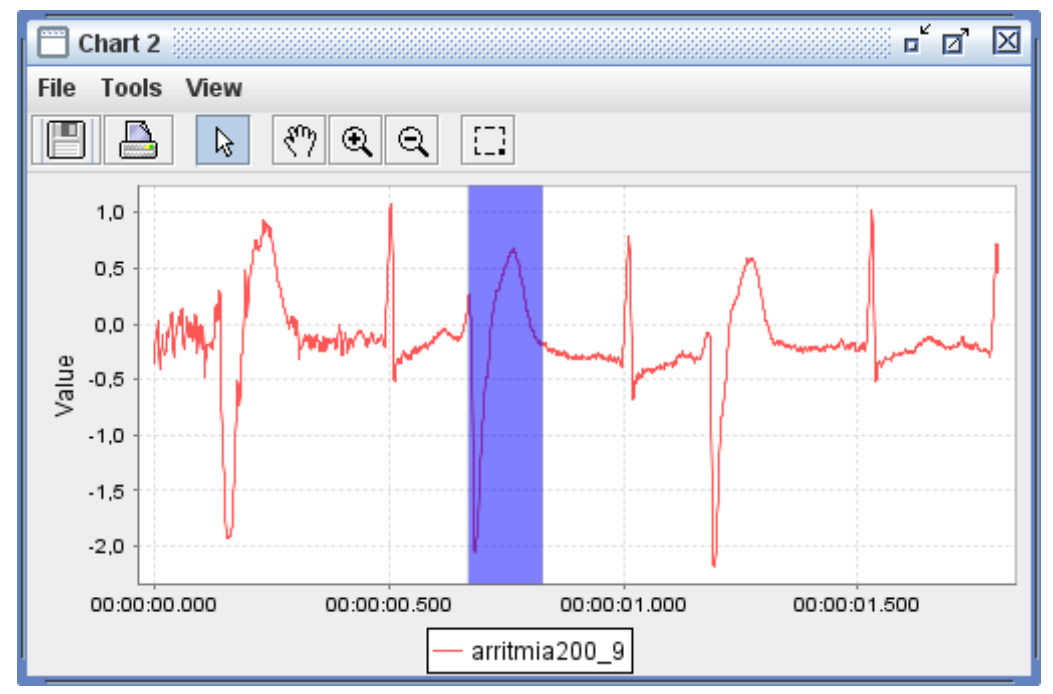

(c) Localização da contração ventricular prematura

Figura 4.13: Casamento de subseqüências para busca por batimentos anormais em um ECG. 


\subsubsection{Vazões Médias Mensais de Usinas Brasileiras}

Uma vez que o sistema brasileiro de distribuição de energia elétrica é predominantemente hidroelétrico, a análise de vazões é de particular importância. As vazões registradas nos rios, isto é, a quantidade de água disponível em um determinado período de tempo em um ponto do rio, constituem o insumo básico para os reservatórios das usinas hidrelétricas. Quanto maior a vazão disponível, mais energia elétrica poderá ser produzida em uma usina, limitada apenas pela sua potência instalada e pela capacidade de engolimento das turbinas. Essas vazões dependem apenas de dois fatores: condições geológicas do rio, como largura, inclinação, tipo de solo, obstáculos e quedas; e índice pluviométrico da região. Essa dependência em relação à quantidade de chuvas confere um caráter sazonal às vazões, acarretando grande variação na capacidade de produção de energia ao longo do ano.

A análise de vazões de diferentes bacias hidrográficas colecionadas durante anos tem papel estratégico no planejamento e operação do sistema nacional de distribuição, já que todo o sistema deve ser ajustado para operar corretamente durante os períodos chuvosos e secos. Ademais, qualquer plano para expansão do sistema elétrico deve considerar algumas restrições em relação ao risco de déficit no suprimento de energia, que podem ser estimadas por meio da simulação de operação com base em vazões representativas registradas.

O conjunto de dados analisado nesta seção é um dos resultados do projeto "Vazões Médias Mensais nos Aproveitamentos Hidrelétricos - Período 1931 a 2005", que abordou estudos de consistência e reconstituição das séries históricas de vazões (ONS, 2006). A função de planejamento e programação da operação do Sistema Interligado Nacional (SIN) - sistema de produção e transmissão de energia elétrica do Brasil - está sob a responsabilidade do Operador Nacional do Sistema Elétrico (ONS), que disponibiliza os dados referentes às vazões utilizadas para seu planejamento na forma de séries temporais. Dessa forma, a otimização da operação energética, em qualquer horizonte temporal, depende essencialmente da quantidade e qualidade das informações que podem ser extraídas dessas séries de vazões.

Essas séries se destinam aos modelos de planejamento de médio e curto prazo para operação das usinas hidrelétricas. Devido ao horizonte de planejamento, que se estende até o ano de 2011, as séries de vazões devem estar disponíveis não só para as usinas em operação, como também para as usinas em expansão, aquelas que não estão construídas, mas que têm o início de seu enchimento previsto até 2011. O ONS obteve essas séries por um processo de reconstituição para que os dados de vazões estivessem disponíveis para todo o período de 1931 a 2005. Para usinas em operação esse processo é baseado em 
dados operativos fornecidos pelas concessionárias de energia elétrica. Já para as usinas em expansão, toma-se como base dados de estações pluviométricas da bacia em que será instalada a usina, bem como as séries de usinas em operação que tenham influência direta sobre a usina em expansão.

Dessa forma, o conjunto de dados inclui uma série temporal para cada usina, a qual registra a vazão média mensal na usina por um período de 75 anos, de 1931 a 2005, em um total de 900 valores, coletados ou estimados. As séries de vazões médias mensais estão disponíveis para 151 usinas hidrelétricas do SIN. A Figura 4.14(a) mostra o gráfico da série temporal relativa à usina Furnas. Esta mesma série pode ser dividida em períodos anuais (ver Figura 4.14(b)), obtendo-se 75 séries temporais que descrevem o comportamento anual desta usina. A Figura 4.14(b) ilustra a sazonalidade dessas séries.

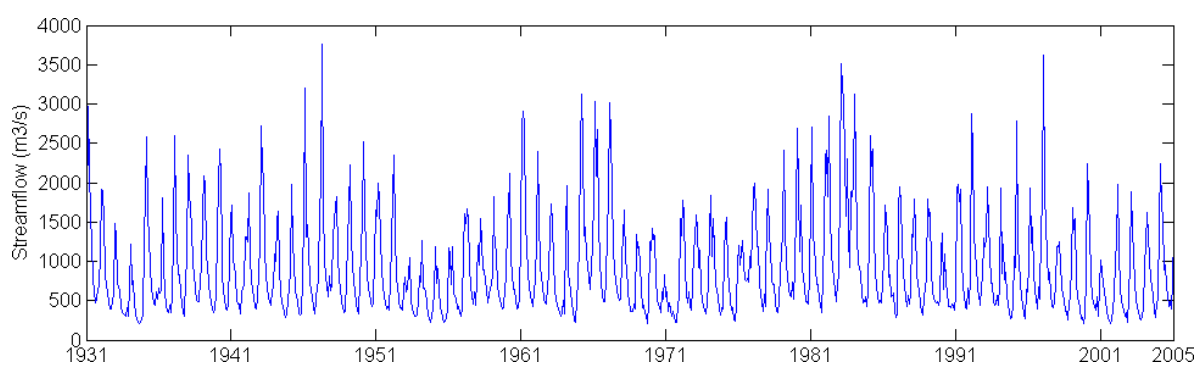

(a)

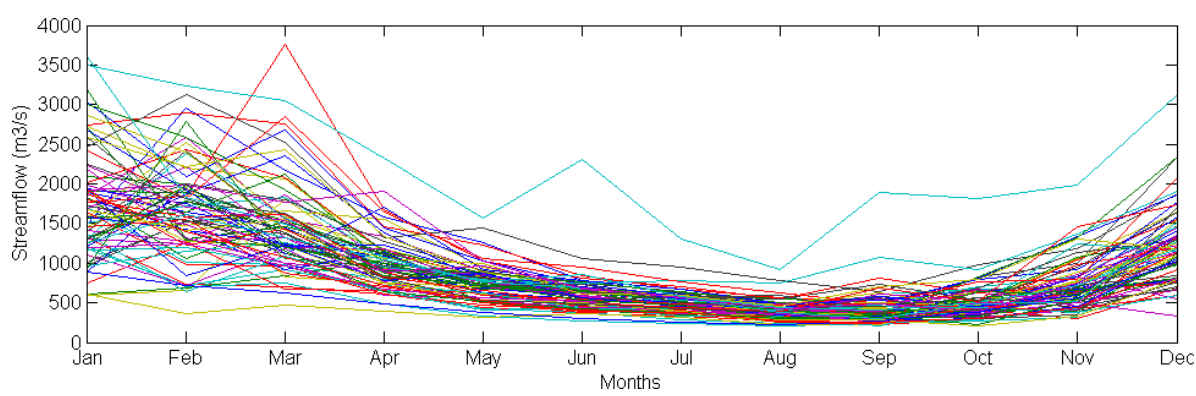

(b)

Figura 4.14: Usinas Hidrelétrica de Furnas.

O comportamento das vazões das usinas também está altamente relacionado à região hidrográfica onde elas estão localizadas. Atualmente, o Conselho Nacional de Recursos Hídricos divide o Brasil em 12 regiões hidrográficas: Amazônica, Tocantins/Araguaia, Atlântico Nordeste Ocidental, Parnaíba, Atlântico Nordeste Oriental, São Francisco, Atlântico Leste, Atlântico Sudeste, Paraná, Paraguai, Uruguai e Atlântico Sul. Na Figura 4.15 é mostrada a localização dessas regiões, juntamente com a média anual de contribuição hídrica da região, em $\mathrm{km}^{3}$. Quanto maior a contribuição hídrica da região, maior o seu 
potencial hidrelétrico. A usina de Furnas, por exemplo, pertence à região hidrográfica do Paraná.

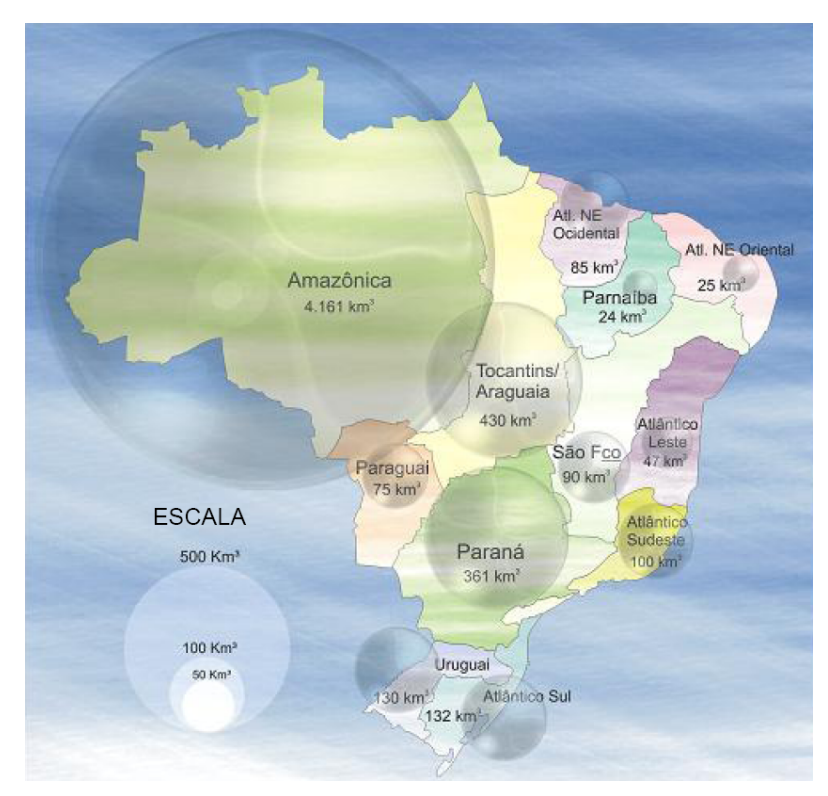

Figura 4.15: Regiões hidrográficas do Brasil.

\subsubsection{Detecção de Anos Chuvosos e Secos}

A deteç̧ão de anos chuvosos e secos é um tema crítico no planejamento de produção de energia no Brasil, já que uma seqüência de anos secos representa uma ameaça potencial à operação do sistema inteiro. Nesta análise utilizamos as séries obtidas pela divisão dos dados de vazão em períodos anuais, como exemplificado na Figura 4.14(b). A Figura 4.16 mostra a projeção gerada na ferramenta Temporal-PEx, relativa às séries anuais referentes à usina Furnas. Esta projeção foi gerada com a técnica IDMAP e com a medida de distância Euclidiana. O valor médio das séries anuais foi mapeado para a cor. O mapeamento de cores segue a escala do arco-íris, com tons próximos ao vermelho representando médias menores de vazão, e tons próximos ao azul representando médias maiores.

Nenhuma normalização foi aplicada às séries antes da projeção, visto que o interesse é comparar a magnitude das vazões para identificar, por exemplo, períodos críticos como anos muito secos. Identificam-se três áreas principais na projeção: uma correspondendo a vários anos secos (representados em vermelho); outra representando anos médios (verdeamarelado); e uma terceira correspondendo a anos chuvosos, representados por círculos verdes. De fato, o período de 1953 a 1956 é conhecido como o mais seco entre os registra- 


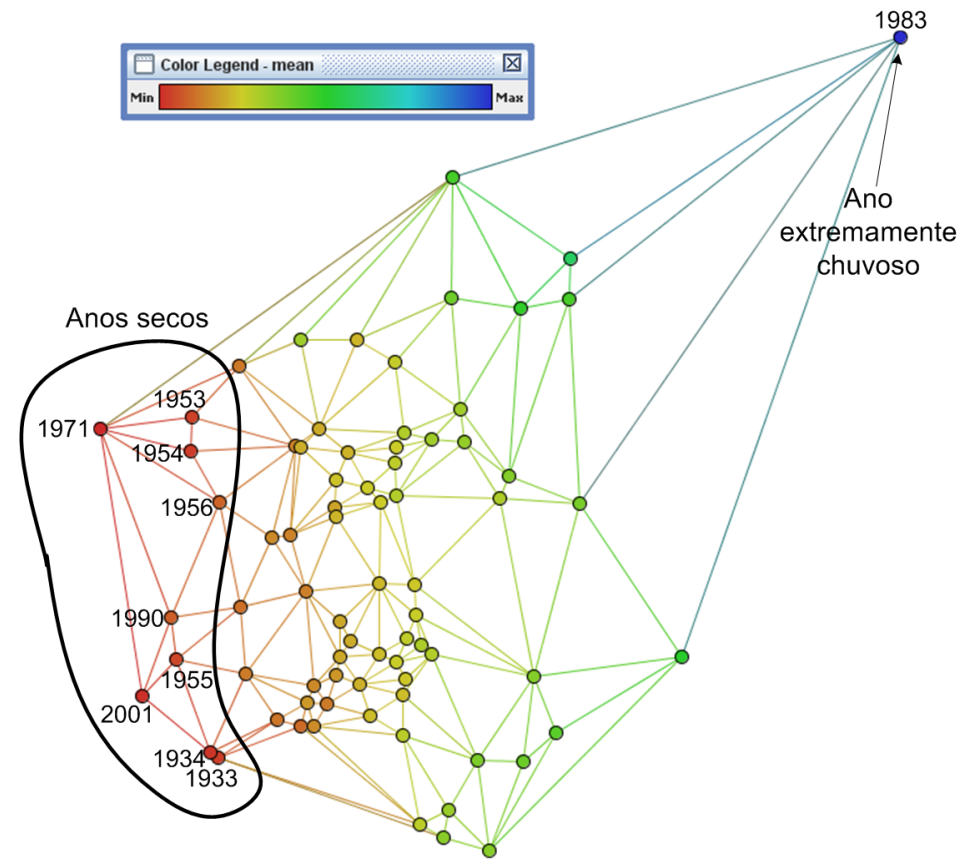

Figura 4.16: Projeção das séries de vazões anuais da usina Furnas ao longo dos anos de 1931 a 2005. Projeção criada com a técnica IDMAP e com a distância Euclidiana.

dos. O ano de 2001, que também foi um ano muito seco, foi marcado por uma séria crise energética, uma vez que o sistema de produção de energia elétrica brasileiro não conseguiu atender a demanda de energia. Já o ano de 1983 (em azul) é um ano atípico, caracterizado por ter sido extremamente chuvoso - a vazão média para este ano é de $2,253 \mathrm{~m}^{3} / \mathrm{s}$, que é bem acima da vazão anual média típica de $927 \mathrm{~m}^{3} / \mathrm{s}$. A figura mostra que a projeção das séries anuais conseguiu agrupar os anos conforme o comportamento (seco, normal, chuvoso), bem como realçar a ocorrência de um ano atípico (1983).

A detecção de anos secos é importante para o planejamento operacional do sistema hidrelétrico, já que a energia mínima disponível para uma usina - energia firme - é calculada com base nesses anos. O planejamento é tipicamente baseado no pior cenário visto, buscando evitar a dependência de chuvas. Quando a demanda energética excede a energia firme estimada, o risco de déficit cresce - a crise energética de 2001 surgiu de um cenário como este.

\subsubsection{Região Hidrográfica do Paraná}

Apesar da região hidrográfica Amazônica ter o maior potencial hidrelétrico, o maior aproveitamento hidrelétrico corresponde ao da região hidrográfica do Paraná, que abriga a usina de Itaipu, entre outras. A região do Paraná sofreu maior número de represamen- 
tos para geração de energia, visando atender à demanda energética da região Sudeste. Nesta região destacam-se as sub-bacias denominadas Grande, Iguaçu, Paraná, Paranaíba, Paranapanema e Tietê.

Para esta análise foram extraídas do conjunto de dados as séries de vazões das usinas localizadas na região hidrográfica do Paraná, que são 76 no total. Nem todas se encontram em operação, algumas estão em construção e outras em planejamento - como discutido, os dados relativos a essas usinas não foram coletados, mas sim estimados. Cada série foi classificada de acordo com a sub-bacia na qual a usina associada está inserida. A Figura 4.17 mostra um diagrama esquemático da localização geográfica dessas usinas de acordo com as sub-bacias mencionadas.

Como o interesse não é compará-las em sua magnitude e sim quanto as suas características estocásticas (variabilidade, correlação temporal, etc.), as séries de vazões devem ser normalizadas na etapa de pré-processamento. A normalização garante que séries relativas a usinas como Itaipu, cuja vazão média anual é de 131.105,475 $\mathrm{m}^{3} / \mathrm{s}$, não se destaquem das demais. Como mencionado anteriormente, as séries de vazões também são sazonais. Para efetuar a normalização das séries e remover essa sazonalidade foi aplicado o Método dos Momentos Sazonais (ver Seção 3.4.3) às séries de vazões na etapa de pré-processamento.

A Figura 4.18 exibe a projeção das séries pré-processadas gerada com a técnica de projeção IDMAP e a distância Euclidiana. É possível observar que a projeção conseguiu agrupar as usinas de acordo com suas sub-bacias - ou seja, usinas pertencentes a uma mesma sub-bacia permanecem próximas na projeção. A cor e a numeração que rotula os círculos são as mesmas utilizadas no diagrama da Figura 4.17, e permitem identificar a qual usina a série (representada pelo círculo) pertence.

Observando mais atentamente a projeção é possível identificar outras características do sistema, como o papel de reservatórios na regularização das vazões. Reservatórios regularizam a vazão ao longo do rio, armazenando o excesso de água em períodos chuvosos para que esta reserva esteja disponível durante os períodos secos. Quando um rio tem uma usina com reservatório, as usinas subseqüentes se beneficiam dessa regularização da vazão e apresentam comportamento similar entre si. Como exemplo, pode-se mencionar as usinas Estreito (4), Jaguará (10), Igarapava (8), Volta Grande (14) e Porto Colômbia (13) da sub-bacia do Grande, que na projeção estão localizadas perto da usina de Mascarenhas de Moraes (12), que possui um reservatório.

Também é possível observar que as usinas localizadas na sub-bacia do Paraná (usinas de Ilha Solteira (26), Itaipu (27), Jupiá (28) e Porto Primavera (29)) estão localizadas 


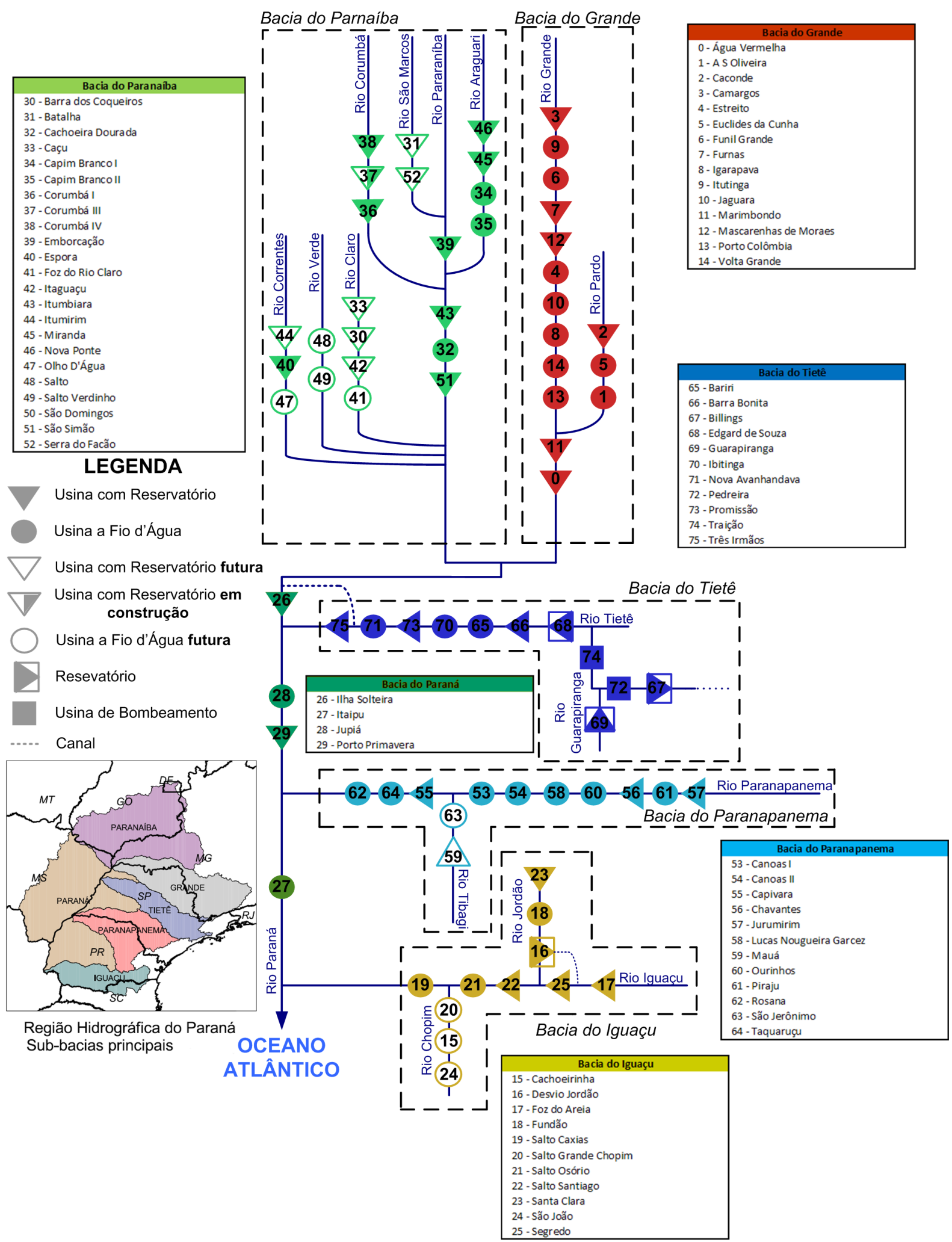

Figura 4.17: Diagrama da localização geográfica das usinas da região hidrográfica do Paraná. 


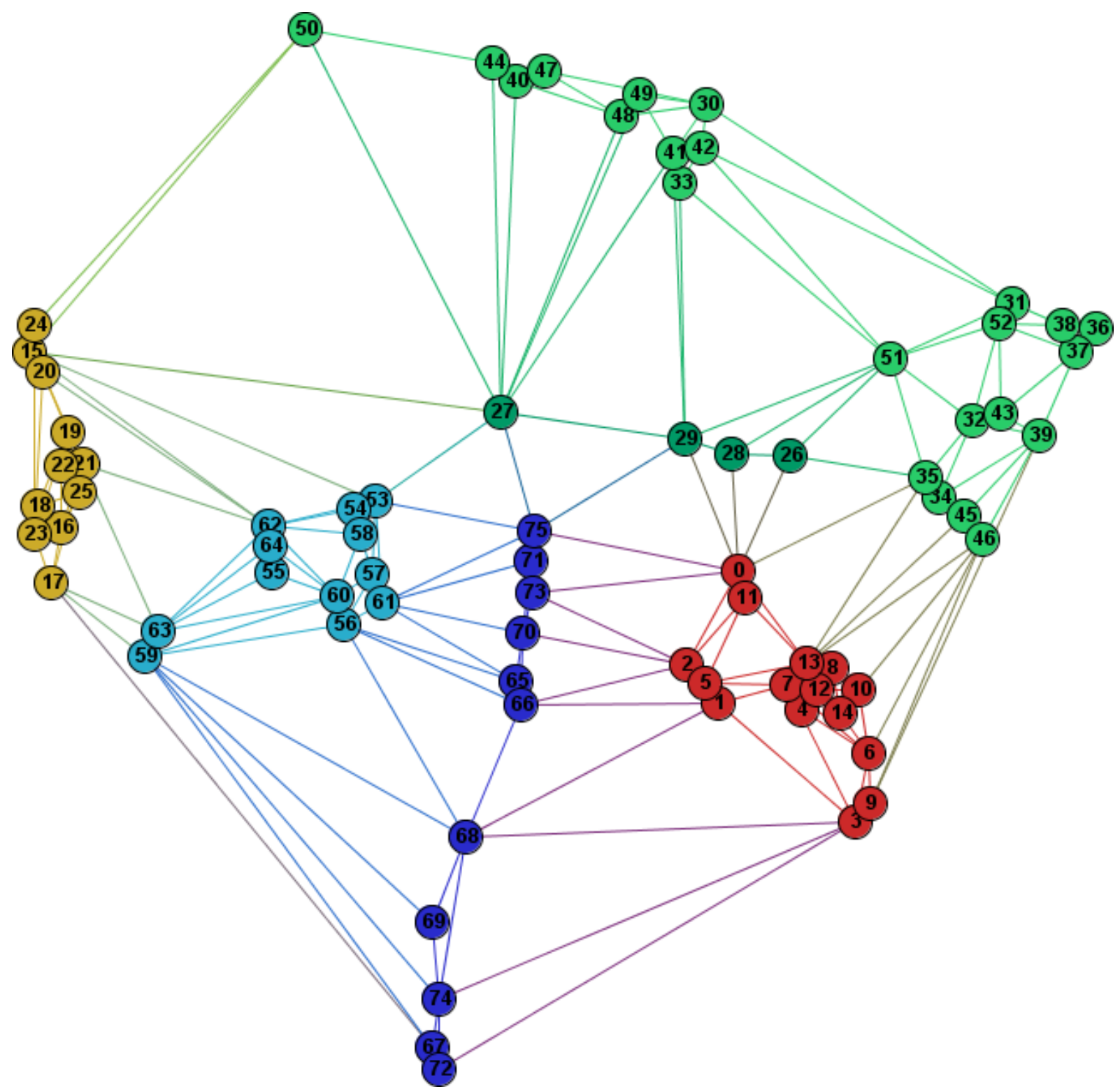

Figura 4.18: Projeção para a Região Hidrográfica do Paraná. 
no centro da projeção. As demais sub-bacias deságuam no rio Paraná, influenciando nas vazões dessas usinas.

Outro fato interessante foi a divisão da bacia do Paranaỉa em dois grupos distintos. O primeiro grupo é composto pelas usinas dos rios Correntes, Verde e Claro. Já o segundo grupo é composto pelas usinas dos rios Corumbá, São Marcos, Paranáiba e Araguari. Essa distinção é explicada pela distância geográfica entre esses grupos de rios, o que se reflete em diferenças climáticas e de padrões de chuva.

\subsubsection{Comportamento climático de um ano}

Nesta terceira análise sobre o conjunto de dados de vazões, o comportamento climático das sub-bacias da região do Paraná ao longo de um ano é investigado. Séries temporais compostas pelas vazões do ano de 1982, para cada usina, foram selecionadas para este propósito. A Figura 4.19(a) mostra a projeção desses séries usando a técnica IDMAP e a distância Euclidiana. As séries foram normalizadas antes da projeção.

Já a Figura 4.19(b) mostra as séries médias que representam o comportamento climático no ano de 1982 das sub-bacias da região hidrográfico do Paraná. Usinas localizadas na região central do Brasil, nas sub-bacias do Paranaíba e do Grande, apresentam um comportamento bem definido, no qual o período chuvoso ocorre nos meses de Novembro a Abril. O mesmo não ocorre na região sul, nas sub-bacias do Iguaçu e do Paranapanema, que exibem um comportamento distinto característico do clima subtropical. Essa região possui um regime hidrológico indefinido, no qual cheias podem ocorrer tanto no verão como no inverno. Já as usinas localizadas na sub-bacia do Tietê apresentam um comportamento transitório. Esse tipo de projeção é interessante para futuras aplicações, pois uma animação de projeções desse tipo, mapeando o comportamento de diferentes anos pode revelar, por exemplo, mudanças climáticas ao longo dos anos.

\subsection{Escolha da técnica de projeção e da medida de dis- similaridade}

A escolha da técnica de projeção e da medida de dissimilaridade para gerar projeções é extremamente dependente das características do conjunto de séries a ser projetado e de que tipo de informação deseja-se destacar na projeção. Sendo assim, as Tabelas 4.5 e 4.6 mostram, em linhas gerais, as vantagens e desvantagens das técnicas de projeção e das medidas de dissimilaridade disponíveis, respectivamente. Essas tabelas fornecem uma 


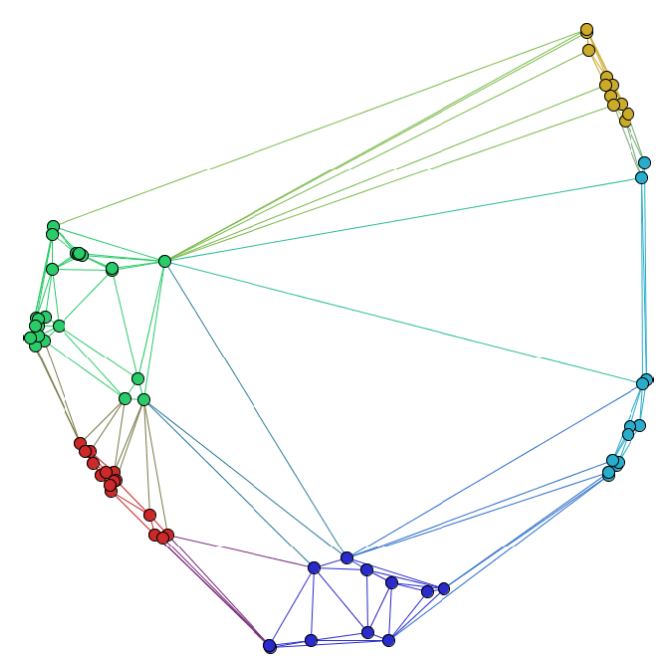

(a)
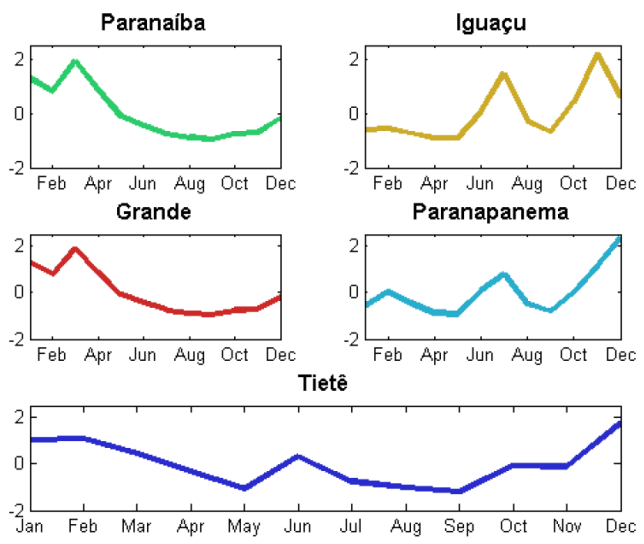

(b)

Figura 4.19: Projeção IDMAP e distância Euclidiana) das séries de vazões registradas no ano de 1982, nas usinas da região hidrográfica do Paraná. Cada cor identifica uma sub-bacia. 
visão geral das características das técnicas e das medidas, nas quais o usuário pode-se basear para sua escolha.

Tabela 4.5: Técnicas de projeção: vantagens e desvantagens

\begin{tabular}{|c|c|c|}
\hline & $\begin{array}{l}\text { Interactive Document Map ID- } \\
\text { MAP }\end{array}$ & Least Square Projection $(\mathrm{LSP}$ \\
\hline Vantagens & $\begin{array}{l}\text { - Mais indicada para dados } \\
\text { que apresentam uma distribuição } \\
\text { uniforme, sem agrupamentos evi- } \\
\text { dentes }\end{array}$ & $\begin{array}{l}\text { - Promove maior agrupamento, } \\
\text { por desconsiderar similaridade } \\
\text { entre objetos pertencentes a } \\
\text { diferentes grupos durante a } \\
\text { projeção } \\
\text { - Maior tolerância à presença de } \\
\text { outliers } \\
\text { - Rápida }\end{array}$ \\
\hline Desvantagens & $\begin{array}{l}\text { - Sensível à presença de outliers } \\
\text { - } O\left(N^{2}\right)\end{array}$ & $\begin{array}{l}\text { - Não recomendada quando não } \\
\text { se deseja evidenciar as fronteiras } \\
\text { entre possíveis agrupamentos } \\
\text { nos dados. }\end{array}$ \\
\hline
\end{tabular}

\subsection{Tempo de Processamento}

A Tabela 4.7 mostra o tempo de processamento para gerar as projeções apresentadas neste capítulo. Os tempos de processamento apresentados foram calculados em um computador com processador Intel Pentium 3.2 GHz e com 1 GB de RAM, e incluem todas as etapas do processo apresentado. Para a geração de uma projeção, por exemplo, os tempos incluem leitura do arquivo fonte, pré-processamento, cálculo da matriz de distância, projeção dos dados e exibição do resultado na tela.

\subsection{Considerações Finais}

A mineração visual aplicada a séries temporais é de extrema dificuldade pela alta dimensionalidade desses dados, determinada pelo número de pontos de observação no eixo do tempo. A ferramenta Temporal-PEx, desenvolvida neste projeto, visa abordar o problema de mineração visual de séries temporais. A aplicabilidade da ferramenta para a análise de séries foi ilustrada por meio de estudos de caso em conjuntos de dados de diferentes domínios: segurança, ações de empresas, eletrocardiogramas e vazões de usinas 
Tabela 4.6: Medidas de Dissimilaridade: vantagens e desvantagens

\begin{tabular}{|c|c|c|c|}
\hline & Euclidiana & $\begin{array}{ll}\text { Dynamic Time-Warping } \\
\text { (DTW) }\end{array}$ & $\begin{array}{l}\text { Compression-based Dissi- } \\
\text { milarity Measure (CDM) }\end{array}$ \\
\hline Vantagens & $\begin{array}{l}\text { - Rápida }(O(N)) \text { e sim- } \\
\text { ples de calcular. }\end{array}$ & $\begin{array}{l}\text { - Capaz de tratar com } \\
\text { séries com distorções no } \\
\text { eixo temporal } \\
\text { - Possível definir o nível } \\
\text { permitido de distorção } \\
\text { (tamanho da janela de } \\
\text { alinhamento), que por } \\
\text { conseqüência diminui o } \\
\text { tempo do cálculo. } \\
\text { - Capaz de tratar com } \\
\text { séries de diferentes } \\
\text { tamanhos. }\end{array}$ & $\begin{array}{l}\text { - Detecta diferenças de } \\
\text { alto nível entre as séries. } \\
\text { - Rápida. }\end{array}$ \\
\hline Desvantagens & $\begin{array}{l}\text { - Sensível a distorções } \\
\text { no eixo temporal. } \\
\text { - Capaz de comparar } \\
\text { somente com séries de } \\
\text { mesmo tamanho. }\end{array}$ & $\begin{array}{l}\text { - } O\left(N^{2}\right), \text { sem aplica- } \\
\text { ção de janelas de alinha- } \\
\text { mento. }\end{array}$ & $\begin{array}{l}\text { - Indicada somente para } \\
\text { séries longas (dimensio- } \\
\text { nalidade maior que } 800 \text { ). }\end{array}$ \\
\hline
\end{tabular}

hidrelétricas, selecionados para ilustrar o potencial da ferramenta e suas funcionalidades. O último conjunto de dados, vazões de usinas hidrelétricas, foi explorado mais a fundo com a colaboração de um especialista no estudo de séries de vazões. O Temporal-PEx revelou-se uma boa ferramenta exploratória, na qual o usuário ganha um conhecimento sobre o conjunto de dados, e a partir desse conhecimento direciona sua busca por padrões de interesse por meio de interações e tarefas de mineração de dados. 
Tabela 4.7: Tempo de processamento.

\begin{tabular}{|c|c|c|c|c|c|}
\hline Conj. de Dados & $\begin{array}{l}\text { Nro. } \\
\text { Séries }\end{array}$ & $\begin{array}{l}\text { Dimensio- } \\
\text { nalidade } \\
\text { das séries }\end{array}$ & $\begin{array}{c}\text { Pré- } \\
\text { processamento }\end{array}$ & \begin{tabular}{l} 
Técnica de \\
Projeção \} $\\
{\text { Distância }}$ & $\begin{array}{l}\text { Tempo de } \\
\text { processa- } \\
\text { mento(segundos) }\end{array}$ \\
\hline \multirow{2}{*}{$\begin{array}{l}\text { Synthetic Control } \\
\text { Chart. Ver Figura } 4.6\end{array}$} & \multirow{2}{*}{600} & \multirow{2}{*}{60} & \multirow{2}{*}{-} & $\begin{array}{l}\text { IDMAP / } \\
\text { Euclidiana }\end{array}$ & $0,393 s$ \\
\hline & & & & 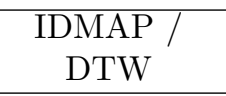 & $104,016 \mathrm{~s}$ \\
\hline $\begin{array}{l}\text { Gun-Point. Ver Figura } \\
4.8\end{array}$ & 150 & 150 & Normalização & $\begin{array}{l}\text { LSP }(n c= \\
15 ; k=10) / \\
\operatorname{DTW}(10 \%)\end{array}$ & $15,234 \mathrm{~s}$ \\
\hline $\begin{array}{l}\text { Séries dos valores de } \\
\text { ações de empresas. Ver } \\
\text { Figura } 4.9\end{array}$ & 1430 & 52 & - & $\begin{array}{l}\text { IDMAP } \\
\text { Euclidiana }\end{array}$ & $16,922 s$ \\
\hline \multirow{2}{*}{$\begin{array}{l}\text { Eletrocardiogramas. } \\
\text { Ver Figura } 4.11\end{array}$} & \multirow[t]{2}{*}{20} & \multirow[t]{2}{*}{10.000} & \multirow[t]{2}{*}{ Normalização } & $\begin{array}{c}\operatorname{LSP}(n c=8 \\
k=5) / \\
\text { Euclidiana }\end{array}$ & $2,406 s$ \\
\hline & & & & $\begin{array}{c}\mathrm{LSP}(n c=8 \\
k=5) / \\
\mathrm{CDM}\end{array}$ & $46,188 \mathrm{~s}$ \\
\hline $\begin{array}{l}\text { Séries de vazões da } \\
\text { usina Furnas. Ver Fi- } \\
\text { gura } 4.16\end{array}$ & 75 & 12 & - & $\begin{array}{l}\text { IDMAP / } \\
\text { Euclidiana }\end{array}$ & $0,393 s$ \\
\hline $\begin{array}{l}\text { Séries de vazões das } \\
\text { usinas da região hidro- } \\
\text { gráfica do Paraná. Ver } \\
\text { Figura } 4.18\end{array}$ & 76 & 900 & $\begin{array}{l}\text { Remoção de } \\
\text { Sazonalidade }\end{array}$ & $\begin{array}{l}\text { IDMAP / } \\
\text { Euclidiana }\end{array}$ & $0,797 s$ \\
\hline $\begin{array}{l}\text { Séries das usinas da } \\
\text { região hidrográfica do } \\
\text { Paraná no ano de } 1982 \text {. } \\
\text { Ver Figura } 4.19\end{array}$ & 76 & 12 & Normalização & $\begin{array}{l}\text { IDMAP / } \\
\text { Euclidiana }\end{array}$ & $0,313 s$ \\
\hline
\end{tabular}
\end{tabular}




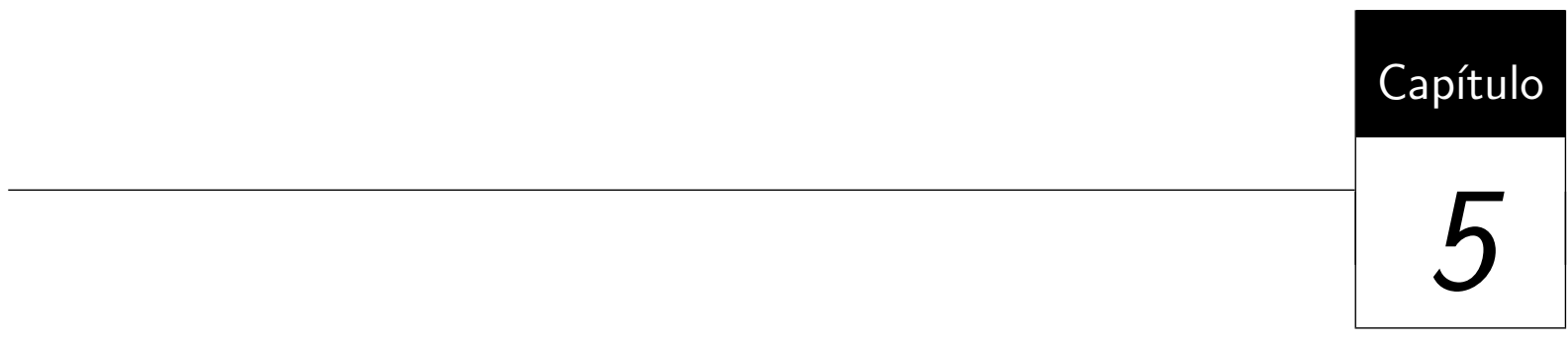

\section{Conclusões}

Neste capítulo são apresentadas as principais contribuições deste trabalho para a análise de séries temporais, bem como suas limitações. Tambéms são apresentados desenvolvimentos futuros que podem dar continuidade à abordagem proposta, superando algumas limitações e gerando outras contribuições.

O principal objetivo deste trabalho de mestrado foi a geração de uma abordagem para a análise de séries temporais. Isso motivou o estudo em duas áreas: Visualização de Informação e Mineração de Dados, e especificamente visualização e mineração de series. O conhecimento adquirido com esses estudos motivou a proposta e desenvolvimento de uma ferramenta chamada Temporal-PEx, que gera uma representação visual que reflete a distribuição interna das séries dentro da coleção, oferecendo um ponto de partida para a busca de padrões de interesse. A busca por padrões também é auxiliada por duas tarefas de mineração de dados: casamento de subseqüências e classificação.

\subsection{Limitações}

O emprego efetivo da ferramenta para gerar projeções de séries temporais, requer certo conhecimento prévio sobre as técnicas de projeção e medidas de dissimilaridade disponíveis. No entanto, esse conhecimento pode ser facilmente adquirido com o uso da ferramenta, 
gerando e observando projeções resultantes do mesmo conjunto de séries de diferentes combinações dessas opções. Uma visão geral das características dessas técnicas de projeção e dessas medidas de dissimilaridade também pode ser obtida consultando um pequeno arquivo de instruções que acompanha a ferramenta. O arquivo de instruções traz, entre outras informações, um descrição do formato do arquivo entrada - Time Series Datafile (TSD).

Entre as limitações também encontra-se a falta de capacidade da ferramenta de analisar séries com mais de uma informação associada a cada ponto. Séries sobre dados metrológicos, por exemplo, podem conter informações sobre temperatura e umidade para um mesmo instante no tempo. A ferramenta atualmente também não é capaz de incorporar informações geográficas das séries a representação visual gerada. As séries de vazões de usinas, por exemplo, possuem associadas a si a localização geográficas das usinas.

Outra dificuldade é o tamanho da coleção que a ferramenta consegue lidar atualmente. Foram geradas coleções de séries aleatórias, em caráter de teste, para determinar o tamanho máximo da coleção que a ferramenta suporta. O limite máximo foi atingido por um conjunto com 75 séries de tamanho 10.000 cada, totalizando 750.000 valores.

Quanto à exibição das séries, o círculo é a atual forma de exibição de uma série dentro da projeção, que permite o mapeamento de informações somente para a cor e o tamanho. O círculo é uma forma ideal por ocupar pouco espaço, se considerarmos o aproveitamento da tela. No entanto, seria extremamente interessante fornecer a opção de usar formas alternativas de exibição das séries, que utilizem a idéia da projeção, mas que consigam transmitir mais informação sobre o comportamento individual das séries.

\subsection{Desenvolvimentos Futuros}

As limitações mencionadas na seção anterior e outras características desejáveis indicam os principais desenvolvimentos futuros a serem seguidos. Dentre eles destacam-se:

- Escalonamento da ferramenta para lidar com conjuntos de dados maiores.

- Incorporação de mais tarefas de mineração de dados, como dectção de anomalias e descobrimento de motifs - padrões freqüentes previamente desconhecidos.

- Capacidade de lidar com séries multivariadas, que contém mais de um atributo para o mesmo eixo temporal. Identificando, por exemplo, correlações entre os atributos. 
- Incorporação de formas alternativas de exibição das séries. Um possibilidade seria o uso da técnica Intelligent Icons (Keogh et al., 2006b), que constrói ícones de forma que séries similares apresentem ícones similares.

- Cooperação com a Prof. Dra. Wu-Shin Ting, prosseguindo com o processo de validação e aperfeiçoamento da ferramenta por meio da sua utilização mais extensiva em diversos dominós de aplicação.

- Adaptação da técnica de projeção LSP para incorporar informações geográficas associadas às séries no processo de projeção, de modo que o posicionamento dos pontos também leve em consideração essa informação geográfica.

- Adição de outras atividades de pré-processamento, como a remoção de tendência. Detecção automática da presença de sazonalidade nas séries, e do tamanho do ciclo sazonal.

- Incorporação de mais interações com a ferramenta por parte do usuário. Por exemplo: coordenação entre projeções diferentes do mesmo conjunto de dados. 


\section{Referências Bibliográficas}

Agrawal, R.; Faloutsos, C.; Swami, A. N. Efficient similarity search in sequence databases. In: FODO '93: Proceedings of the 4th International Conference on Foundations of Data Organization and Algorithms, London, UK: Springer-Verlag, 1993, p. 69-84.

Alcock, R. J.; Manolopoulos, Y. Time-series similarity queries employing a feature-based approach. In: Proceedings of the 7th Hellenic Conference on Informatics, 1999.

Andrade, M. G. Modelos de séries temporais para previsão de vazões médias mensais. Relatório Técnico, Universidade de São Paulo, 2004.

Berkhin, P. Survey of clustering data mining techniques. Relatório Técnico, Accrue Software, San Jose, CA, 2002.

Disponível em citeseer.ist.psu.edu/berkhin02survey.html

Berndt, D. J.; Clifford, J. Using dynamic time warping to find patterns in time series. In: KDD Workshop, 1994, p. 359-370.

Buono, P.; Aris, A.; Plaisant, C.; Khella, A.; Shneiderman, B. Interactive pattern search in time series. In: VDA 2005: Proceedings of Conference on Visualization and Data Analysis, 2005.

Card, S. K.; Mackinlay, J. D.; Shneiderman, B., eds. Readings in information visualization: Using vision to think. San Francisco, CA, USA: Morgan Kaufmann Publishers Inc., 1999. 
Carlis, J. V.; Konstan, J. A. Interactive visualization of serial periodic data. In: UIST '98: Proceedings of the 11th annual ACM Symposium on User Interface Software and Technology, New York, NY, USA: ACM Press, 1998, p. 29-38.

Chakrabarti, K.; Keogh, E.; Mehrotra, S.; Pazzani, M. Locally adaptive dimensionality reduction for indexing large time series databases. ACM Transactions on Database Systems, v. 27, n. 2, p. 188-228, 2002.

Chan, K.-P.; Fu, A. W.-C. Efficient time series matching by wavelets. In: ICDE '99: Proceedings of the 15th International Conference on Data Engineering, Washington, DC, USA: IEEE Computer Society, 1999, p. 126.

Delaunay, B. Sur la sphère vide. Izvestia Akademii Nauk SSSR, v. 7, p. 793-800, 1934.

Edelsbrunner, H. Geometry and topology for mesh generation. New York, NY, USA: Cambridge Monographs On Applied And Computational Mathematics, 2001.

Faloutsos, C.; Lin, K.-I. Fastmap: a fast algorithm for indexing, data-mining and visualization of traditional and multimedia datasets. In: SIGMOD '95: Proceedings of the 1995 ACM SIGMOD international conference on Management of data, 1995, p. 163-174.

Faloutsos, C.; Ranganathan, M.; Manolopoulos, Y. Fast subsequence matching in time-series databases. In: SIGMOD '94: Proceedings of the 1994 ACM SIGMOD international conference on Management of data, New York, NY, USA: ACM Press, 1994, p. 419-429.

Fayyad, U.; Piatetsky-Shapiro, G.; Smyth, P. From data mining to knowledge discovery in databases. Ai Magazine, v. 17, p. 37-54, 1996a.

Fayyad, U. M.; Piatetsky-Shapiro, G.; Smyth, P. Knowledge discovery and data mining: Towards a unifying framework. In: Knowledge Discovery and Data Mining, 1996b, p. 82-88.

FloAter, M. S. Parametrization and smooth approximation of surface triangulations. Computer Aided Geometric Design, v. 14, n. 3, p. 231-250, 1997.

Gardner, JR., E. S. Exponential smoothing: The state of the art. Journal of Forecasting, v. 4, p. 1-28, 1985. 
Goldberger, A. L.; Amaral, L. A. N.; Glass, L.; Hausdorff, J. M.; Ivanov, P. C.; Mark, R. G.; Mietus, J. E.; Moody, G. B.; Peng, C.-K.; Stanley, H. E. PhysioBank, PhysioToolkit, and PhysioNet: Components of a new research resource for complex physiologic signals. Circulation, v. 101, n. 23, p. e215-e220, circulation Electronic Pages: http://circ.ahajournals.org/cgi/content/full/101/23/e215, 2000.

Guttman, A. R-trees: a dynamic index structure for spatial searching. In: SIGMOD '84: Proceedings of the 1984 ACM SIGMOD international conference on Management of data, New York, NY, USA: ACM Press, 1984, p. 47-57.

Hao, M. C.; Dayal, U.; Keim, D. A.; Schreck, T. Importance-driven visualization layouts for large time series data. In: INFOVIS '05: Proceedings of the 2005 IEEE Symposium on Information Visualization, Washington, DC, USA: IEEE Computer Society, 2005, p. 27.

Hettich, S.; BAy, S. D. The uci kdd archive. 1999.

Disponível em http://kdd.ics.uci.edu Acesso em: 27 abr. 2007

Hochheiser, H.; Shneiderman, B. Dynamic query tools for time series data sets: timebox widgets for interactive exploration. Information Visualization, v. 3, n. 1, p. 1-18, 2004.

ItAKura, F. Minimum prediction residual principle applied to speech recognition. IEEE Transactions on Acoustics, Speech, and Signal Processing, v. 23, n. 1, p. 67-72, 1975.

KeIM, D. A. Information visualization and visual data mining. IEEE Transactions on Visualization and Computer Graphics, v. 8, n. 1, p. 1-8, 2002.

KeOGH, E. Data mining and machine learning in time series databases. 2003.

Disponível em http://www.cs.ucr.edu/\%7Eeamonn/KEOGH_time_series_tutorial_ PKDD03.ppt Acesso em: 10 out. 2005

KEOGH, E. 2004.

Disponível em http://www.cs.ucr.edu/ eamonn/SIGKDD2004/

Keogh, E.; Kasetty, S. On the need for time series data mining benchmarks: a survey and empirical demonstration. In: KDD '02: Proceedings of the eighth ACM SIGKDD international conference on Knowledge discovery and data mining, New York, NY, USA: ACM Press, 2002, p. 102-111. 
KeOGH, E.; Lin, J.; Fu, A. Hot sax: Efficiently finding the most unusual time series subsequence. In: The Fifth IEEE International Conference on Data Mining, 2005.

Keogh, E.; Lin, J.; Truppel, W. Clustering of time series subsequences is meaningless: Implications for previous and future research. In: ICDM '03: Proceedings of the Third IEEE International Conference on Data Mining, Washington, DC, USA: IEEE Computer Society, 2003, p. 115.

Keogh, E.; Lonardi, S.; Ratanamahatana, C. A.; Wei, L.; Lee, S.-H.; HanDLEY, J. Compression-based data mining of sequential data. Data Mining and Knowledge Discovery, v. 14, n. 1, p. 99-129, 2007.

Keogh, E.; Ratanamahatana, C. A. Exact indexing of dynamic time warping. Knowledge and Information Systems, v. 7, n. 3, p. 358-386, 2005.

Keogh, E.; Wei, L.; XI, X.; Lee, S.-H.; Vlachos, M. Lbkeogh supports exact indexing of shapes under rotation invariance with arbitrary representations and distance measures. In: VLDB 2006: Proceedings of the 32 nd International Conference on Very Large Data Bases, 2006a.

Keogh, E.; Wei, L.; XI, X.; Lonardi, S.; Shieh, J.; Sirowy, S. Intelligent icons: Integrating lite-weight data mining and visualization into gui operating systems. In: ICDM '06. Sixth International Conference on Data Mining, 2006b.

Keogh, E.; Xi, X.; Wei, L.; Ratanamahatana, C. A. The ucr time series classification/clustering homepage. 2006c.

Disponível em www.cs.ucr.edu/ ${ }^{\sim}$ eamonn/time_series_data/ Acesso em: 30 jul. 2007

Keogh, E. J.; Chakrabarti, K.; Pazzani, M. J.; Mehrotra, S. Dimensionality reduction for fast similarity search in large time series databases. Knowledge and Information Systems, v. 3, n. 3, p. 263-286, 2000.

Kim, S.-W.; PARK, S.; Chu, W. W. An index-based approach for similarity search supporting time warping in large sequence databases. In: Proceedings of the 17th International Conference on Data Engineering, Washington, DC, USA: IEEE Computer Society, 2001, p. 607-614.

Kolmogorov, A. N. Three approaches to the quantitive definition of information. Problems of Information Transmission, v. 1, p. 1-17, 1965. 
Korn, F.; Jagadish, H. V.; Faloutsos, C. Efficiently supporting ad hoc queries in large datasets of time sequences. SIGMOD Rec., v. 26, n. 2, p. 289-300, 1997.

Lin, J.; KeOgh, E.; Lonardi, S.; Chiu, B. A symbolic representation of time series, with implications for streaming algorithms. In: DMKD '03: Proceedings of the 8th ACM SIGMOD workshop on Research issues in data mining and knowledge discovery, New York, NY, USA: ACM Press, 2003, p. 2-11.

Lin, J.; Keogh, E.; Lonardi, S.; Patel, P. Finding motifs in time series. In: Proceedings of the Second Workshop on Temporal Data Mining, Edmonton, Alberta, Canada, 2002.

Minghim, R.; Paulovich, F. V.; Andrade Lopes, A. Content-based text mapping using multi-dimensional projections for exploration of document collections. In: Erbacher, R. F.; Roberts, J. C.; Gröhn, M. T.; Borner, K., eds. Visualization and Data Analysis 2006, Proceedings SPIE-ISET Electronic Imaging, San Jose, California: SPIE, 2006, p. 60600S.

Morettin, P. A.; Toloi, C. M. C. Análise de séries temporais, cáp. 4 Editora Edgard Blücher, p. 88-93, 2004.

Morinaka, Y.; Yoshikawa, M.; Amagasa, T.; Uemura., S. The l-index: An indexing structure for efficient subsequence matching in time sequence databases. In: PAKDD 2001: Proceedings of 5th Pacific-Asia Conference on Knowledge Discovery and Data Mining, 2001.

Novotny, M. Visually effective information visualization of large data. In: $C E S C G^{\prime} 04$ : Eighth Central European Seminar on Computer Graphics, 2004.

Oliveira, M. C. F.; Levkowitz, H. From visual data exploration to visual data mining: A survey. IEEE Transactions on Visualization and Computer Graphics, v. 9, n. 3, p. 378-394, 2003.

ONS Vazões médias mensais nos aproveitamentos hidrelétricos Ü período 1931 a 2005. Relatório Técnico, 2006.

Paulovich, F.; Oliveira, M. C.; Minghim, R. The projection explorer: A flexible tool for projection-based multidimensional visualization. In: SIBGRAPI'0\%: The Brazilian Symposium on Computer Graphics and Image Processing, 2007. 
Paulovich, F. V.; Nonato, L. G.; Minghim, R.; Levkowitz, H. Visual mapping of text collections through a fast high precision projection technique. IEEE Transactions on Visualization and Computer Graphics, 2008.

Playfair, W. The commercial and political atlas: Representing, by means of stained copper-plate charts, the progress of the commerce, revenues, expenditure and debts of england during the whole of the eighteenth century. 1786.

Rezende, S. O.; Pugliesi, J. B.; Melanda, E. A.; Paula, M. F. Sistemas inteligentes: Fundamentos e aplicações, cáp. 12 - Mineração de Dados Editora Manole, p. 307-335, 2003.

Rodríguez, J. J.; Alonso, C. J. Interval and dynamic time warping-based decision trees. In: SAC '04: Proceedings of the 2004 ACM symposium on Applied computing, New York, NY, USA: ACM Press, 2004, p. 548-552.

SaIto, N. Local feature extraction and its applications using a library of bases. Tese de Doutoramento, Yale University, director-Ronald R. Coifman, 1994.

Sakoe, H.; Chiba, S. Dynamic programming algorithm optimization for spoken word recognition. IEEE Transactions on Acoustics, Speech, and Signal Processing, v. 26, n. 1, p. 43-49, 1978.

Sorkine, O.; Cohen-Or, D.; Lipman, Y.; Alexa, M.; Rössl, C.; Seidel, H.-P. Laplacian surface editing. In: SGP '04: Proceedings of the 2004 Eurographics/ACM SIGGRAPH symposium on Geometry processing, New York, NY, USA: ACM Press, 2004, p. $175-184$.

TAN, P.-N.; Steinbach, M.; Kumar, V. Introduction to data mining. Addison Wesley, 487 - 568 p., 2005.

Tejada, E.; Minghim, R.; Nonato, L. G. On improved projection techniques to support visual exploration of multidimensional data sets. Information Visualization, v. 2, n. 4, p. 218-231, 2003.

Tominski, C.; Abello, J.; Schumann, H. Interactive poster: 3d axes-based visualizations for time series data. In: INFOVIS '05: Proceedings of the 2005 IEEE Symposium on Information Visualization, 2005.

Vlachos, M. Similarity and indexing in multidimensional spaces. Tese de Doutoramento, University of California Riverside, 2004. 
Weber, M.; Alexa, M.; Muller, W. Visualizing time-series on spirals. In: INFOVIS '01: Proceedings of the 2001 IEEE Symposium on Information Visualization, 2001.

Wegman, E. J. Hyperdimensional data analysis using parallel coordinates. Journal of the American Statistical Association, v. 85, n. 411, p. 664-675, 1990.

Welch, D.; Quinn, P. Machco project. 1999.

Disponível em http://wwwmacho.mcmaster.ca/Project/Overview/status.html Acesso em: 10 out. 2005

WiJK, J. J. V.; SElow, E. R. V. Cluster and calendar based visualization of time series data. In: INFOVIS '99: Proceedings of the 1999 IEEE Symposium on Information Visualization, Washington, DC, USA: IEEE Computer Society, 1999, p. 4.

Yi, B.-K.; Jagadish, H. V.; Faloutsos, C. Efficient retrieval of similar time sequences under time warping. In: ICDE '98: Proceedings of the Fourteenth International Conference on Data Engineering, Washington, DC, USA: IEEE Computer Society, 1998, p. 201-208. 